IVANI CAETANO DOS PASSOS PIZZITOLA

EFEITO DA INCORPORAÇÃO DE FIBRAS CURTAS DE SÍLICA AMORFA EM COMPÓSITOS DE POLIPROPILENO UTILIZADOS PELA INDÚSTRIA AUTOMOTIVA NACIONAL 
IVANI CAETANO DOS PASSOS PIZZITOLA

\section{EFEITO DA INCORPORAÇÃO DE FIBRAS CURTAS DE SÍLICA AMORFA EM COMPÓSITOS DE POLIPROPILENO UTILIZADOS PELA INDÚSTRIA AUTOMOTIVA NACIONAL}

Dissertação apresentada à Escola Politécnica da Universidade de São Paulo para obtenção do título de Mestre em Ciências dos Materiais 
Dissertação apresentada à Escola

Politécnica da Universidade de São

Paulo para obtenção do título de

Mestre em Ciências dos Materiais

Área de Concentração:

Engenharia Metalúrgica e de

Materiais

Orientador:

Prof. Doutor Hélio Wiebeck 
Este exemplar foi revisado e alterado em relação à versão original, sob responsabilidade única do autor e com anuência do seu orientador.

São Paulo, ...... de julho de 2011.

Assinatura do autor

Assinatura do orientador

FICHA CATALOGRÁFICA

Pizzitola, Ivani Caetano dos Passos

Efeito da incorporação de fibras curtas de sílica amorfa em compósitos de polipropileno utilizados pela indústria automotiva nacional / I.C.P. Pizzitola. - ed.rev. - São Paulo, 2011.

$115 \mathrm{p}$.

Dissertação (Mestrado) - Escola Politécnica da Universidade de São Paulo. Departamento de Engenharia Metalúrgica e de Materiais.

1. Materiais compósitos de fibras I. Universidade de São Paulo. Escola Politécnica. Departamento de Engenharia Metalúrgica e de Materiais II. t. 
Dedico este trabalho ao meu pai, Aluizio Francisco dos Passos (in memorian), meu exemplo. 


\section{AGRADECIMENTOS}

$\checkmark$ Primeiramente a Deus, por estar presente em minha vida.

$\checkmark$ Ao meu marido Pedro, à minha filha Marina e a toda a minha família, pelo amor, companheirismo, motivação e compreensão.

$\checkmark$ Ao Professor Dr. Hélio Wiebeck, orientador deste trabalho, pelos ensinamentos, pela paciência e pela confiança.

$\checkmark$ À Mariana M. Machado, por toda a imensa contribuição e, principalmente, pela amizade.

$\checkmark$ Aos professores Dr. Leonardo Gondim de Andrade e Silva, do CTR do IPEN/CNEN - SP, bem como, à Dra. Ticiane S. Valera, pela valiosa orientação e ensinamentos durante o exame de qualificação.

Ao Marcos H. C. Silveira, ao Fabio Basani e ao Silvio F. Souza, gestores da Volkswagen do Brasil, pelo incentivo, pela confiança e por todo o apoio.

$\checkmark$ Aos amigos da LyondellBasell, em especial ao Genilson Vieira da Silva, ao Marcelo Rodrigues Melo, ao Fernando Batista e ao Sérgio Meneguetti, pelo incentivo e pela colaboração.

Aos amigos do Centro Tecnológico de Materiais da Volkswagen do Brasil, em especial ao André Pereira, ao Cesar Filipini, à Gabriella R. C. Spedo, à Maria de Lourdes Feitosa di Franco, à Priscila Tibold e ao Michael Matz, pelo coleguismo e pela cooperação.

$\checkmark$ Ao Ricardo Kaneko, pela ajuda e amizade.

$\checkmark$ Ao Nelson Franco e ao Marcelo Donegá, pelos conselhos, livros e apostilas. 
$\checkmark$ Ao Amauri C. Oliveira, da Magnesita, pela colaboração.

$\checkmark$ Aos professores e funcionários do Departamento de Engenharia de Metalurgia e de Materiais da Escola Politécnica da Universidade de São Paulo, pelo apoio.

$\checkmark$ A todos que de alguma forma contribuíram para a realização deste trabalho. 


\section{RESUMO}

A adição de fibras de sílica em compósitos de polipropileno (PP) foi investigada neste trabalho como uma proposta de desenvolvimento de novos materiais utilizados pela indústria automotiva, os quais permitam a redução de peso do veículo e a consequente economia de combustível. As fibras são leves, constituídas de sílica amorfa e tratadas com aminossilano para uma melhor interação com a matriz polimérica. Compósitos de PP homopolímero, bem como de compósitos de PP heterofásico modificados com o copolímero etileno e 1-octeno (POE), foram formulados utilizando-se $20 \%$ de fibras de sílica e com PP funcionalizado com anidrido maleico (PP-g-MAH) como compatibilizante. As amostras foram avaliadas quanto às propriedades mecânicas, térmicas, características morfológicas, anisotropia e quanto a requisitos específicos, como emissões de voláteis, odor e resistência a riscos. O compósito de PP homopolímero na presença de $2 \%$ de PP-g$\mathrm{MAH}$ apresentou o melhor balanço de propriedades, porém com comprometimento quanto à tenacidade. A análise morfológica desta formulação indicou a presença de fibras descoladas, demonstrando que o tratamento das fibras com o aminossilano, não foi totalmente efetivo para a redução das tensões interfaciais. Os compósitos de PP heterofásico modificados com POE (5\% em peso) e com fibras de sílica apresentaram boa dispersão, forma e tamanho de domínios elastoméricos, os quais promoveram um bom efeito de tenacificação. O copolímero POE atuou como um agente compatibilizante, melhorando a adesão fibra-polímero. Por outro lado, estes compósitos apresentaram um grande número de partículas de borracha descoladas da matriz por cavitação, sugerindo que a adesão entre as fases pode ser melhorada, apesar da afinidade química da blenda PP/POE. De uma forma geral, as fibras curtas de sílica constituem uma alternativa potencial para o reforço de compósitos de PP. Além de menor densidade, os compósitos estudados apresentaram bons resultados quando comparados a formulações com o emprego de talco, o qual é muito empregado em peças automotivas.

Palavras-chave: Compósitos de polipropileno. Fibras de sílica. Agente compatibilizante. POE. 


\begin{abstract}
The addition of silica fibers in polypropylene (PP) composites was investigated on this work as a proposal to develop new materials used in automotive industry, in order to enable the reduction of vehicle weight and the resulting fuel economy. The fibers are lightweight, made of amorphous silica and treated with amine silane for better interaction with the polymer matrix. Composites of PP homopolymer and PP heterophasic composites modified with ethylene and 1-octene (POE) were formulated using $20 \%$ of silica fibers as reinforcement and PP functionalized with maleic anhydride (PP-g-MAH) as compatibilizer agent. The samples were evaluated for mechanical, thermal, morphological, anisotropy, as well as specific requirements such as emissions of volatiles, odor and scratch resistant. The composite of PP homopolymer in the presence of $2 \%$ of PP-g-MAH showed the best balance of properties, however the tenacity was impaired. The morphological analysis of this formulation indicated the presence of detached fibers, demonstrating that treatment of fibers with the amine silane was not totally effective in reducing the interfacial tensions. Heterophasic PP composites modified with POE (5 wt\%) and silica fibers presented good dispersion, shape and size of elastomeric domains, promoting a good toughening effect. The POE copolymer acted as a coupling agent, enhancing the adhesion fiber-polymer. On the other hand, these composites showed a large number of rubber particles detached from the matrix by cavitation, suggesting that the adhesion between the phases can be improved, despite the chemical affinity of the blend PP/POE. In general, short silica fibers are a potential alternative for polypropylene composites reinforcement. In addition to lower density, the studied composites demonstrated good results when compared to formulations with the use of talc, which is very used in automotive parts.
\end{abstract}

Keywords: Polypropylene composites. Silica fibers. Compatibilizer agent. POE. 


\section{LISTA DE FIGURAS}

Figura 1 - Esquema da reação de polimerização do polipropileno .7

Figura 2 - Estruturas isoméricas do polipropileno: polipropileno atático (a), polipropileno isotático (b) e polipropileno sindiotático (c)

Figura 3 - Características dos níveis de estrutura morfológica do polipropileno ....11

Figura 4 - Célula unitária (cristal)

Figura 5 - Principais fatores que afetam a resistência mecânica dos compósitos de termoplásticos reforçados

Figura 6 - Reação de interação entre o agente trialcoxissilano e fibra de vidro.....21

Figura 7 - Mecanismo de reações possíveis para enxertia de anidrido maleico na cadeia de polipropileno no estado fundido na presença de peróxido orgânico 23

Figura 8 - Modelo de "Escova Polimérica" em um sistema de polipropileno reforçado com fibra de vidro

Figura 9 - Representação da reação entre SEBS-MA e os grupos hidroxílicos presentes na superfície das fibras de vidro

Figura 10 - Variação da tensão na ruptura de compósitos híbridos em relação à resistência ao impacto, em diferentes concentrações de borracha

Figura 11 - Evolução de micro defeitos para várias forças interfaciais normalizadas entre PP e EPR, sob determinado valor de tensão 40

Figura 12 - Dispositivo de teste para resistência a riscos Multi-Finger Scratch (modelo 710), fabricado pela Taber.

Figura 13 - Dispositivo para testes, conforme ASTM D7027-05 e ISO19252, Scratch 4 Machine ${ }^{\circledR}$, produzido pela empresa SMS

Figura 14 - Micrografia das fibras de sílica Silexil ${ }^{\circledR}$

Figura 15 - Esquema do método de medição da contração diferencial (anisotropia) do material .57

Figura 16 - Representação do princípio de medição de emissões totais de compósitos orgânicos, através de frascos tipo head-space . 59

Figura 17 - Frasco para determinação de odor

Figura 18 - Equipamento Erichsen, modelo 430P. 
Figura 19 - Distribuição dos comprimentos das fibras de sílica (estado de recebimento)

Figura 20 - Distribuição dos comprimentos das fibras após moldagem do compósito com $10 \%$ de talco, $10 \%$ de sílica e $2 \%$ de agente compatibilizante

Figura 21 - Distribuição dos comprimentos das fibras após moldagem do compósito com $20 \%$ de sílica e $2 \%$ de agente compatibilizante

Figura 22 - Valores comparativos entre os diversos compósitos, obtidos para a propriedade de resistência à tração.

Figura 23 - Variação da resistência à tração em função do percentual de compatibilizante

Figura 24 - Valores comparativos entre os diversos compósitos, obtidos para a propriedade de alongamento na ruptura... 68

Figura 25 - Variação do alongamento na ruptura em função do percentual de compatibilizante

Figura 26 - Mecanismo de reação entre a superfície da fibra de sílica e o agente de acoplamento aminossilano

Figura 27 - Valores comparativos entre os diversos compósitos, obtidos para a propriedade de resistência à flexão.

Figura 28 - Valores comparativos entre os diversos compósitos, obtidos para a propriedade de módulo à flexão

Figura 29 - Variação a resistência à flexão em função do percentual de compatibilizante

Figura 30 - Variação do módulo à flexão em função do percentual de compatibilizante

Figura 31 - Valores comparativos entre os diversos compósitos, obtidos para a propriedade de resistência ao impacto Charpy sem entalhe

Figura 32 - Variação da resistência ao impacto Charpy, sem entalhe, em função do percentual de compatibilizante

Figura 33 - Valores comparativos entre os diversos compósitos, obtidos para a propriedade de resistência ao impacto Charpy com entalhe.

Figura 34 - Variação da temperatura de amolecimento Vicat, em função do percentual de compatibilizante, para os diversos compósitos 76

Figura 35 - Micrografias obtidas por microscópio eletrônico de varredura de superfície de fratura de amostras: 10T/10S (a), 10T/10S-2 (b) 
Figura 36 - Micrografias obtidas por microscópio eletrônico de varredura de superfície de fratura das amostras (a e b) obtidas para o compósito $20 \mathrm{~S}-1$

Figura 37 - Micrografias obtidas por microscópio eletrônico de varredura de superfície de fratura das amostras: 20S (a), 20S (b), 20S-2 (c) e 20S-4(d) 83

Figura 38 - Valores comparativos entre os compósitos tenacificados (E/P) e não tenacificados (PP homopolímero), obtidos para a propriedade de resistência à tração no escoamento

Figura 39 - Valores comparativos entre os compósitos tenacificados (E/P) e não tenacificados (PP homopolímero), obtidos para a propriedade de resistência à tração na ruptura

Figura 40 - Valores comparativos entre os compósitos tenacificados (E/P) e não Tenacificados (PP homopolímero), obtidos para a propriedade de resistência à flexão

Figura 41 - Valores comparativos entre os compósitos tenacificados (E/P) e não tenacificados (PP homopolímero), obtidos para a propriedade de módulo de flexão

Figura 42 - Valores comparativos entre os compósitos tenacificados (E/P) e não tenacificados (PP homopolímero), obtidos para a propriedade de alongamento na ruptura.

Figura 43 - Valores comparativos entre os compósitos tenacificados (E/P) e não tenacificados (PP homopolímero), obtidos para a propriedade de alongamento no escoamento

Figura 44 - Valores comparativos entre os compósitos tenacificados (E/P) e não tenacificados (PP homopolímero), obtidos para a propriedade de impacto Charpy com entalhe a $23^{\circ} \mathrm{C}$

Figura 45 - Valores comparativos entre os compósitos tenacificados (E/P), obtidos para a propriedade de impacto Charpy com entalhe a $-30^{\circ} \mathrm{C}$

Figura 46 - Valores comparativos entre os compósitos tenacificados (E/P) e não tenacificados (PP homopolímero), obtidos para a propriedade de temperatura de amolecimento segundo Vicat

Figura 47 - Comparação visual entre amostras das superfícies riscadas dos 
compósitos tenacificados E/P-10T/10S, E/P-20T e E/P-20S

Figura 48 - Comparação visual entre a superfície de uma placa injetada com o compósito E/P-20S antes (a) e após (b) o ensaio de resistência a riscos

Figura 49 - Deformações plásticas ocorridas nas superfícies dos compósitos E/P20T (a) e E/P-20S (b) 99

Figura 50 - Micrografias das superfícies dos compósitos E/P-10T/10S (a) e E/P-20T (b) 100

Figura 51 - Micrografias da superfície do compósito E/P-20S (a e b) ...................101

Figura 52 - Micrografia da superfície do compósito E/P-20S .................................102

Figura 53 - Micrografia da superfície do compósito E/P-20S ...............................103 


\section{LISTA DE TABELAS}

Tabela 1 - Composição das amostras de PP homopolímero, em peso ...................54

Tabela 2 - Composição as amostras de PP copolímero/POE, em peso .................54

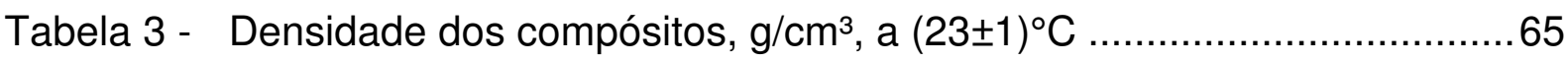

Tabela 4 - Temperatura de cristalização $\left(T_{c}\right)$, temperatura de fusão $\left(T_{m}\right)$, entalpia de fusão $\left(\Delta \mathrm{H}_{\mathrm{m}}\right)$ e grau de cristalinidade $\left(\mathrm{X}_{\mathrm{c}}\right)$ para os diversos compósitos estudados ................................................................ 77

Tabela 5 - Resultados obtidos para as propriedades de contração longitudinal, transversal e anisotropia para os compósitos 20T, 10T/10S-2, 20S-2 e $20 \mathrm{~S}-4$

Tabela 6 - Resultados obtidos para as propriedades de emissão de carbono e de odor dos compósitos 10T/10S-2 e 20S-2

Tabela 7 - Densidade dos compósitos tenacificados, $\mathrm{g} / \mathrm{cm}^{3}$, a $(23 \pm 1)^{\circ} \mathrm{C}$ 85

Tabela 8 - Temperatura de cristalização $\left(T_{c}\right)$, temperatura de fusão $\left(T_{m}\right)$, entalpia de fusão $\left(\Delta \mathrm{H}_{\mathrm{m}}\right)$ e grau de cristalinidade $\left(\mathrm{X}_{\mathrm{c}}\right)$ para os compósitos tenacificados

Tabela 9 - Resultados obtidos para as propriedades de contração longitudinal, transversal e anisotropia para os compósitos tenacificados.

Tabela 10 - Resultados obtidos para a propriedade de resistência a riscos para os compósitos tenacificados. 


\section{SUMÁRIO}

1 INTRODUÇÃO............................................................................

1.1 OBJETIVO

2 REVISÃO DA LITERATURA ......................................................... 7

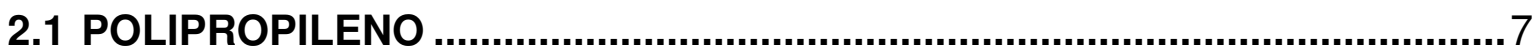

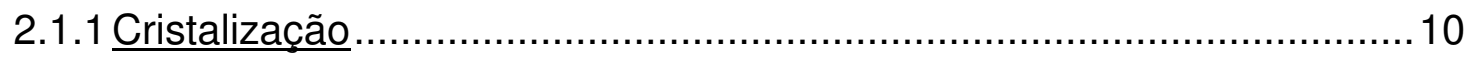

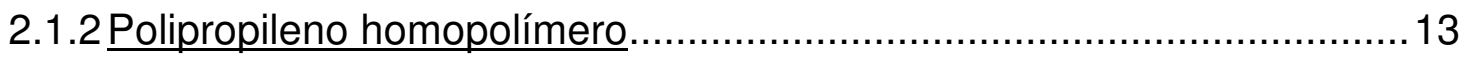

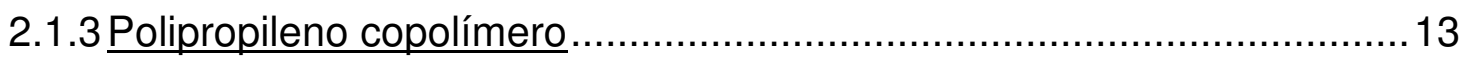

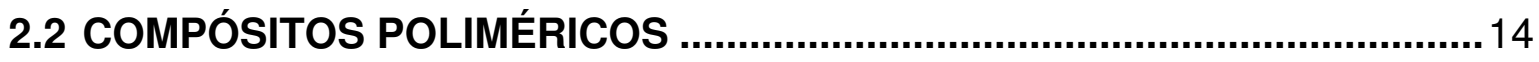

2.2.1 Compósitos reforçados com partículas .............................................. 15

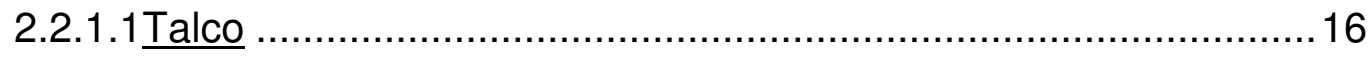

2.2.2 Compósitos reforçados com fibras curtas ..........................................17

2.2.2.1 Comprimento, orientação e concentração das fibras ..................18

2.2.2.2 Adesão interfacial fibra-matriz..............................................19

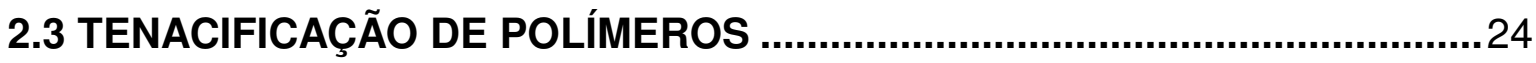

2.3.1 Tenacificação de polipropileno com elastômeros................................26

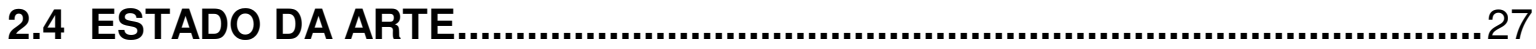

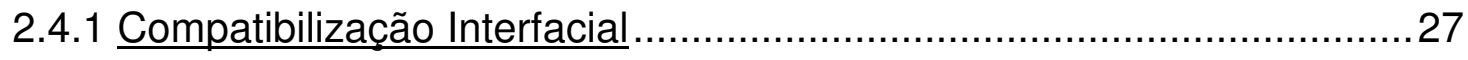

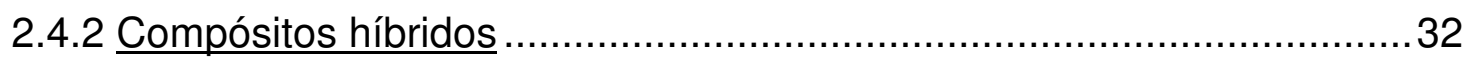

2.4.3 Compósitos de polipropileno modificados com elastômeros..................35

2.5 REQUISITOS ESPECÍFICOS PARA A INDÚSTRIA AUTOMOTIVA ..............42

2.5.1. Controle de emissões de voláteis ……..............................................42

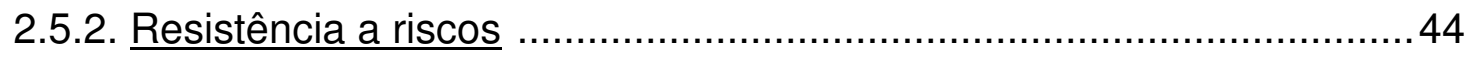

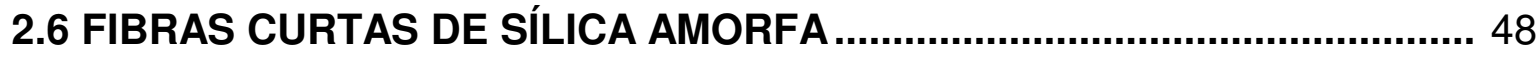

3 MATERIAIS E MÉTODOS ..........................................................51

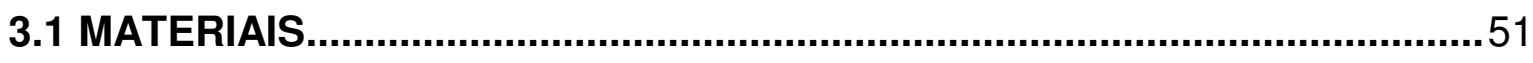

3.1.1 Compósitos de polipropileno homopolímero .......................................51

3.1.2 Compósitos de polipropileno copolímero modificados com POE ..........52

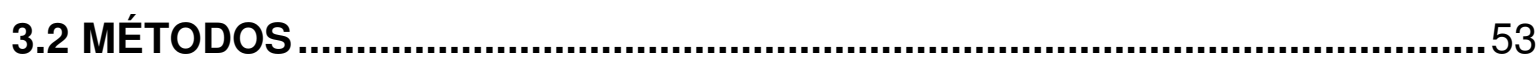

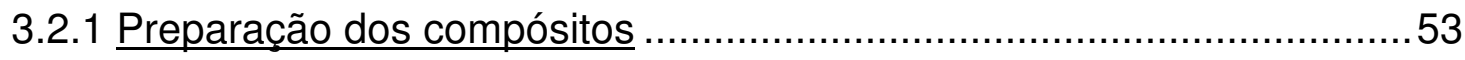

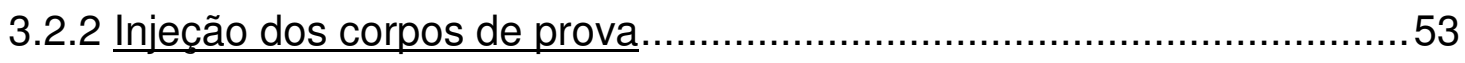


3.2.3 Composição das amostras .54

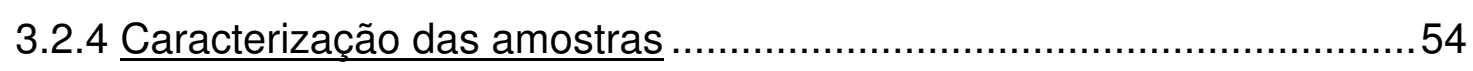

3.2.4.1 Distribuição e comprimento das fibras antes e após moldagem 54

3.2.4.2 Densidade dos compósitos .................................................. 55

3.2.4.3 Propriedades mecânicas dos compósitos.................................55

3.2.4.4 Propriedades térmicas dos compósitos ……............................56

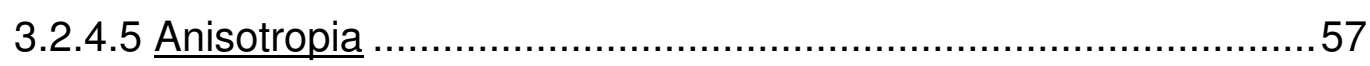

3.2.4.6 Caracterização morfológica..................................................57

3.2.4.7 Caracterização de propriedades específicas - comportamento a

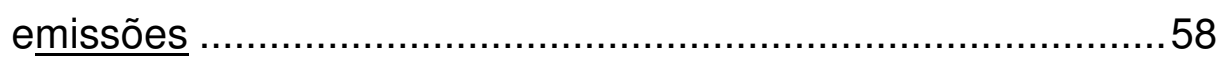

3.2.4.7.1 Emissão total de compósitos orgânicos ................... 58

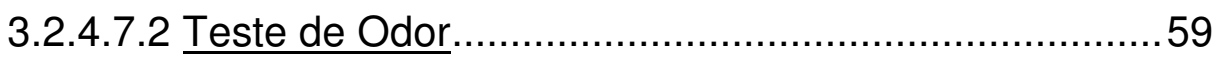

3.2.4.8 Teste de resistência a riscos .................................................. 60

4 RESULTADOS E DISCUSSÃO ......................................................62

4.1 COMPÓSITOS DE POLIPROPILENO HOMOPOLÍMERO ............................62

4.1.1 Distribuição e comprimentos das fibras antes e após moldagem...........62

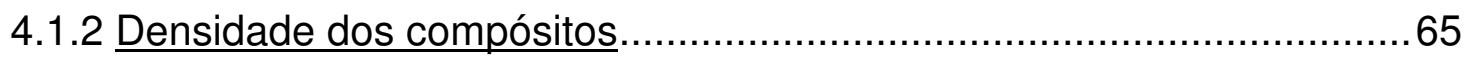

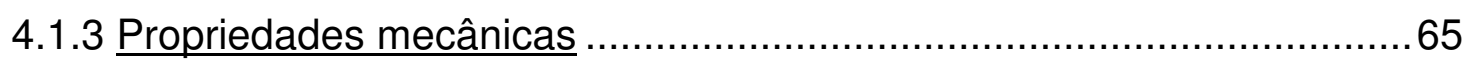

4.1.4. Propriedades térmicas.............................................................. 76

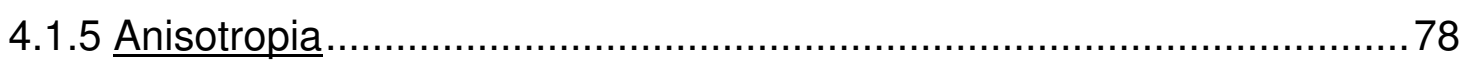

4.1.6 Propriedades específicas - comportamento a emissões ......................79

4.1.7 Caracterização morfológica (MEV) ……....................................... 80

4.2 COMPÓSITOS DE POLIPROPILENO MODIFICADOS COM POE .................84

4.2.1 Densidade dos compósitos............................................................... 84

4.2.2 Propriedades mecânicas .............................................................. 85

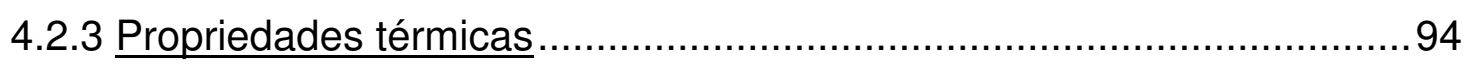

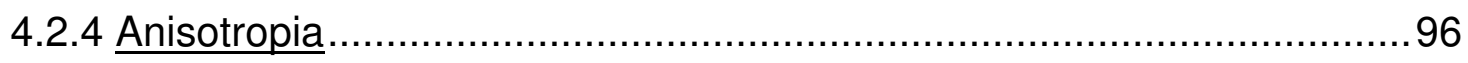

4.2.5 Propriedades específicas - resistência ao risco ....................................96

4.2.6 Caracterização morfológica (MEV) ………................................... 100

5 CONCLUSÕES ......................................................................... 104

5.1 COMPÓSITOS DE POLIPROPILENO HOMOPOLÍMERO ...........................104

5.2 COMPÓSITOS DE POLIPROPILENO MODIFICADOS COM POE ..............106 REFERÊNCIAS BIBLIOGRÁFICAS..................................................107 


\section{INTRODUÇÃO}

A segurança dos ocupantes, a funcionalidade, o desempenho e a qualidade final do veículo sempre estiveram entre os requisitos primordiais considerados pela indústria automotiva durante a escolha e o desenvolvimento de materiais utilizados em peças e componentes, refletindo o desejo dos consumidores finais.

As crescentes preocupações sobre o impacto que os automóveis exercem sobre o meio ambiente motivam novos regulamentos ambientais, como o recém proposto pela Comissão Européia (CE), nำ 443/2009 de 23 de abril de 2009, com metas para a redução de emissões de dióxido de carbono $\left(\mathrm{CO}_{2}\right)$ para automóveis novos de passageiros, os quais representam, aproximadamente, $12 \%$ das emissões de carbono da União Européia. O objetivo é atingir uma redução média de $160 \mathrm{~g}$ $\mathrm{CO}_{2} / \mathrm{km}$ para $130 \mathrm{~g} \mathrm{CO}_{2} / \mathrm{km}$, de forma escalonada, a partir de 2012 até 2015, orientada por uma curva de valores limites. As medidas prevêem sansões aos fabricantes que não cumprirem os limites estipulados, entretanto, por outro lado, aqueles que tiverem os seus níveis de emissões acima da curva limite, receberão incentivos na forma de créditos de carbono. ${ }^{1}$

Apesar dos sucessivos fracassos das negociações relativas à tomada de medidas para evitar o aquecimento global, ocorridas nas últimas conferências mundiais, o novo regulamento proposto pela CE gerou debates e novos desafios para a indústria automobilística quanto ao desenvolvimento de produtos com melhor desempenho e inseridos no conceito de sustentabilidade, porém sem comprometimento à competitividade tão determinante e exigida pelo mercado atual.

Dentre os novos princípios para o desenvolvimento sustentável de produtos encontram-se a redução do consumo de combustíveis, a melhoria da eficiência e da manutenção dos recursos (reciclagem, utilização de materiais de fontes renováveis, desenvolvimento de novas tecnologias, alternativas de sistemas para 0 armazenamento de energia), bem como a proteção à saúde humana.

A preocupação com a saúde humana leva a atuações como a de redução de emissões não só provenientes de combustíveis, mas também de voláteis no interior dos automóveis, os quais se tratam de substâncias presentes nas composições dos materiais empregados nos revestimentos internos, liberadas sob a ação de 
temperaturas altas. O controle de tais emissões internas não é uma atividade recente para algumas indústrias automotivas, que a tempo dispõem de normas e especificações adequadas para a avaliação e determinação dos valores permitidos. O "cheirinho do carro novo" é mantido sem comprometimentos à saúde ou ao bem estar dos ocupantes.

Quanto ao controle das emissões externas, a economia de combustível, antes vista como apenas uma vantagem, torna-se primordial neste novo contexto, e a diminuição do peso do veículo, pelo emprego de novos materiais, é um dos pontos chaves para se atingir esse propósito em curto prazo.

Nas últimas décadas, o uso dos plásticos tem contribuindo significativamente para inovações tecnológicas, substituindo materiais tradicionais com vantagens em vários aspectos, tais como a segurança, o desempenho, o menor consumo de combustível, além da liberdade de criação de conceitos diferenciados. A utilização de peças plásticas internas moldadas por injeção, como os painéis de porta, por exemplo, além de reduzirem o peso final do veículo, mantêm ou melhoram o desempenho em testes que simulam impactos laterais e que fazem parte dos requisitos de segurança do veículo. Além disso, os revestimentos plásticos internos permitem a diminuição dos níveis de ruído e vibração. O emprego de componentes plásticos externos, como aerofólios, parachoques, paralamas, dentre outros, permitem abaixar o centro de gravidade do veículo, trazendo-o mais próximo do equilíbrio, melhorando características como estabilidade e dirigibilidade. As vantagens proporcionadas por polímeros e compósitos são realmente inúmeras e, em razão disto, atualmente, para um veículo de médio porte, estima-se que $8,3 \%$ do peso do mesmo correspondam à presença destes.

O polipropileno é um versátil termoplástico olefínico e possui uma ampla faixa de aplicação em peças automotivas, oferecendo, além do custo baixo, uma combinação de propriedades mecânicas boas, facilidade de moldagem, acabamento superficial excelente, resistência química, estabilidade à luz U.V, dentre outras. A boa resistência à luz solar permite que peças em polipropileno não sejam pintadas, melhorando a reciclabilidade e reduzindo custos de processos. Sendo, em média, de 15 a 20\% mais leve que outros polímeros, é uma solução muito atrativa para o cumprimento das novas regulamentações ambientais. É um dos polímeros mais estudados quando o assunto é compósitos poliméricos. A adição de minerais funcionais e/ou fibras, ou a combinação destas, em matrizes de polipropileno, além 
de proporcionar sistemas com propriedades mecânicas elevadas, permite também a extensão do uso do mesmo em aplicações nas quais são utilizados plásticos de engenharia mais onerosos, como, por exemplo, o $\mathrm{ABS}^{2,3}$

Talco e sílica são exemplos de minerais utilizados em compósitos de polipropileno. O talco, silicato de magnésio hidratado, está presente em várias aplicações industriais. ${ }^{4}$ Diferentemente de outros minerais, é bem eficiente como reforço em polipropileno com relação às propriedades mecânicas e à estabilidade térmica e dimensional (melhor orientação macromolecular dos compósitos). A adição de talco interfere na temperatura de início de cristalização, aumentando ciclos de processo pela redução do tempo de moldagem por injeção. ${ }^{5}$ A sílica apresenta-se em diversas fases distintas e quimicamente definidas como $\mathrm{SiO}_{2}$. Alguns tipos de sílica, como a sintética ou coloidal, a pirogênica ou fumed silica, a fundida e a precipitada, são empregadas em polímeros e apresentam diferentes comportamentos. ${ }^{6}$ Compósitos poliméricos com cargas extraídas do solo foram sempre objeto de estudos científicos. Algumas publicações recentes ${ }^{5,7}$ citam o aumento da resistência à abrasão, ao calor, à resistência ao risco, bem como a redução do coeficiente de expansão térmica, para compósitos de polipropileno reforçados com sílicas específicas.

As fibras curtas de vidro são muito utilizadas em polímeros em geral, incluindo polipropileno, por apresentarem vantagens em termos de custo e de desempenho mecânico, apesar das desvantagens relacionadas à densidade alta, ao difícil processamento (dispersão baixa, liberação de calor alta e ação abrasiva sobre o molde), à tenacidade baixa obtida pelos compósitos e aos efeitos de anisotropia, como os de empenamento de peças moldadas. ${ }^{8,9}$

Em se tratando de aplicações automotivas, compósitos de polipropileno reforçados com talco (em concentrações de 10 a 40\% em peso), assim como, com fibras curtas de vidro (com 20 a $30 \%$ em peso), são os mais utilizados e estão presentes ao longo de todo o veículo. Estes são empregados em componentes funcionais, estruturais ou de aparência, pertencentes ao acabamento interno e externo do veículo, bem como em peças próximas ou na região do motor (under-thehood). Por outro lado, o uso de cargas reforçantes em compósitos de polímeros semicristalinos como o polipropileno, restringem a aplicação em peças ou componentes que requerem um melhor comportamento quanto à resistência ao impacto em temperaturas baixas, por exemplo. Para que a tenacidade do compósito 
seja melhorada, alguns agentes são adicionados à formulação, como plastificantes, uso de comonômeros para sintetizar polímeros e adição de modificadores de impacto. ${ }^{10}$ Elastômeros como EPDM (monômero de etileno-propileno-dieno) e EPR (borracha de etileno-propileno) têm sido modificadores usuais para polipropileno. Mais recentemente, os copolímeros de etileno e alfa-olefinas, bem como os elastômeros termoplásticos (TPEs), também passaram a ser utilizados com resultados muito satisfatórios. O uso de elastômeros olefínicos metalocênicos à base de etileno e 1-octeno (POE) para a tenacificação do polipropileno é muito conveniente face à similaridade química entre ambos, proporcionando assim uma melhor adesão interfacial. Compósitos de polipropileno tenacificados e reforçados com talco são empregados em painéis de instrumentos, por exemplo. Tais peças devem atender a especificações rígidas com relação ao balanço de rigidez e tenacidade em ampla faixa de temperatura $\left(-30^{\circ} \mathrm{C}\right.$ a $\left.+110^{\circ} \mathrm{C}\right)$, estabilidade dimensional e fratura dúctil.

A impressão do interior de um veículo depende muito da qualidade de superfície de peças plásticas, como coberturas de colunas, painéis de portas e painel de instrumentos. Em veículos mais luxuosos isto é conseguido pela aplicação de revestimentos de policloreto de vinila (PVC), termoplásticos poliolefínicos (TPOs), tecidos, couros, pintura, dentre outros. Entretanto, para os veículos mais populares, com peças em polipropileno sem pintura e moldadas em diferentes cores, a qualidade superficial está diretamente relacionada a aspectos como textura, brilho baixo, isenção de marcas e linhas de fluxo (defeitos de injeção) e resistência a riscos. Este último requisito tornou-se um importante parâmetro de investigações não só com relação à definição de metodologias de análise, desenvolvimento de aditivos, mas também pelo efeito deletério proporcionado por cargas minerais, como o talco.

Pesquisadores ${ }^{8,11,12}$ citam o efeito de uma fibra natural inorgânica curta $\left(\right.$ Silexi $\left.{ }^{\circledR}\right)$, obtida de recursos minerais em abundância no Brasil, quanto à incorporação como agente de reforço em plásticos. Este tipo de fibra apresenta perto de $100 \%$ em massa de sílica amorfa e densidade de $1,73 \mathrm{~g} / \mathrm{cm}^{3}$, sendo proveniente de minerais denominados espongilitos, que são espículas de sílica originadas de esqueletos de esponjas de água doce e de organismos semelhantes. O material natural é oco, de cor branca, tratado superficialmente com aminossilano para melhor acoplamento com a matriz polimérica. ${ }^{8}$ Em um estudo recente, Sato ${ }^{11}$ 
analisou a aplicação desta fibra em compósitos híbridos de polipropileno homopolímero com fibra de madeira e agente de acoplagem, os quais apresentaram boas propriedades mecânicas e redução de peso. As mesmas fibras foram ainda avaliadas por Segatelli ${ }^{12}$ como agentes de reforço em compósitos ternários de poliamida 6, borracha de etileno-propileno-dieno funcionalizada com anidrido maleico (EPDM-g-AM), também com resultados satisfatórios, inclusive evidenciando tenacidade boa sem comprometimento crítico à rigidez.

Neste trabalho, utilizou-se polipropileno como matriz polimérica e a fibra de sílica natural Silexil ${ }^{\circledR}$ como principal agente de reforço. O interesse no emprego desta fibra deve-se a fatores como disponibilidade imediata, volumes altos de produção (os quais constituem requisitos primordiais para o fornecimento à indústria automobilística), bons resultados presentes na literatura e, principalmente, pela massa específica baixa, comparada à da fibra de vidro e à do talco.

\subsection{OBJETIVO}

O objetivo principal deste trabalho foi avaliar a viabilidade do uso de fibras curtas de sílica como agente de reforço, tanto em compósitos de polipropileno homopolímero, como em compósitos de polipropileno heterofásico modificados com o copolímero etileno e 1-octeno (POE). Visou-se à aplicação em peças internas automotivas, com a vantagem de diminuição da densidade (em função da massa específica baixa das fibras).

Com este propósito, foram estabelecidos os seguintes passos:

- Desenvolver formulações com $20 \%$ de fibras de sílica, em peso, e caracterizá-las quanto às propriedades mecânicas, às térmicas, às características morfológicas e à anisotropia. Avaliá-las também, de acordo com possível aplicação, quanto à resistência a riscos e ao comportamento a emissões, os quais constituem requisitos específicos de uma montadora de veículos.

- Estabelecer comparações com compósitos de mesma formulação, porém, reforçados com talco em igual teor, bem como com os polímeros puros. 
- Caracterizar compósitos de polipropileno híbridos com o emprego de talco, com a meta de redução do efeito de anisotropia causado pela presença das fibras.

- Proporcionar o aumento da afinidade entre as fibras inorgânicas e a matriz de polipropileno homopolímero por meio da variação de teores de polipropileno funcionalizado com anidrido maleico (0, 1, 2 e 4\% em peso de PP-g-MAH) e determinar a concentração ótima deste aditivo. 


\section{REVISÃO DA LITERATURA}

Este capítulo será iniciado por uma breve abordagem sobre conceitos e dados relevantes ao estudo de compósitos reforçados de matriz de polipropileno, visando proporcionar subsídios para uma melhor compreensão do trabalho experimental e das referências bibliográficas citadas. $O$ objetivo do item seguinte é a realização de uma revisão que permita um conhecimento do estado da arte, com a seleção de trabalhos interessantes nas áreas de compatibilização interfacial em compósitos de polipropileno com fibras e partículas e de efeitos de hibridização em compósitos e blendas de polipropileno com elastômeros (com ou sem adição de cargas). $O$ assunto do penúltimo item deste capítulo é sobre os requisitos específicos de comportamento a emissões e de resistência a riscos, os quais são considerados pela indústria automotiva na avaliação e escolha de compósitos poliméricos. O capítulo será finalizado com a descrição da fibra curta de sílica Silexil ${ }^{\circledR}$, que é base de referência para esta pesquisa.

\subsection{POLIPROPILENO}

O polipropileno é produzido pela polimerização do propileno, o qual é um subproduto gasoso de refino de petróleo, na presença de um catalisador e sob controlados parâmetros de pressão e temperatura. ${ }^{13}$ Esta reação de polimerização está mostrada na Figura 1.

n

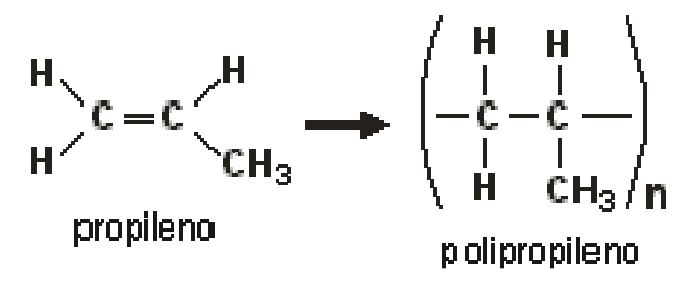

Figura 1 - Esquema da reação de polimerização do polipropileno 
Os principais fatores que podem alterar as propriedades do polipropileno são a taticidade (regularidade espacial do grupo $\mathrm{CH}_{3}$ na cadeia polimérica), a massa molar e as condições de cristalização. Esses parâmetros e o mecanismo envolvido na cristalização são relevantes para as propriedades do produto final, que por sua vez dependem do tamanho dos esferulitos, do grau de cristalinidade, da região interfacial e amorfa, e da sua morfologia. ${ }^{14}$

A viabilidade comercial do polipropileno foi possível com base em pesquisas do Professor G. Natta da Polietecnico di Milano, em 1954, na Itália, por meio da utilização do sistema de catalisador esteroespecífico de Ziegler. As macromoléculas de polipropileno podem conter milhares de unidades monoméricas e massa molar alta. O termo estereoespecífico do catalisador se refere à característica de controlar a posição do grupo metila $\left(\mathrm{CH}_{3}\right)$ na cadeia polimérica de forma ordenada, o que resulta na obtenção de materiais com estruturas regulares, como os polipropilenos sindiotático e isotático, de grande interesse comercial. ${ }^{15}$

O polipropileno pode ser sintetizado nas formas isotática, sidiotática e atática. No polipropileno isotático (Figura (2b)), os grupos metila estão todos no mesmo lado e no mesmo plano da cadeia polimérica. Quando os grupos metila apresentam-se acima e abaixo do plano da cadeia polimérica, alternadamente, como mostrado na Figura 2(c), o polipropileno é classificado como sindiotático. Não há regularidade de disposição para os atáticos (Figura (2a)). O catalisador Ziegler-Natta é utilizado apenas para a produção de polipropilenos isotáticos e sindiotáticos. Em razão da formação de arranjos cristalinos regulares, os polipropilenos isotático e sindiotático são cristalinos, entretanto, o isotático possui um grau de cristalinidade maior, o que resulta em propriedades mecânicas boas de rigidez e de resistência à tração. $O$ polipropileno sindiotático é menos rígido e apresenta ponto de fusão menor que o isotático, porém possui melhor resistência ao impacto. O polipropileno atático, com estrutura quase que totalmente amorfa, apresenta-se mais flexível e macio, sendo utilizado em adesivos e selantes. ${ }^{13}$ 
(a)

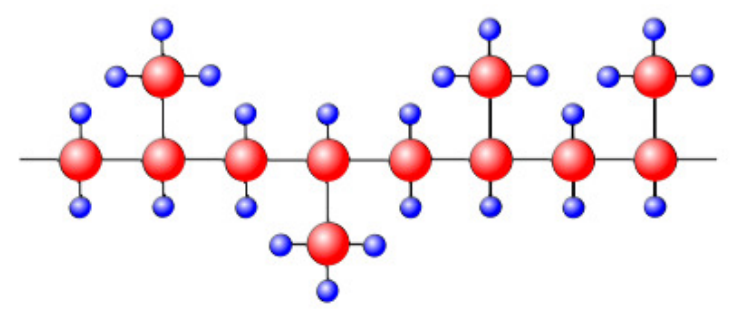

(b)

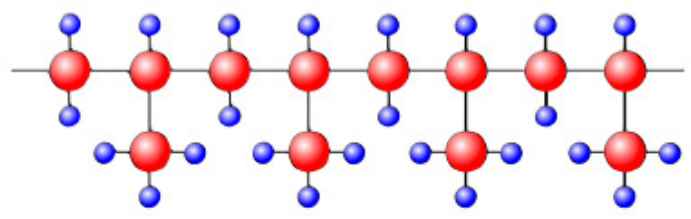

(c)

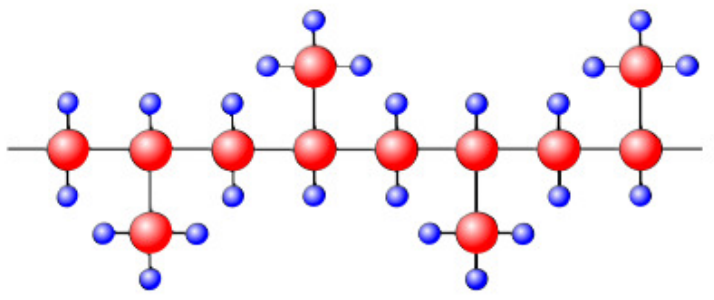

Figura 2 - Estruturas isoméricas do polipropileno: polipropileno atático (a), polipropileno isotático (b) e polipropileno sindiotático (c) ${ }^{16}$

Um grande número de pesquisas no âmbito da microestrutura química tem sido realizado nos últimos cinquenta anos, com o propósito de contornar as deficiências do polipropileno, aproximando-o aos plásticos de engenharia quanto às propriedades finais. Assim, destacam-se o surgimento de copolímeros e de catalisadores de controle microestrutural alto como os metalocenos. Através desta nova geração de catalisadores, a sexta para o polipropileno, torna-se possível, por exemplo, obter polímeros de isotaticidade alta, com massas molares muito mais altas que aqueles obtidos pelo tipo Ziegler-Natta. ${ }^{17}$

As propriedades físicas e as características de processamento do polipropileno também são determinadas pela massa molar e pela distribuição desta, bem como do tipo e a quantidade do monômero copolimerizado. No processo de polimerização as cadeias obtidas apresentam comprimentos variados. Equações foram então formuladas para a determinação da massa molar do polímero $\left(\mathrm{M}_{\mathrm{n}}\right)$, da massa molar ponderal $\left(M_{w}\right)$ e para a polidispersividade, a qual é determinada pela razão $M_{w} / M_{n}$. Normalmente, o polipropileno possui $M_{n}$ de 38.000 a $68.000, M_{w}$ de 220.000 a 700.000 e razão $M_{w} / M_{n}$ de 5 a 12 , o que resulta em cadeias moleculares da ordem 
de $1000 \AA$ Å. Uma das técnicas de avaliação da massa molar é a determinação do índice de fluidez (MFI). ${ }^{18,19}$

\subsubsection{Cristalização}

A cristalização de materiais poliméricos é descrita como a solidificação organizada das cadeias pelo empacotamento destas, gerando uma matriz atômica ordenada. Ao aumentar a cristalinidade de um material, aumentam-se também propriedades como rigidez, resistência mecânica e densidade, entretanto, por outro lado, diminuem os requisitos de resistência ao impacto, de tenacidade e de ductilidade. Por ser semicristalino, o polipropileno apresenta regiões cristalinas dispersas em uma matriz amorfa. A região amorfa está associada à desordem da cadeia e é responsável pelo comportamento visco elástico do material. ${ }^{18}$

A cristalinidade do polipropileno é influenciada principalmente por fatores estruturais (como linearidade de cadeia, taticidade, copolimerização, entre outros), pela presença de fatores externos (como aditivos) e pelas condições de processamento. $^{14}$

Segundo Tokumoto $^{17}$, a estrutura cristalina do polipropileno (em uma peça injetada, por exemplo) apresenta os seguintes níveis de organização, os quais também estão mostrados na Figura 3:

- Macroestrutura da superfície e centro da peça, a qual é dependente da condição de processamento;

- Morfologia esferulítica e fase de blenda (estrutura de organização cristalina do polipropileno);

- Morfologia lamelar, tamanho e organização (os esferulitos são compostos por lamelas na forma de feixes que crescem radialmente com base em um núcleo central);

- Estrutura do cristal. 


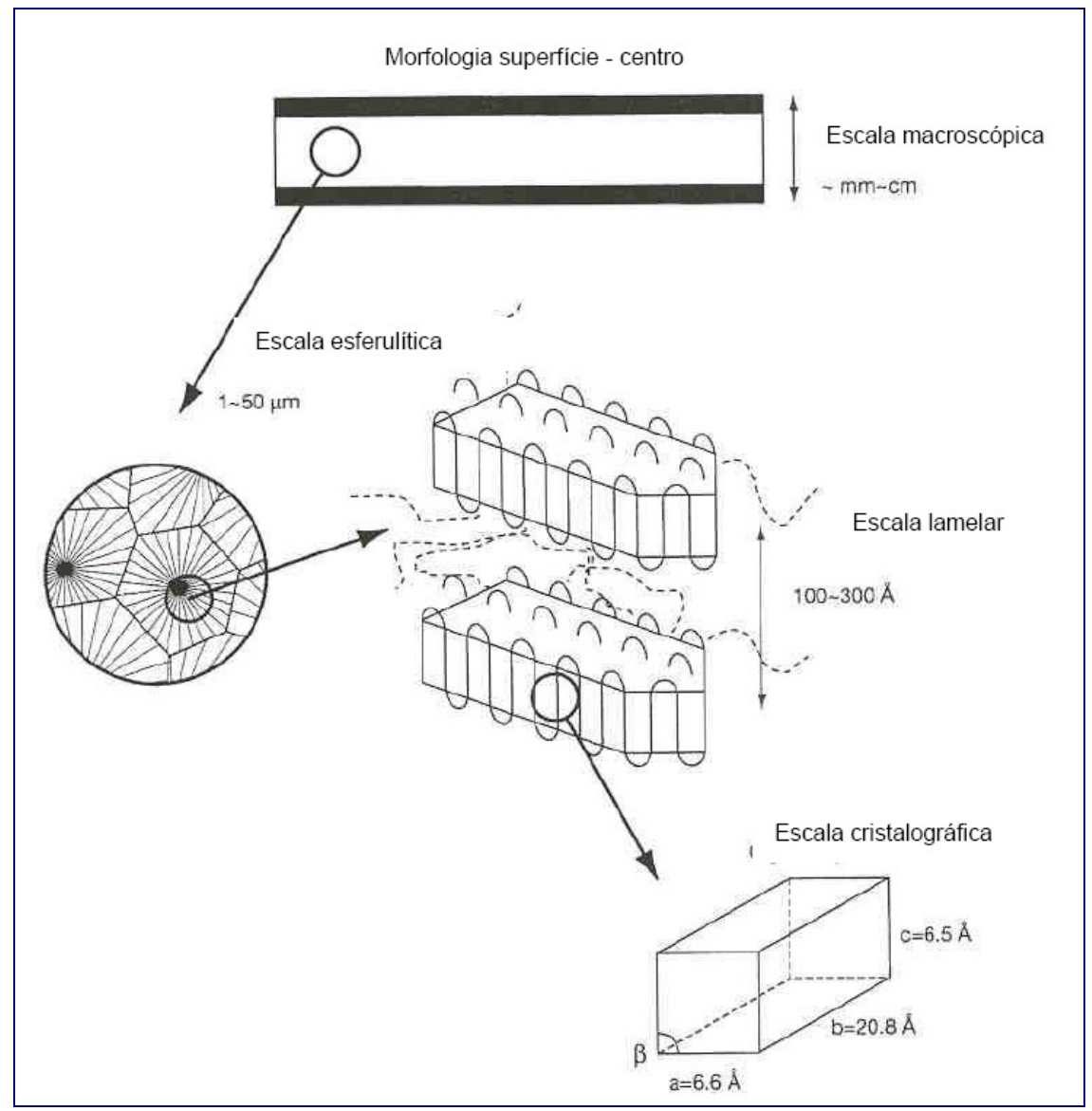

Figura 3 - Características dos níveis de estrutura morfológica do polipropileno ${ }^{17}$

A forma de cristalização das cadeias é muito importante para a morfologia final de um polímero. A cristalização ocorre entre a temperatura de transição vítrea $\left(T_{g}\right)$ e a temperatura de fusão $\left(T_{m}\right)$, pois em temperatura inferior à $T_{g}$, o polímero não teria energia interna suficiente para a mobilidade das cadeias e formação dos esferulitos. A temperatura de cristalização $\left(T_{c}\right)$ é definida como a temperatura na qual ocorre a maior taxa de conversão da cristalização. A cristalização ocorre por difusão em temperaturas mais baixas e por nucleação em temperaturas elevadas. $O$ crescimento e a quantidade de esferulitos dependem do número de núcleos formados sob certa velocidade de nucleação. Quanto maior a velocidade, maior o número de núcleos formados, e menores serão os tamanhos dos esferulitos. Desta forma, o grau de cristalização é geralmente favorecido por um resfriamento suave a partir da fusão. ${ }^{18}$

A presença de agentes nucleantes propicia núcleos adicionais para 0 crescimento de cristais, contribuindo para a formação de esferulitos menores e em 
maior número no polímero cristalizado. ${ }^{13}$ Estes agentes podem ser impurezas, defeitos na cadeia polimérica, cargas, pigmentos ou a parede do molde de injeção. As cargas minerais com melhor capacidade de nucleação induzem a uma maior temperatura de cristalização. ${ }^{10}$

O polipropileno também apresenta polimorfismo, podendo existir em diferentes formas morfológicas, dependendo da taticidade da resina e das condições de processamento. O polipropileno apresenta as seguintes formas cristalinas: monoclínica $\left(\alpha^{\prime}\right)$, hexagonal $\left(\beta^{\prime}\right)$, triclínica $\left(\gamma^{\prime}\right)$ e esmética $\left(S_{m}\right)$. Estas formas divergem entre si de acordo com os ângulos $\alpha, \beta, \gamma$, e com os eixos $a, b, c$, de uma célula cristalina, conforme mostrado na Figura 4. Com relação ao polipropileno isotático, a forma $\alpha$ ' ou monoclínica é a mais usual, com conformação de cadeia na forma de hélice. A forma $\beta$ ', apresenta maior grau de desordem que a forma $\alpha$, para a qual pode ser convertida sob aquecimento. A forma $\gamma$ não é usual para o polipropileno em condições típicas de processamento. Esta ocorre pela presença de cadeias curtas, pela adição de comonômeros e, principalmente, pela cristalização sob pressão. A forma esmética $(\mathrm{Sm})$ ocorre geralmente em resfriamentos bruscos, sendo comum em filmes. ${ }^{18,20,21}$

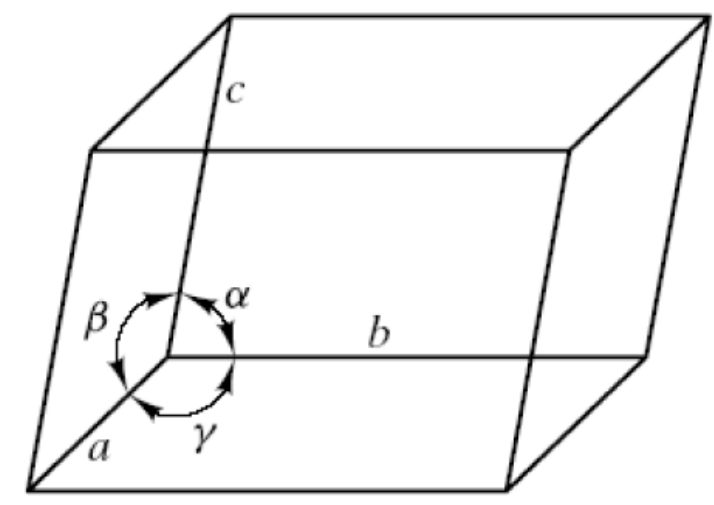

Figura 4 - Célula unitária (cristal) ${ }^{18}$

O polipropileno isotático apresenta uma célula monoclínica ( $\alpha$ ') com os seguintes parâmetros de rede: $a=6,65 \pm 0,05 \AA ; b=20,96 \pm 0,15 \AA$; $c=6,50 \pm$ $0,04 \AA ; \alpha=\gamma=90^{\circ}$ e $\beta=99^{\circ} 20^{\prime} .^{14}$ 


\subsubsection{Polipropileno homopolímero}

O polipropileno homopolímero, de maior emprego comercial, possui configuração isotática na temperatura ambiente, sendo obtido por catálise estereoespecífica de Ziegler-Natta. A cristalinidade deste polímero varia em torno de 40 a $70 \%$, e o grau de isotaticidade por volta de 93 a $95 \% .{ }^{18}$ As suas principais propriedades são uma rigidez boa e resistência térmica alta, com resistência ao impacto limitada à temperatura baixa.

\subsubsection{Polipropileno copolímero}

O polipropileno é produzido comercialmente em formas diferentes, dependendo das propriedades almejadas. Além do homopolímero, descrito anteriormente, os copolímeros randômicos e os de impacto (ou heterofásicos) são muito empregados industrialmente. O polipropileno homopolímero é formado apenas de monômeros de propileno, enquanto que os copolímeros possuem um ou mais tipos diferentes de monômeros na cadeia principal, o que lhes atribuem uma faixa de propriedades e aplicações maior. Nos copolímeros randômicos, o etileno é adicionado no reator durante o processo de polimerização, cujas unidades são inseridas ao longo da cadeia de polipropileno "perturbando" a estrutura regular e repetitiva, comparativamente ao polipropileno isotático. A introdução de um comonômero melhora as propriedades ópticas pelo decréscimo da cristalinidade. Os copolímeros randômicos podem conter até $7 \%$ de etileno. No caso de copolímeros heterofásicos, uma fase elastomérica de eteno-propeno é dispersa uniformemente na matriz do homopolímero de polipropileno, durante a polimerização no reator. A quantidade de etileno final pode ser maior que $25 \%$. A introdução do elastômero aumenta a resistência ao impacto da resina, principalmente em temperaturas baixas, em razão da diminuição na rigidez, na dureza e na resistência do material. ${ }^{13,20}$

Antes da descoberta de catalisadores suportados em $\mathrm{MgCl}_{2}$, de atividade catalítica alta, os copolímeros heterofásicos eram produzidos pelos processos de 
mistura posterior, em extrusoras. As propriedades finais dos materiais obtidos por estes processos eram limitadas. As grandes diferenças de viscosidade dos vários componentes na mistura originavam a formação de domínios microscópicos de partículas de borracha de módulo baixo. Durante um impacto, um tamanho ótimo de partícula é necessário para que a energia seja absorvida, aliviando-se tensões de estresse e reduzindo a possibilidade de fratura frágil do material. Atualmente, com o emprego de catalisadores com atividade catalítica baseada em sais de Titânio (Ti), suportados em $\mathrm{MgCl}_{2}$, tornou-se possível a obtenção de estruturas ideais de polímeros heterofásicos diretamente no reator. Este processo é capaz de controlar a polimerização da fase borracha, a qual deve ser dispersa de forma mais homogênea possível na matriz de polipropileno, com tamanhos de partículas ideais para que o melhor balanço em termos de tenacidade e resistência ao impacto seja atingido. ${ }^{22}$

\subsection{COMPÓSITOS POLIMÉRICOS}

A definição de material compósito, segundo Ferrante ${ }^{23}$, é de um material composto de dois ou mais componentes, com natureza e formas diferentes, os quais se conservam distintos após o processamento, sendo separados por uma região de interface. O grau de adesão entre estes componentes deve permitir que as tensões sejam transferidas para os elementos de maior módulo e resistência mecânica, sendo geralmente dispersas no componente de fase contínua ou matriz.

Para a grande parte dos compósitos poliméricos, onde a matriz é um polímero como o polipropileno, a fase dispersa compreende partículas (cargas minerais ativas e funcionais) e fibras (de origem natural ou sintética), como elementos de reforço. A forma, o tamanho, a distribuição e a orientação dessas partículas e fibras, são parâmetros que influenciam diretamente as propriedades dos compósitos. ${ }^{24}$

Além das características individuais e das quantidades relativas das fases constituintes, fatores determinantes para a melhoria da resistência mecânica e de outras propriedades para os compósitos são: a natureza da interface matriz-reforço e a eficiência dos processos de composição e de conformação para a obtenção da forma final. 


\subsubsection{Compósitos reforçados com partículas}

Compósitos reforçados com partículas geralmente apresentam cargas de reforço mais duras e rígidas, as quais restringem o movimento da matriz ao seu redor. A matriz transfere parte da tensão aplicada às partículas, as quais devem suportar parte desta carga. Neste caso, a melhoria das propriedades mecânicas está diretamente relacionada a uma ligação forte na interface matriz-partícula. ${ }^{24}$

Alguns estudos encontrados na literatura são contraditórios quanto às propriedades mecânicas proporcionadas pelas cargas de reforço nos compósitos poliméricos. De uma forma geral, a resistência mecânica e o módulo aumentam com a diminuição do tamanho de partícula, por outro lado, a flexibilidade e a tenacidade diminuem. O conhecimento da distribuição granulométrica é um item relevante. A concentração de tensões no compósito se eleva com o aumento do tamanho da carga mineral. Por outro lado, com a redução do tamanho de partícula há uma tendência de aglomeração destas, que se tornam sítios de iniciação de trinca e que podem proporcionar a redução da rigidez ou da tenacidade. A forma da partícula também é um item importante em relação às propriedades mecânicas. As partículas com forma lamelar, como o talco e a mica, conferem ao PP uma melhor característica de reforço, comparativamente a partículas esféricas de vidro. ${ }^{25}$

Quanto menor for o tamanho da partícula, maior será a área superficial da carga, que constitui um fator primordial para a melhoria da interface polímero-carga. Um aumento dos pontos de adesão entre as duas fases implica em melhores propriedades mecânicas. Por outro lado, quanto maior a área superficial da partícula (geralmente medida em $\mathrm{m}^{2} / \mathrm{g}$ ), maior será a dificuldade de dispersão da mesma no polímero, bem como o controle da viscosidade durante o processamento da mistura. $^{18}$

Apesar de não se tratar de um tema recente, a melhoria da adesão entre a matriz polimérica e cargas inorgânicas particuladas continua sendo objeto de investigação de muitos estudos, principalmente em razão dos diferentes fatores envolvidos. Além dos já mencionados, entre esses fatores estão as características da superfície das partículas, como o caráter hidrofóbico ou hidrofílico, e a presença de grupos funcionais, os quais constituem considerações relevantes na busca de soluções. Tratamentos de superfície com agentes compatibilizantes são usualmente 
empregados para uma melhor aderência entre o mineral e o polímero, por meio de ligações químicas. ${ }^{5}$

\subsubsection{Talco}

O talco é a partícula de reforço usada neste estudo. Trata-se de um silicato hidratado de magnésio, com fórmula teórica $3 \mathrm{MgO} 4 \mathrm{SiO}_{2} \cdot \mathrm{H}_{2} \mathrm{O}$, cuja composição irá variar de acordo com o local de extração mineralógica. A estrutura cristalina do talco é formada por duas folhas de sílica $\left(\mathrm{SiO}_{2}\right)$, unidas por uma camada de brucita (hidróxido de magnésio, $\mathrm{MgO} \cdot \mathrm{H}_{2} \mathrm{O}$ ), de forma octaédrica. Em função da inexistência de grupos hidroxilas ou íons ativos nas superfícies das folhas elementares, denominadas basais, o talco é hidrofóbico e inerte. Estas camadas (lamelas) são sobrepostas umas sobre as outras, atribuindo a característica de tenacidade. A dureza baixa do talco (1 a 10 Moh's) é função da energia baixa das ligações de van der Waals, as quais unem as camadas adjacentes deste mineral. ${ }^{5,26}$

A presença da estrutura lamelar do talco contribui para a melhoria de propriedades de compósitos de polipropileno, principalmente quanto à relação rigidez-tenacidade. Quanto menores as partículas do talco, mais efetivos serão os ganhos para as propriedades citadas. A interação entre a superfície do talco e o grupo metil do polipropileno ocorre por meio de ligações de hidrogênio. A adição de talco também eleva a temperatura de deflexão térmica (HDT) e melhora as condições de processamento, reduzindo e uniformizando as contrações de moldagem. Análises por difusão de raios $X$ demonstraram que as partículas de talco contribuem para uma orientação dos cristais do polipropileno, o que corresponde a um crescimento epitaxial, onde o eixo-c das partículas do talco é alinhado com o eixo-b dos cristais do polipropileno., 27

O talco, em compósitos de polipropileno, age como um agente de nucleação. Análises por microscopia revelam que, na presença deste mineral, a densidade nuclear do polipropileno aumenta significativamente. O aumento da temperatura de cristalização $\left(T_{c}\right)$ diminui o tempo de processamento em moldagens por injeção. ${ }^{5}$ 


\subsubsection{Compósitos reforçados com fibras curtas}

Em sua maioria, os compósitos com fibra, como forma dispersa, apresentam melhor resistência e melhor rigidez em relação a compósitos reforçados com partículas.

Lopes e Souza ${ }^{28}$ mostraram por meio da Figura 5, os principais parâmetros (comprimento, orientação e concentração das fibras, assim como a adesão interfacial fibra-matriz) que interferem na qualidade de reforço de polímeros com fibras de vidro curtas. Segundo os autores citados, este gráfico permite verificar que a resistência de um compósito desloca ao longo da curva sigmoidal, por meio do ponto de referência na curva em "S", para valores maiores ou menores em função do comprimento da fibra. Um aumento na concentração e grau de orientação da fibra desloca a curva verticalmente para cima. A curva em " $S$ " também é deslocada à esquerda para comprimentos menores da fibra com o aumento da adesão interfacial fibra-polímero.

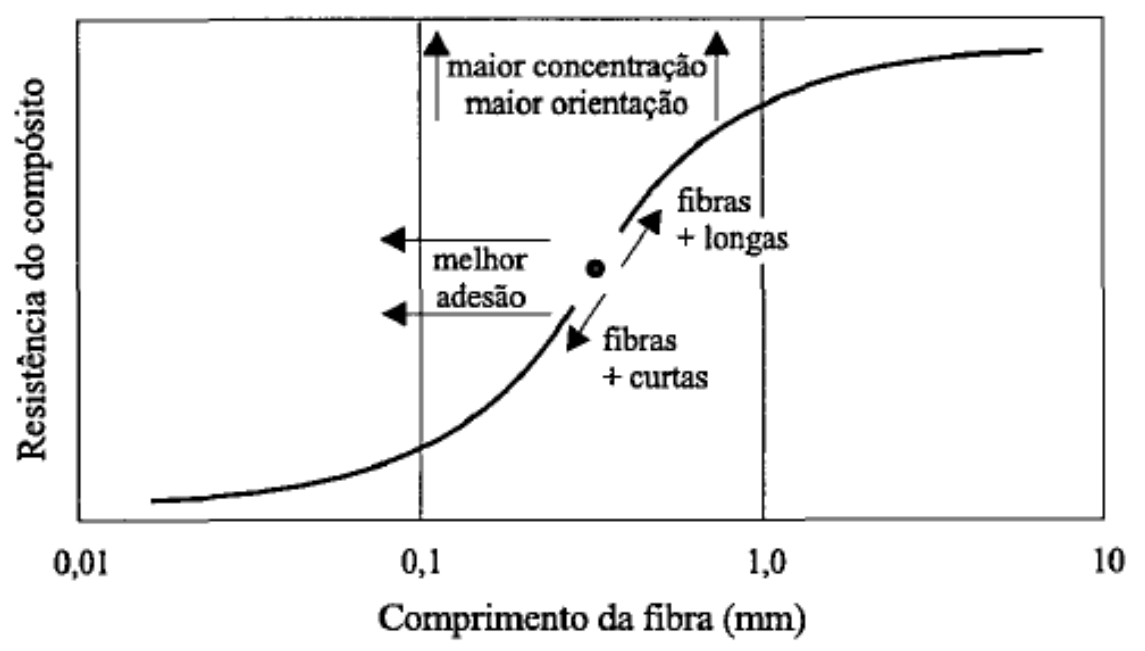

Figura 5 - Principais fatores que afetam a resistência mecânica dos compósitos de termoplásticos reforçados ${ }^{28}$ 


\subsubsection{Comprimento, orientação e concentração das fibras}

O grau pelo qual uma tensão é transmitida para as fibras pela fase matriz possui extrema importância para o reforço de compósitos. A magnitude da ligação interfacial entre fibra-matriz é um fator relevante para a extensão desta transmissão, que não ocorre nas extremidades da fibra. No caso de fibras contínuas, longas, quando o comprimento da fibra ( $($ ) é muito maior que o comprimento acima do qual a transferência de tensão ocorre, os efeitos das extremidades das fibras podem ser desconsiderados. Entretanto, para os compósitos com fibras curtas, a tensão é transferida da matriz para a fibra por meio do efeito de atrito e cisalhamento na região de interface e, desta forma, os efeitos dos finais das fibras não podem ser desprezados. Face ao exposto, o aumento efetivo na resistência e na rigidez de um compósito reforçado com fibras curtas está relacionado com a razão de aspecto crítica $(I / d)_{c}$, o qual é função do comprimento crítico $\left(I_{c}\right)$, do diâmetro $(d)$, da resistência à tração $\left(\sigma_{f}\right)$ e da resistência ao cisalhamento interfacial fibra-matriz $\left(\tau_{m}\right)$, de acordo com a eq. (1), desenvolvida por Kelly e Tyson: ${ }^{29}$

$$
(l / d)_{c}=\sigma_{f} / 2 \tau_{m}
$$

Portanto, para um grau maior de adesão fibra-matriz, o comprimento médio da fibra presente no compósito deve ser acima do seu comprimento mínimo crítico $\left(I_{c}\right)$. Logo, a preservação do comprimento médio das fibras, após os processos de preparação de misturas, compostagem e de transformação, é imprescindível para a obtenção de melhores propriedades mecânicas.

Durante um ensaio de tração, as respostas mecânicas dos compósitos dependem de fatores que incluem o arranjo ou orientação das fibras umas em relação às outras, bem como sua concentração e distribuição. Quanto à distribuição, quanto mais uniforme, melhores serão as propriedades mecânicas. Um aumento da concentração ou do teor de fibras resulta, geralmente, em um aumento do módulo e tensão máxima, em razão da contribuição da resistência mecânicas das fibras. Em relação à orientação, as fibras podem apresentar-se com o alinhamento em uma única direção ou em um alinhamento totalmente aleatório. A primeira possibilidade 
geralmente inclui as fibras contínuas, enquanto que a situação mais comum em compósitos com fibras contínuas é estas estarem aleatoriamente ou parcialmente orientadas. Os compósitos com fibras orientadas são intrinsecamente anisotrópicos, ou seja, a máxima resistência mecânica é obtida ao longo da direção do alinhamento, sendo que na direção transversal ao alinhamento, o reforço é praticamente desprezível. Para outras orientações de aplicação de tensão, a resistência terá um comportamento intermediário. ${ }^{24}$

Durante o processamento de compósitos poliméricos reforçados com fibras curtas, a orientação das fibras é alterada de forma significativa pela forma de escoamento proporcionado pelo fluxo do material fundido. Este tipo de comportamento pode gerar uma orientação preferencial das fibras após a moldagem, principalmente para os processos de injeção. Há a possibilidade de geração de camadas de moldado com fibras orientadas com maior ou menor intensidade e, como consequência, a variação das propriedades mecânicas. ${ }^{29}$

\subsubsection{Adesão interfacial fibra-matriz}

Pela equação de Kelly e Tyson, citada anteriormente, verifica-se que, quanto maior o valor da resistência à tração, obtido pela melhoria da adesão interfacial, menor será a dependência com o valor da razão de aspecto crítica, $(I / d)_{c}{ }^{18}$

A interface é a região de contato entre as fases constituintes de um compósito polimérico, sendo a principal responsável pela transferência de tensões da matriz para a fibra. Geralmente, as tensões localizadas se concentram nas proximidades da interface e, dependendo da natureza das interações entre o polímero e o tipo de fibras, podem iniciar uma falha prematura do compósito. É definida como uma superfície matematicamente bidimensional, fina e rígida, a qual divide as fases constituintes de um compósito. Isolada, não atribui nenhuma propriedade ao compósito. Uma vez que a transferência de tensões ocorre na interface, a única propriedade que a caracteriza é a resistência ao cisalhamento interfacial. ${ }^{30}$

Alguns pesquisadores, opondo-se à teoria da interface rígida, propuseram a teoria da camada interfacial deformável, a interfase, que promove um maior alívio das tensões interfaciais à medida que a espessura aumenta. ${ }^{31} \mathrm{~A}$ interfase é 
constituída por uma camada tridimensional ao redor da superfície da fibra, de ductilidade alta e resistência ao cisalhamento interfacial alta, proporcionando a transferência das tensões pelo polímero para as fibras e, consequentemente, um melhor equilíbrio das propriedades de rigidez e tenacidade do compósito. Com diferentes propriedades em relação às fases do compósito, a interfase é normalmente apenas referenciada para camadas introduzidas de forma intencional e controlada. ${ }^{30,31}$

A adesão interfacial entre a matriz polimérica e a fibra depende dos seguintes fatores: grau de contato (molhabilidade) das diferentes superfícies na interface, bem como das forças coesivas nesta mesma região. Uma adesão satisfatória é resultante de ligações atômicas e moleculares, localizadas de forma homogênea ao longo da região de interface. A magnitude destas ligações pode variar de fraca (como as do tipo van der Waals) a forte (como as covalentes ou iônicas). ${ }^{32}$

A molhabilidade está relacionada à capacidade do polímero (na forma líquida) "molhar" ou ser espalhado sobre a superfície das fibras. Quanto maior a molhabilidade, maior será o contato entre ambos, que é possível a nível molecular. A molhabilidade é dependente de um equilíbrio de forças ou energias superficiais durante o processo de molhamento das fibras pelo polímero. Um molhamento completo durante a etapa de incorporação da fibra só deverá ocorrer se a energia superficial do polímero for menor que a energia superficial crítica da superfície da fibra. A rugosidade superficial da fibra, bem como a temperatura, são fatores que alteram a molhabilidade. A molhabilidade não significa adesividade. Enquanto a molhabilidade está relacionada à extensão do contato entre fibra-matriz, a adesividade dependerá das interações entre as moléculas ou átomos de ambas as superfícies. ${ }^{29,32}$

Os agentes de acoplagem e os compatibilizantes interfaciais são utilizados em compósitos, visando à melhoria da adesão interfacial fibra-matriz. As fibras de reforço geralmente possuem caráter polar, entretanto o polipropileno é apolar. Este fato impede o molhamento eficiente de fibras por esse polímero, fazendo com que os compósitos apresentem propriedades finais baixas. Essa deficiência pode ser superada pelo tratamento superficial das fibras com agentes de acoplagem, como os titanatos, zirconatos, bem como os silanos. Os últimos são compostos semiorgânicos à base de silício, que tornam a superfície mais hidrofílica. Os agentes de 
acoplagem à base de silano são bifuncionais, ou seja, possuem substâncias que reagem com a superfície das fibras e com os grupos reativos do polímero. ${ }^{32,33}$

A equação $Y\left(\mathrm{CH}_{2}\right)_{3}$ SiX $X_{3}$, demonstra a estrutura geral de um organossilano, em que $Y$ representa um grupo facilmente hidrolisável (por exemplo, grupos metóxi, etóxi, cloreto) e $X$ corresponde ao grupo orgânico funcional reativo (grupos epóxi, amina, entre outros). Como exemplo, na Figura 6 é mostrado um esquema de reação entre fibra de vidro e trialcoxissilano, como agente de acoplamento. O trialcoxissilano, na presença de água, hidrolisa para formar grupos silanóis correspondentes, os quais são agentes ativos da reação de funcionalização. Os silanóis formados podem condensar entre si e também interagir com as hidroxilas $\left(\mathrm{OH}^{-}\right)$, presentes na superfície da fibra de vidro, formando ligações siloxano, covalentes. $O$ grupo $X$, por sua vez, irá reagir com o polímero, caso o mesmo tenha funcionalidade adequada. ${ }^{12}$

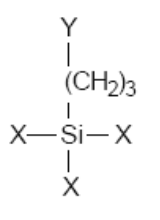

trialcoxissilano

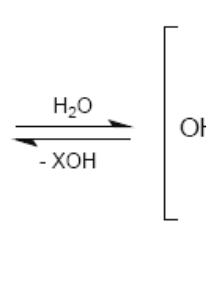

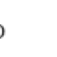

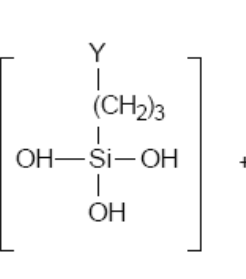

silanol

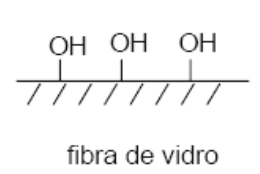

fibra de vidro

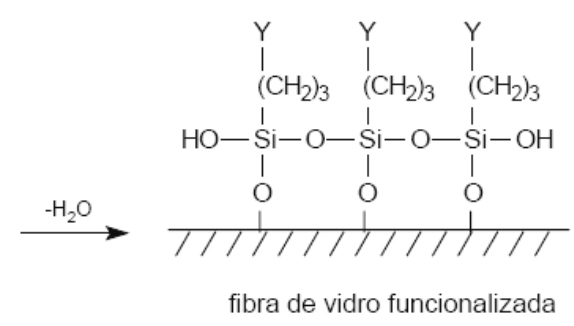

Figura 6 - Reação de interação entre o agente trialcoxissilano e fibra de vidro ${ }^{12,34}$

Existem agentes silanos adequados para cada tipo de polímero. A melhor escolha para o tratamento da fibra irá depender muito do grau de molhabilidade desejado para esta, bem como da interação desejada com o polímero. A tensão superficial da fibra, após a aplicação do agente silano, é um dos indicativos para a escolha dentre os diversos tipos disponíveis. Quanto menor a tensão superficial residual, maior é o nível de molhabilidade para o polímero. As fibras devem ser tratadas com silanos com grupos funcionais $X$ mais compatíveis ou de maior afinidade com a estrutura química da matriz. Os aminossilanos, por exemplo, que apresentam o grupo funcional amina $\left(-\mathrm{NH}_{2}\right)$, são adequados para as poliamidas do tipo 6 ou 6.6, pois reagem quimicamente com grupos funcionais carboxílicos existentes nas extremidades das moléculas destes materiais. ${ }^{29}$ 
Em razão de sua natureza apolar, o polipropileno não possui grupos reativos em sua superfície, o que dificulta a adesão fibra-polímero mesmo com a presença de agentes de acoplagem. Neste caso, visando uma melhor eficiência de adesão e de molhabilidade, uma das melhores opções é o uso combinado de um silano com um compatibilizante interfacial polimérico, normalmente o próprio polipropileno contendo grupos funcionais (anidrido maleico - MAH ou ácido acrílico - AA).

O polipropileno enxertado ou grafitizado com anidrido maleico (PP-g-MAH) é um exemplo de compatibilizante interfacial que promove uma transferência mais efetiva de tensões da matriz polimérica para as fibras. A funcionalização ou enxertia do polipropileno é obtida por meio de um processo de degradação controlada, ou extrusão reativa, pela incorporação do anidrido maleico, o qual é derivado de ácidos carboxílicos [OCOCH:CHCO]. Técnicas como aditivação térmica ou em solução, apesar de apresentarem maior custo de processo, também são utilizadas para a enxertia deste monômero funcional ao polipropileno. ${ }^{33} \mathrm{Em}$ razão de seu preço baixo e tendência baixa à polimerização, o anidrido maleico é o mais empregado em processos de enxertia em comparação a outros monômeros. Um processo convencional de funcionalização de polipropileno baseia-se na iniciação por peróxido e adição do anidrido maleico, sob temperatura alta. O iniciador se decompõe gerando radicais primários que atacam o átomo de hidrogênio no carbono terciário da cadeia do polipropileno, gerando macro-radicais. Estes, por sua vez, reagem com o $\mathrm{MAH}$ formando o polímero enxertado. ${ }^{35}$ Entretanto, existem controvérsias sobre o mecanismo de enxertia e a sua estrutura química resultante. As reações possíveis são mostradas de forma resumida na Figura $7 .^{36,37}$ 


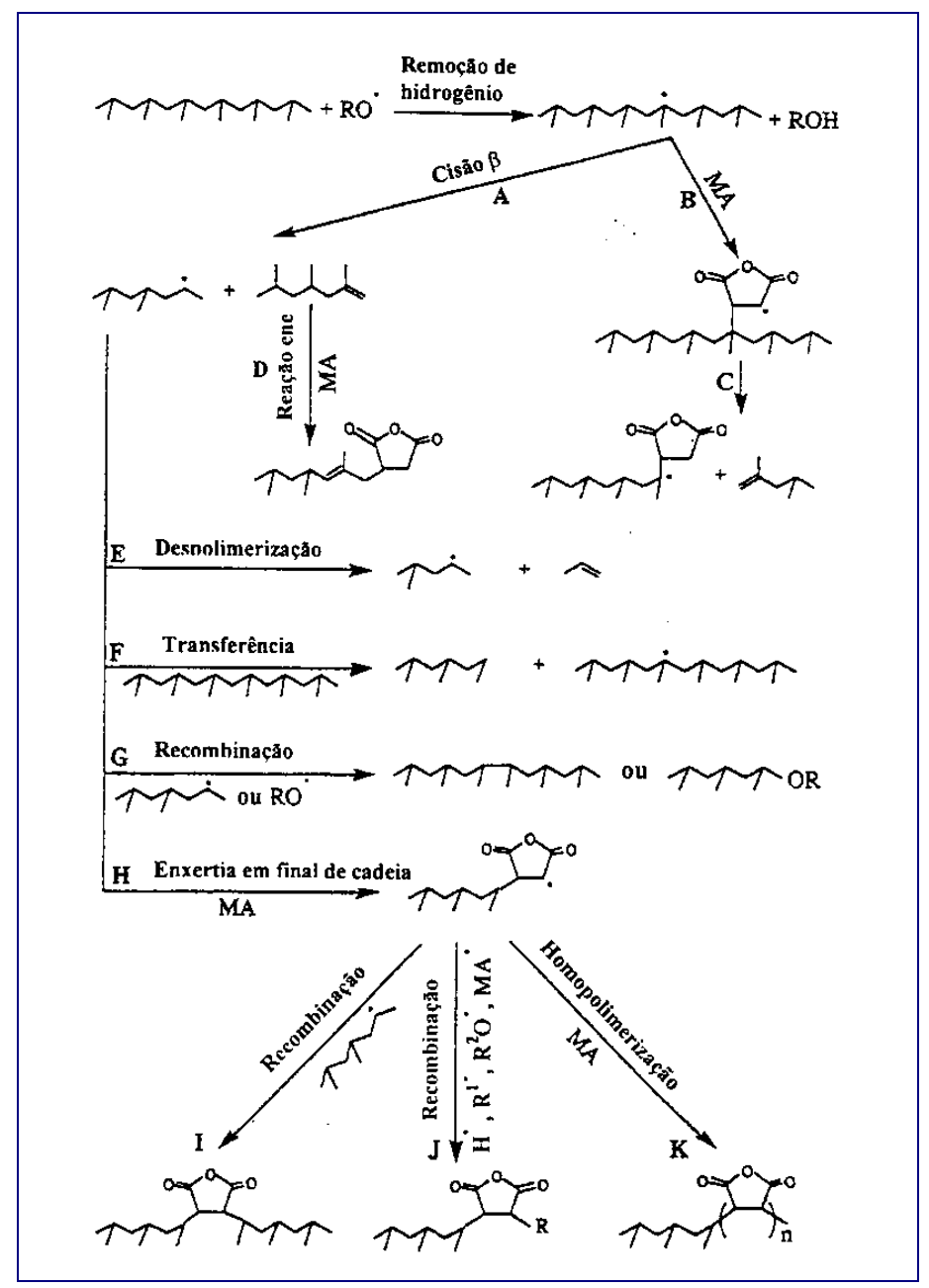

Figura 7 - Mecanismo de reações possíveis para enxertia de anidrido maleico na cadeia de polipropileno no estado fundido na presença de peróxido orgânico ${ }^{37}$

O mecanismo de adesão interfacial por meio da utilização de compatibilizantes envolve dois tipos de interações: a química e a física. Na química, os grupos reativos carboxílicos do PP-g-MAH reagem com os grupos organofuncionais (amino, metacrilato, entre outros) do silano presente na fibra, formando um copolímero grafitizado na interface polímero-fibra. ${ }^{31}$ A interação física se dá entre os finais da cadeia do compatibilizante e a matriz polimérica.

H.G. Karian ${ }^{38}$ apresentou o modelo de "Escova Polimérica", mostrado na Figura 8, para demonstrar a presença de uma região de interfase formada entre a matriz de PP e fibras de vidro pré-tratadas com silano, onde o grupo funcional anidrido maleico (MAH) reage quimicamente com o grupo organofuncional do siloxano na superfície da fibra e fisicamente pelas cadeias moleculares emaranhadas. 


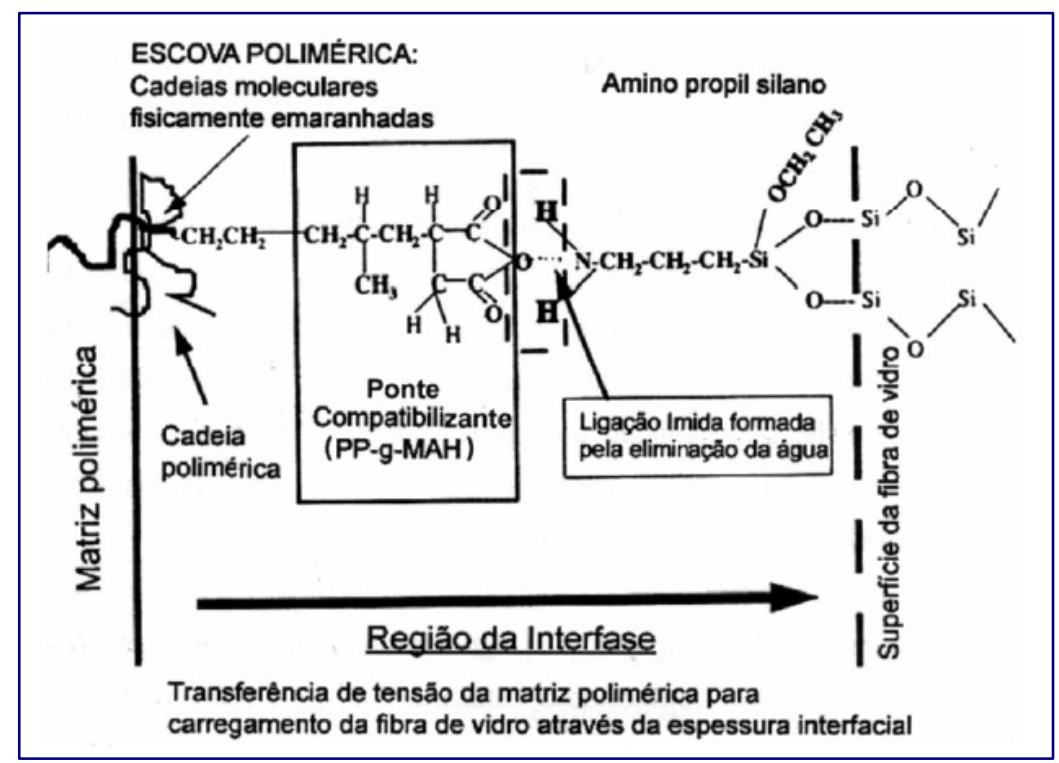

Figura 8 - Modelo de "Escova Polimérica" em um sistema de polipropileno reforçado com fibra de vidro ${ }^{38}$

\subsection{TENACIFICAÇÃO DE POLÍMEROS}

Segundo Calister $^{24}$, tenacidade corresponde à uma medida da habilidade de um determinado material em absorver energia até a ocorrência da sua fratura. $O$ comportamento dúctil de um material é determinado pela incidência de uma grande deformação do mesmo antes da propagação de uma trinca ou fratura. A deformação e a energia de fratura em polímeros são analisadas pelos ensaios de tensão-deformação e resistência ao impacto. No ensaio de tensão-deformação as amostras são tensionadas até a ruptura e os valores de tensão estão relacionados ao de alongamento. A resistência ao impacto avalia a resistência do material a um golpe forte. A iniciação de uma fratura e a consequente ruptura em todos os materiais ocorre por meio de algum tipo de fissura ou defeito, que pode ser desde um risco, um corte ou um defeito microscópico como uma partícula de impureza na cadeia polimérica. Os ensaios de impacto com entalhe simulam os efeitos desta iniciação.

Os polímeros vítreos ou semicristalinos apresentam baixa resistência ao impacto em temperaturas baixas. A adição de plastificantes, 0 uso de comonômeros para sintetizar polímeros e o emprego de modificadores de impacto, 
são procedimentos utilizados para a tenacificação de polímeros, ou seja, para a elevação da resistência ao impacto. ${ }^{10}$ Dentre os procedimentos mencionados, a adição de borrachas (fase dispersa) como modificadores de impacto constitui um dos métodos mais empregados e permite que, em casos de tensão-deformação ou impacto, a energia seja absorvida pelo polímero por deformação visco-elástica das cadeias poliméricas por meio de mecanismos como microfibrilação (crazing), escoamento por cisalhamento (shear yielding) e cavitação (cavitation or craking).

Ao se aplicar uma tensão em um polímero vítreo, há a formação de microvazios no material, os quais se desenvolvem em um plano perpendicular à direção da tensão. O mecanismo de deformação por microfibrilação corresponde à estabilização dos microvazios formados no polímero por meio da estabilização de tensões por fibrilas compostas pelo material polimérico orientado. As partículas de borracha impedem a propagação das trincas formadas dentro das fibrilas, retardando a fratura do material. ${ }^{12}$ Há um aumento do volume em função dos vazios formados. Um material que apresenta microfibrilação pode apresentar superfície esbranquiçada em razão dos efeitos de dispersão de luz.

O escoamento por cisalhamento inicia-se pela formação de bandas de cisalhamento entre as partículas localizadas a $45^{\circ}$ em relação à tensão externa aplicada. A concentração de tensão aumenta nessas partículas e, no interior destas, surgem microvazios, ou seja, elas cavitam. A deformação ocorre por cisalhamento induzido causado por tensão local alta, simultaneamente em todas as áreas da matriz. A deformação por cisalhamento geralmente ocorre quando a tensão para a formação das microfibrilações for maior do que a tensão de escoamento do material. $^{10}$

Existem casos em que o material se deforma por meio de dois mecanismos, microfibrilação e cisalhamento, ao mesmo tempo. O efeito resultante desta combinação é sinérgico, tendo como resultado um material de tenacidade excelente. $^{10}$

A cavitação corresponde ao mecanismo de formação de vazios na fase elastomérica, aliviando a tensão triaxial entre as partículas, transformando em um estado de tensão uniaxial e, desta forma, permitindo a deformação plástica da matriz. Entretanto, a cavitação de forma isolada não é considerada como um mecanismo de tenacificação. ${ }^{12}$ 


\subsubsection{Tenacificação de polipropileno com elastômeros}

O polipropileno apresenta um comportamento frágil quando submetido a ensaios de resistência ao impacto sob temperaturas abaixo da sua temperatura de transição vítrea $\left(T_{g}\right)$. Para superar esta desvantagem, elastômeros são adicionados a este polímero como uma solução economicamente viável e com resultados plenamente satisfatórios para aplicações específicas, principalmente na indústria automotiva. As borrachas de EPDM (monômero de etileno-propileno-dieno) e EPR (borracha de etileno-propileno) são muito usadas como modificadores de impacto em blendas de polipropileno. Entretanto, o desenvolvimento de novas tecnologias e de processos viabilizou a utilização de novos polímeros elastoméricos, como os copolímeros de etileno e alfa-olefinas, bem como alguns elastômeros termoplásticos (TPEs), como modificadores de impacto ou agentes compatibilizantes em blendas de polipropileno ${ }^{39}$. Segundo Tedesco ${ }^{20}$, copolímeros de eteno-octeno têm demonstrado um bom comportamento como modificadores, quando comparados ao EPR e a copolímeros de eteno-buteno.

Usualmente, a tenacificação do polipropileno por meio de elastômeros resulta na diminuição de propriedades como resistência mecânica e rigidez, o que limita o teor destes modificadores na composição da blenda. Por outro lado, este efeito pode ser compensado por meio da adição de cargas rígidas como talco, carbonato de cálcio, mica e fibras de vidro. Desta forma, um bom balanço em termos de rigidez-tenacidade pode ser obtido pela incorporação de ambos, reforço e fase elastomérica, na matriz de PP. ${ }^{39,40}$

Os parâmetros micro estruturais como tipo ou natureza da matriz, tamanho e distribuição das partículas de borracha, fração volumétrica da carga, características da carga (forma, diâmetro para partículas, comprimento para fibras, dispersão e distribuição), distância interpartículas e interface carga-matriz, interferem muito nas propriedades finais de blendas reforçadas de polipropileno com elastômeros. Além disso, em caso de compósitos com fibras, a adição de compatibilizantes interfaciais apropriados, é muito importante para a otimização de propriedades mecânicas pela melhor adesão fibra-matriz.

Como já mencionado neste trabalho, sendo o polipropileno um polímero semicristalino, os efeitos de processamento e as condições de moldagem, também 
são itens importantes de controle e influenciam diretamente nas propriedades finais das blendas com adição de elastômeros. ${ }^{20}$

\subsection{ESTADO DA ARTE}

\subsubsection{Compatibilização Interfacial}

Há um número significativo de trabalhos publicados que tratam a compatibilização interfacial e a sua influência nas propriedades de compósitos de polipropileno reforçados com diversos tipos de fibras e partículas.

Lopes e Sousa ${ }^{41}$ investigaram a influência da massa molar $\left(M_{w}\right)$ e da concentração de andrido maleico (MAH), em diversos tipos comerciais do compatibilizante PP-g-MAH, nas propriedades mecânicas de compósitos de polipropileno com diversos teores de fibras curtas de vidro tratadas com aminossilano. A eficiência da interação fibra-polímero foi demonstrada pelos resultados obtidos para as propriedades de resistência à tração e de resistência impacto Izod. Como teor mínimo de MAH, foi estipulado a de concentração ótima, ou seja, o que obteve os valores máximos para as propriedades analisadas. Concluiu-se que, para certo teor de fibra de vidro, o aumento na concentração do agente compatibilizante PP-g-MAH promove uma melhoria das propriedades de tensão e impacto até atingir uma concentração ótima, acima da qual, estas propriedades não apresentaram alterações significativas. Esta concentração ótima, expressa em $\mathrm{mg}$ de $\mathrm{MAH}$ pela área superficial da fibra $\mathrm{em}^{2}$, corresponde ao nível de saturação da superfície da fibra com o copolímero grafitizado de PP-co-siloxano formando na interfase. $O$ tipo de PP-g-MAH com menor $\mathrm{M}_{w}$ e maior teor de $\mathrm{MAH}$, apresentou a melhor eficiência de compatibilização, pelo critério de concentração ótima. Por outro lado, por meio de diferentes formas analíticas de apresentação de resultados, verificou-se que, independentemente do tipo de compatibilizante utilizado, o aumento nas propriedades mecânicas é função da concentração efetivamente reagida de MAH com os grupos funcionais presentes na superfície das fibras. Já em concentrações constantes de $\mathrm{MAH}$, a redução da massa molar levou a 
um aumento pequeno na resistência à tração e ao impacto, sendo este atribuído à maior facilidade de penetração das cadeias de PP-g-MAH na superfície da fibra. Outra conclusão deste estudo é de que a concentração ótima do compatibilizante pode ser reduzida pelo aumento do teor de fibra no compósito. Esta observação conduziu à interpretação de que quanto maior for o conteúdo das fibras no compósito, maior será a probabilidade estatística quanto à migração das moléculas de PP-g-MAH para a superfície destas. Apesar das importantes observações realizadas pelos autores, há um consenso na literatura de que, efetivamente, o teor dos grupos reativos de $\mathrm{MAH} / \mathrm{NH}_{2}$ presentes no sistema são de primeira importância nas propriedades de interface, sendo a massa molar do compatibilizante um fator secundário. $^{42}$

Ismail et al. ${ }^{43}$ avaliaram os efeitos de uma substituição parcial de cinza da casca de arroz por sílica, com e sem a presença do compatibilizante PP-g-MAH, com relação a propriedades mecânicas, absorção de umidade e morfologia. A sílica utilizada foi do tipo precipitado (código comercial Vulcasil ${ }^{\circledR} \mathrm{S}$, fonte Bayer). As características mencionadas para a cinza da casca de arroz foram de um diâmetro médio de partícula de 5,4 $\mu \mathrm{m}$ e uma área superficial de 1,42 $\mathrm{m}^{2} / \mathrm{g}$. Os resultados mostraram que o aumento da concentração da cinza da casca de arroz, melhora as propriedades de módulo de tração e de flexão, porém diminui a de tensão no escoamento e na ruptura, bem como, alongamento à ruptura e absorção de umidade. Os compósitos híbridos com a presença do compatibilizante apresentaram melhor balanço de propriedades. Os autores atribuem os valores de módulo alto obtidos para os compósitos com concentração maior de cinza de casca de arroz, ao tamanho maior desta partícula $(5,4 \mu \mathrm{m})$ comparado ao da sílica $(0,011-0,019 \mu \mathrm{m})$, e consequente razão de aspecto maior. Por outro lado, o tamanho menor de partícula da sílica, bem como sua área superficial maior e sua melhor interação com a matriz de PP, promovem uma melhor transferência de tensões, resultando em valores mais altos para a tensão no escoamento e para o alongamento na ruptura. Com relação ao melhor comportamento das formulações com a presença de PP-g$\mathrm{MAH}$, os autores verificaram, não só pelas propriedades mecânicas, mas também pela análise morfológica, que este agente permite esta melhor interação entre sílica, cinza de casca de arroz e matriz, por meio de ligações de hidrogênio e de van der Waals. A resistência à umidade também é maior na presença de PP-g-MAH, o qual 
esterifica alguns dos grupos - $\mathrm{OH}$ livres na superfície das partículas (em maior quantidade na sílica), restringindo a absorção de água.

O efeito de agentes compatibilizantes na dispersão de sílica não tratada (precipitada, amorfa e hidrofílica) em uma matriz de polipropileno foi investigado por Zoukrami et al.. ${ }^{44}$ Dentre outras conclusões principais, os autores verificaram que a adição de PP-g-MAH aumentou os valores de Módulo Young para a formulação com sílica e que, após processamento, os diâmetros das partículas são mais preservados, mantendo-se, em sua maioria, entre 1 e $200 \mu \mathrm{m}$. Por outro lado, uma dispersão mais efetiva, com a diminuição do diâmetro de partículas, foi obtida para os compatibilizantes à base de gricerol monoestearado (GMS) e ionômero ácido de etileno acrílico (IAAZE), promovendo melhoria para a resistência ao impacto Izod. Os autores sugeriram que estes agentes proporcionam regiões interfaciais entre a partícula e a matriz, mais resistentes à propagação de trincas do que o próprio polímero. A extensão deste efeito depende do tipo de compatibilizante e das condições de processo. Outra interessante observação é relativa às propriedades térmicas obtidas por meio de ensaios de DSC, as quais indicaram que a sílica utilizada se comportou como um agente nucleante para o polipropileno e que a adição de PP-g-MAH não prejudicou esta habilidade. Os pesquisadores explicam este comportamento pelo modelo termodinâmico proposto por Ebengou ${ }^{45}$, o qual aponta a adsorção como um possível mecanismo para a atividade de nucleação de uma superfície. Zoukrami et al. ${ }^{44}$ propõem que, quando as cadeias do polipropileno são adsorvidas na superfície da sílica, a entropia configuracional da cadeia completa diminui, ajudando a atingir um volume de núcleo crítico. Outro ponto importante é que este efeito de nucleação foi prejudicado quando foram utilizados os compatibilizantes GMC e IAAZE. Neste caso, estes agentes limitaram este efeito em razão da formação de uma camada amorfa das regiões de interface partícula-matriz.

Toro et al. ${ }^{46}$ realizaram um estudo sobre as características morfológicas e as propriedades mecânicas de compósitos de polipropileno copolímero reforçados com diferentes tipos comerciais de sílicas e com cinza da casca de arroz. Investigou-se o efeito da adição de dois compatibilizantes para diminuição da tensão interfacial entre o polipropileno copolímero (PP-co-PE) e as diferentes cargas funcionais. Os compatibilizantes escolhidos foram o polipropileno grafitizado com monometil itaconato (PP-g-MMI), e o polipropileno grafitizado com viniltrietoxissilano (PP-gVTES). Os tipos comerciais de sílica, produzidas por solubilização de vidros, 
apresentaram tamanhos de partículas $\left(d_{50}\right)$ variando entre 19 a $184 \mu \mathrm{m}$. Outra sílica natural, objeto de estudo, foi obtida da cinza da casca de arroz, após calcinação, com tamanho de partícula $\left(d_{50}\right)$ de $370 \mu \mathrm{m}$. Os resultados dos ensaios de tensão para os compósitos formulados com as sílicas particuladas (PP-co-PE-sílica) demonstraram que os valores do módulo de tensão aumentaram à medida que se aumentou o conteúdo de sílica nos compósitos, para tamanho de partículas menores e com distribuição melhor. Por outro lado, observou-se resultados mais altos de módulo de tensão para os compósitos formulados com a sílica de tipo comercial EP10X (fonte Crosfield Group), com a adição do compatbilizante PP-gVTES. Na presença do compatibilizante PP-g-MMl, compósitos equivalentes apresentaram valores menores para esta mesma propriedade. Pelos resultados das propriedades mecânicas, bem como pela análise morfológica por microscopia eletrônica de varredura, os autores concluíram que a natureza química do compatibilizante PP-g-VTES, assim como a similaridade entre os grupos funcionais do silano - PP-co-PE grafitizado e os grupos silanóis presentes na superfície das partículas da sílica comercial, promoveram uma melhor dispersão e/ou incorporação por meio de uma maior interação entre a sílica e a matriz polimérica. As formulações com cinza da casca de arroz $(\mathrm{RH})$ demonstraram uma melhor adesão interfacial somente com a utilização do compatibilizante PP-g-MMI. Segundo os autores, este comportamento é decorrente da maior afinidade química dos principais componentes desta fibra (resíduos glicosídicos e lignina) com grupos carboxílicos do MMI. Constatou-se que, quando fibras de casca de arroz são utilizadas, devem ser considerados fatores como morfologia e natureza química da superfície, visando-se obter um melhor balanço de rigidez-tenacidade.

Cruz et al. ${ }^{42}$ investigaram a influência do conteúdo do agente compatibilizante interfacial PP-g-MAH, em compósitos de polipropileno reforçados com $30 \%$ de fibra de vidro, quanto à integridade da interface fibra-polímero após envelhecimento higrotérmico. Foram preparadas amostras com variação de concentração de PP-gMAH de $0 ; 0,25 ; 0,5 ; 1,0 ; 2,5$ e $10 \%$ em peso. As fibras de vidro curtas utilizadas foram do tipo $E$ (cálcio-alumínio-borosilicato), com diâmetro de $13 \mu \mathrm{m} e$ comprimento de $4,5 \mu \mathrm{m}$, porém com dois tipos diferentes de tratamento superficial com agentes de acoplamento aminosilano. Corpos de prova, para cada uma das formulações, foram submetidos ao envelhecimento higrotérmico por meio de 
imersão em um banho de água destilada a $80^{\circ} \mathrm{C}$ por períodos de 24, 48, 120 e 240 horas. Foram avaliadas propriedades de tração e impacto Izod. Inicialmente, para corpos de prova não envelhecidos, os autores verificaram que para a propriedade de tensão na ruptura os valores aumentaram até certa concentração de PP-g-MAH, acima da qual diminuíram. Esta, segundo os autores, seria a concentração ótima correspondente ao ponto de saturação de interface fibra-polímero, com a formação de uma interfase constituída de PP-co-siloxano copolímero. Contudo, as concentrações ótimas foram diferentes para os dois tipos de fibras de vidro estudadas. Após o envelhecimento em curtos períodos de tempo ( 24 e 48 horas), o comportamento das amostras envelhecidas foi semelhante às não envelhecidas, com queda acentuada de propriedades para concentrações de compatibilizante abaixo da concentração ótima. Esta queda de propriedades foi atribuída à deterioração drástica da adesão interfacial fibra-polímero, induzida pela ação da água difusa pelo efeito de capilaridade. Para envelhecimentos mais longos (120 horas), houve uma redução dos valores de tensão na ruptura até a concentração ótima, acima desta os valores continuaram caindo, porém de forma gradual. Os autores acreditam que, neste caso, o excesso de compatibilizante levou à formação de uma fina camada de interfase, formada essencialmente de PP-co-siloxano polar, que foi mais suscetível à degradação por hidrólise.

A funcionalização de polipropileno com anidrido maleico tem sido a mais empregada durante os últimos vinte anos. ${ }^{47}$ Isto se deve não somente ao seu baixo custo, mas também pela reatividade alta do grupo anidrido em reações posteriores, à satisfatória estabilidade térmica dos produtos obtidos, bem como melhor resistência à absorção de umidade. Por outro lado, nota-se que outros agentes compatibilizantes estão sendo pesquisados, com o propósito de otimizar a adesão interfacial e promover a utilização de novas partículas e fibras como agentes de reforço em matrizes poliméricas. 


\subsubsection{Compósitos híbridos}

A hibridização de compósitos, por meio da utilização de dois ou mais tipos de partículas ou fibras de reforço, permite o desenvolvimento de materiais com uma melhor combinação de propriedades, as quais não podem ser obtidas com um único tipo de reforço, bem como de acordo com as características finais desejadas para a aplicação. ${ }^{48} \mathrm{Em}$ se tratando de compósitos de fibras naturais, uma das técnicas utilizadas para aumentar a rigidez, a resistência mecânica e a resistência à umidade é a adição de uma quantidade de fibras sintéticas. ${ }^{49}$ Em compósitos híbridos, as vantagens de um dos tipos de fibras ou partículas podem complementar as deficiências do outro. Os artigos a seguir referem-se à influência da hibridização por fibras e partículas nas propriedades de compósitos de polipropileno.

Jarukumjorn e Suppakarn ${ }^{50}$ estudaram o efeito de hibridização por fibras de vidro nas propriedades mecânicas, térmicas, reológicas e na morfologia de compósitos de polipropileno com fibras de sisal. Para elevar a compatibilidade entre as fibras e a matriz polimérica foi utilizado polipropileno grafitizado com anidrido maleico (PP-g-MAH). As fibras de vidro utilizadas foram do tipo E, com $4 \mathrm{~mm}$ de comprimento. Observou-se que, com o aumento do teor das fibras de sisal, as propriedades de tensão e flexão também foram elevadas. Este comportamento foi atribuído à melhor adesão interfacial entre a fibra e a matriz, proporcionada pelo agente compatibilizante (formação de ligações covalentes entre os grupos de anidrido maleico do PP-g-MAH e os grupos hidroxílicos da celulose presente na fibra de sisal). Por outro lado, o aumento da concentração da fibra de vidro não alterou significativamente a resistência e o módulo de flexão, na presença de PP-g-MAH, cujo efeito foi atribuído à quebra das fibras após mistura (constatado mediante análises de caracterização via microscopia óptica). Ao contrário dos resultados obtidos em muitos trabalhos científicos, o efeito de sinergia proporcionado pela incorporação de fibras de vidro nas propriedades mecânicas do compósito de PPsisal não foi representativo neste estudo. Entretanto, este efeito foi percebido para as propriedades de absorção de umidade e de resistência térmica. A incorporação de fibras de vidro alterou significativamente a estabilidade térmica, aumentando os valores obtidos para as temperaturas de decomposição e de deflexão térmica (HDT). 
A influência da hibridização de fibras curtas de vidro e talco mineral nas propriedades mecânicas de compósitos de polipropileno copolímero, com e sem linhas de solda, foi estudada por Morelli et al.. ${ }^{51}$ As fibras de vidro são muito utilizadas por promoverem o aumento das propriedades mecânicas para a matriz polimérica. Entretanto, durante o processo de injeção, os materiais são submetidos a severas condições térmicas e mecânicas que causam tensões residuais. Estas, por sua vez, geram uma orientação preferencial tanto para as cadeias da matriz polimérica como para as fibras, originando compósitos de alta anisotropia. Este efeito torna-se ainda pior quando correm linhas de solda durante a moldagem, uma vez que as fibras com maior razão de aspecto possuem a tendência de orientaremse nos planos mais fracos das linhas de solda. Os autores demonstraram que, além de uma otimização para as propriedades mecânicas, a sinergia obtida pela combinação dos reforços diminuiu a orientação das fibras nos planos das linhas de solda, contribuindo para que a redução das propriedades mecânicas nesta região fosse menos critica. Os compósitos híbridos apresentaram valores de módulo de tensão intermediários aos obtidos para os compósitos reforçados apenas com fibra de vidro ou apenas com talco. Porém, para corpos de prova sem linhas de solda, foi verificado que os valores de módulo de tensão, para as formulações hibridas, foram maiores que os estimados pela regra das misturas, quando comparados compósitos com o mesmo teor de reforço. Este comportamento foi atribuído ao fato de que a adição de partículas rígidas de talco reduz significativamente a mobilidade da matriz polimérica na vizinhança da superfície das partículas. Outro fator de contribuição seria o aumento da orientação das fibras no principal sentido de preenchimento da cavidade, induzida pelo aumento da viscosidade proporcionado pela adição de talco. Neste estudo foram formuladas amostras com fibras de vidro de diâmetro nominal de $13 \mu \mathrm{m}$. Os compósitos híbridos apresentam comprimento de fibra entre 468 e $570 \mu \mathrm{m}$.

Oliveira e Sousa $^{9}$ pesquisaram a influência da hibridização do reforço constituído de fibras de vidro curtas e talco em diversas composições de compósitos de polipropileno. Os autores avaliaram as formulações quanto às propriedades mecânicas de tração, bem como quanto à anisotropia mecânica no módulo elástico $\left(E_{L} / E_{T}\right)$ por ensaio de flexão de três pontos, em que $E_{L}$ é o módulo obtido para os corpos de prova longitudinais, e $\mathrm{E}_{\mathrm{T}}$ é o módulo para os corpos de prova 
transversais. As fibras de vidro utilizadas foram do tipo $E$, na forma picada chopped strand, pré-tratadas com agente de acoplagem, com comprimento de 4,5 mm e diâmetro de $13 \mu \mathrm{m}$. Os compósitos foram preparados utilizando-se concentrações totais de carga variando entre 20 a $50 \%$ em peso. Os autores verificaram que a hibridização das cargas atua de forma diferenciada nas propriedades de resistência à tração e no módulo elástico. Com relação à resistência à tração, ao se adicionar talco a uma concentração fixa de fibra de vidro, houve uma alteração no grau de cristalinidade, na viscosidade do polipropileno e no grau de quebra das fibras de vidro. Para concentrações baixas de fibra de vidro (10\%), houve um aumento da resistência à tração para teores crescentes de talco. Entretanto, para teores fixos de fibra de vidro acima de $20 \%$, houve uma queda acentuada da resistência à tração para teores crescentes de talco. Esta diminuição do efeito de reforço foi interpretada como decorrente da quebra das fibras, devido ao aumento da viscosidade do sistema e à maior interação (colisão) entre fibras e partículas de talco. Por outro lado, com relação ao módulo elástico, o efeito depreciativo pela quebra das fibras, ou seja, pela variação da razão de aspecto, não foi relevante. A adição crescente de talco em teores fixos de fibra gerou um aumento no módulo elástico, atribuído à maior orientação das fibras de vidro e ao provável aumento no grau de cristalinidade. Outra observação dos autores nesta pesquisa foi o aumento praticamente linear do módulo de flexão em compósitos híbridos, os quais foram justificados pela ação nucleante e de reforço do talco na matriz de polipropileno. Como última análise, verificou-se que o efeito de anisotropia, em função dos valores obtidos para a razão $E_{L} / E_{T}$, foi minimizado pela adição do talco graças ao formato lamelar das partículas deste mineral, o qual tende a se orientar paralelamente à superfície do moldado. Dentre as formulações investigadas, considerando-se todas as propriedades mencionadas, o compósito híbrido com $20 \%$ de fibra de vidro e $20 \%$ de talco, em peso, foi considerado o de melhor desempenho e tecnologicamente viável. 


\subsubsection{Compósitos de polipropileno modificados com elastômeros}

O comportamento de cargas e de modificadores de impacto nas propriedades finais do polipropileno, com o intuito de se obter compósitos com propriedades adequadas de rigidez e tenacidade, é citado nos estudos a seguir.

Xie, H; Zhang; Xie, D. ${ }^{52}$, dentre outros tópicos, estudaram a otimização das propriedades de tensão na ruptura, resistência ao impacto e resistência à flexão de compósitos de polipropileno com $30 \%$ em peso de fibras curtas de vidro, mediante a melhoria da adesão interfacial entre as fibras. Utilizaram diferentes tipos de agente de acoplamento silano para as fibras, assim como polipropileno funcionalizado com anidrido maleico. As formulações preparadas foram analisadas quanto à morfologia e às propriedades mecânicas de tensão no escoamento e de resistência à flexão. $O$ efeito dos agentes de acoplamento alquiltrimetoxissilano (WD-10), $\mathrm{N}$-( $\beta$-aminoetil)- $\gamma$ aminopropiltrimetoxissilano (WD-52) e $\gamma$-metacriloxipropiltrimetoxissilano (WD-70), foi investigado em diferentes concentrações. As fibras de vidro utilizadas foram não alcalinas, com comprimento de $6 \mathrm{~mm}$ e diâmetro de $9 \mu \mathrm{m}$. O efeito dos elastômeros borracha de estireno-butadieno (SBR) e cis-1,4 polibutadieno (PB) nas propriedades mecânicas de compósitos de polipropileno com $30 \%$ de fibras de vidro (tratadas com WD-70), contendo anidrido maleico e ácido adípico, também foram alvo de estudos pelos autores. Os resultados mostraram que, na presença de anidrido maleico, o melhor agente de acoplamento é o WD-70, sendo este comportamento atribuído à compatibilidade excelente entre os grupos do WD-70, o anidrido maleico e o polipropileno. Entretanto, na ausência do anidrido maleico, o melhor agente de acoplamento foi o WD-10. Os compósitos com WD-10 e com anidrido maleico evidenciaram propriedades boas para concentrações de anidrido maleico ente $5 \mathrm{e}$ $10 \%$. Porém, acima de $10 \%$, as propriedades mecânicas destes compósitos pioraram. A explicação deste resultado pelos autores é que, tanto o agente silano, como 0 anidrido maleico, melhoraram a adesão entre fibra-matriz porque o grupo alquil do WD-10 e a cadeia principal do anidrido maleico possuem afinidade com as moléculas do polipropileno. Os grupos $\mathrm{Si}-\mathrm{O}$ (do WD-10) e os grupos MAH ou $\mathrm{COOH}$ (provenientes de hidrólise do anidrido maleico) têm interação por ligação de hidrogênio e por esterificação com os grupos $\mathrm{OH}$ das fibras de vidro, 
respectivamente. A interação interfacial, ou reação, pode promover a transferência de tensões da matriz para as fibras de vidro. Um excesso de silano cria uma sobreposição de camadas de acoplamento, assim como o excesso de anidrido maleico destrói a cristalinidade do polipropileno, sendo que ambos os fenômenos resultam na perda de propriedades. De uma forma geral, as propriedades mecânicas aumentaram até a concentração máxima de $5 \%$ de anidrido maleico. $\mathrm{Na}$ presença de elastômeros (0, 10 e 15\% em peso), apenas a formulação com 10\% de SBR apresentou melhoria para a propriedade de impacto. Entretanto, houve uma queda acentuada para as propriedades de tensão de ruptura e de resistência à flexão, para todas as composições estudadas. Os autores concluíram que a adição de elastômeros pode aumentar a tenacidade dos compósitos, porém um excesso dificulta a adesão interfacial entre polipropileno, anidrido maleico e fibras de vidro.

Uma comparação entre a eficiência de reforço entre compósitos de polipropileno (PP) e borracha natural (NR) com a adição de jornal reciclado (RPN), negro de fumo (CB), assim como, compósitos de polipropileno (PP) e borracha natural (NR) com jornal reciclado (RPN), negro de fumo (CB) e sílica, foi efetuada por Osman et al.. ${ }^{13}$ Os compósitos foram preparados com $50 \%$ em peso de PP e $50 \%$ em peso de borracha natural, variando-se a concentração de negro de fumo e sílica (reforço híbrido). O negro de fumo utilizado foi o tipo N330, fonte Cabot Incorporation, com tamanho de partícula de $49,5 \mathrm{~nm}$. Já a sílica, foi do tipo precipitado, código Vulcasil ${ }^{\circledR} \mathrm{S}$, fonte Bayer, com tamanho de partícula de 1,4 nm. As conclusões relativas às análises de calorimetria diferencial de varredura (DSC), indicaram que a temperatura de fusão $\left(T_{m}\right)$, a entalpia de fusão dos compósitos $\left(\Delta \mathrm{H}_{\mathrm{f}(\text { comp })}\right)$, a cristalinidade dos compósitos $\left(\mathrm{X}_{\text {comp }}\right)$ e a cristalinidade do polipropileno $\left(X_{P P}\right)$ apresentam valores mais altos com o aumento do conteúdo de negro de fumo e sílica. Sendo que, com relação à entalpia de fusão e cristalinidade, os compósitos híbridos RPN/sílica apresentaram melhores resultados que os compósitos RNP/CB. Os autores alegaram que, com relação à $T_{m}$, a incorporação de partículas inorgânicas, em função do pequeno tamanho de partícula, reduz a mobilidade de segmentos dos polímeros na região da superfície das lamelas durante o processo de fusão. Além disso, à medida que a concentração de partículas rígidas aumenta, os compósitos adquirem fases amorfas também mais rígidas, contribuindo para o aumento da temperatura de fusão. A sílica utilizada tem menor tamanho de partícula do que o negro de fumo, e os valores de $T_{m}$ para os compósitos RPN/sílica 
foram relativamente maiores que os compósitos RPN/CB. Assumiu-se que o efeito nucleante das partículas inorgânicas contribuiu consideravelmente para a melhor interação carga-polímero.

Garakani; Arefazar; Nazockdast ${ }^{40}$ analisaram compósitos híbridos compostos de polipropileno e de $20 \%$ de fibras curtas de vidro (SGF), com variação do teor de SEBS (copolímero em bloco de estireno - etileno/butileno - estireno) funcionalizado com anidrido maleico como compatibilizante e como modificador de impacto. Foram estudadas propriedades reológicas, morfológicas e as propriedades mecânicas de tensão na ruptura e resistência ao impacto Izod. As análises morfológicas revelaram que uma forte interface entre fibra e matriz foi formada para os compósitos PP/SEBS-MA/SGF. Os autores atribuíram como ocorrência de adesão, o fato de que os grupos funcionais do anidrido maleico, grafitizados ao bloco mediano etileno-butileno (EB) do SEBS, podem reagir com os grupos hidroxílicos presentes na superfície das fibras de vidro, conforme mostrado na Figura 9.

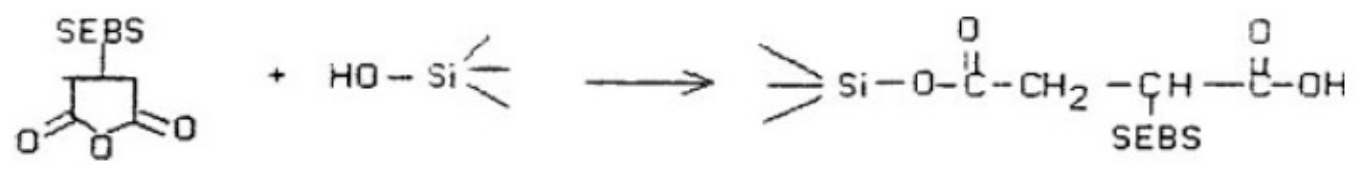

Figura 9 - Representação da reação entre SEBS-MA e os grupos hidroxílicos presentes na superfície das fibras de vidro ${ }^{40}$

A adesão do copolímero SEBS-MA no compósito PP/SGF, ainda segundo os autores, introduziu uma interface dúctil entre fibra-matriz. Esta interface, quando forte, poderia promover plasticidade e, quando fraca, poderia favorecer o efeito pull out das fibras. Com o aumento do conteúdo de borracha nos compósitos híbridos, os tamanhos das partículas diminuíram. Este fato foi sugerido pelos autores como resultado da forte adesão entre SEBS-MA e as fibras, além do aumento da colisão entre partículas de borracha e fibras de vidro, permitindo a diminuição da coalescência das partículas de borracha. $O$ estudo da propriedade mecânica de tensão na ruptura indicou que esta aumenta gradativamente até a concentração de $10 \%$ de borracha, acima da qual se declina. Os autores mencionaram que este comportamento poderia ser atribuído à suposição de que, em baixas concentrações, - SEBS-MA melhora a adesão interfacial, diminuindo a cristalinidade do polipropileno, bem como, reduzindo a mobilidade da cadeia do polipropileno na 
região amorfa. Observou-se também que a propriedade de resistência ao impacto aumenta para concentrações de borracha acima de $10 \%$ em peso, e que o maior valor para este requisito foi obtido para amostras contendo $20 \%$ de borracha. A resistência ao impacto dos compósitos aumentou com o aumento da concentração das fibras de vidro, indicando que um bom balanço de propriedades (rigideztenacidade) poderia ser obtido ajustando-se as concentrações de borracha e fibra de vidro, de acordo com o mostrado na Figura 10, em uma relação não linear.

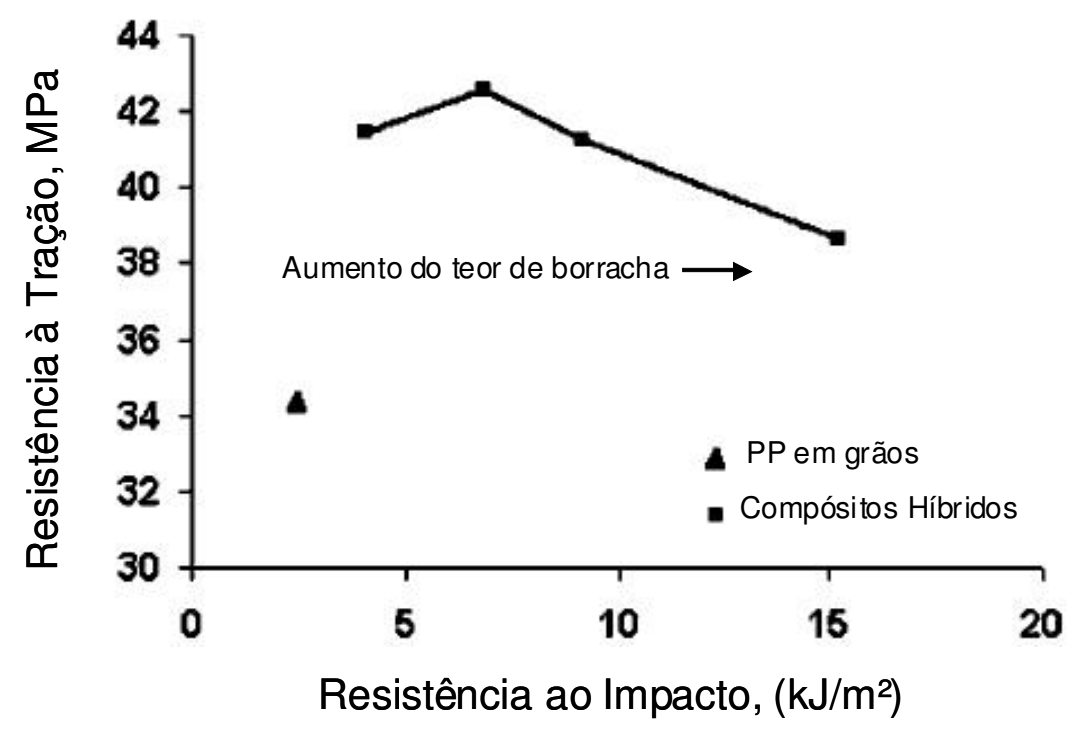

Figura 10 - Variação da tensão na ruptura de compósitos híbridos em relação à resistência ao impacto, em diferentes concentrações de borracha ${ }^{40}$

Denac; Musil; Smit ${ }^{53}$ compararam os efeitos de SEBS [poli(estireno-b-etilenoco-butileno-b-estireno)] e de SEBS funcionalizado com anidrido maleico (SEBS-gMA) nas propriedades mecânicas de compósitos de polipropileno isotático (iPP) com talco tratado superficialmente com aminosilano. $O$ objetivo do trabalho foi verificar como a funcionalização do SEBS (SEBS-g-MA) interfere no processo de cristalização na matriz de iPP, uma vez que o copolímero em bloco SEBS afeta significativamente a nucleação, a taxa de cristalização, a orientação e o crescimento de esferulitos desta matriz polimérica. As blendas binárias iPP/SEBS e iPP/SEBS-gMAH (com variação de concentração), bem como compósitos ternários iPP/talco/SEBS e iPP/talco/SEBS-g-MA (com a mesma variação de concentração, porém com $12 \%$ em volume de incorporação de talco), foram investigados quanto à propriedades de tensão e resistência ao impacto Charpy. Os resultados das análises 
efetuadas demonstraram que, enquanto que os componentes SEBS e SEBS-g-MA aumentaram as propriedades de alongamento na ruptura, alongamento no escoamento e resistência ao impacto do iPP, a incorporação de talco diminuiu tais propriedades. Por outro lado, os mesmos elastômeros diminuíram o módulo de Young e a tensão na ruptura, enquanto que a adição do talco proporcionou um aumento destas. A incorporação dos elastômeros de SEBS e SEBS-g-MA, e a do talco, afetaram as propriedades mecânicas dos compósitos de formas distintas. Estas diferenças seriam decorrentes, segundo os autores, primeiramente, da natureza dos componentes, ou seja, da elasticidade intrínseca dos elastômeros, bem como, da rigidez e da dureza do talco. E, em segundo lugar, SEBS e SEBS-gMA afetariam de forma diferente a estrutura molecular da matriz de iPP e a morfologia final do compósito. A maior resistência ao impacto dos compósitos de iPP/talco/SEBS foi atribuída:

- À massa molar (e a consequente viscosidade alta, elasticidade alta e resistência ao impacto alta) das espessas camadas de SEBS em torno dos cristais de talco (com elevada orientação).

- À melhor miscibilidade ou interatividade do SEBS com as cadeias de polipropileno, comparativamente ao SEBS-g-MA (SEBS com massa molar alta forma grandes partículas dispersas com área superficial baixa, mas com blocos longos de estireno-butadieno, favorecendo a miscibilidade com o iPP).

Por sua vez, os melhores resultados de alongamento no escoamento obtidos para os compósitos iPP/talco/SEBS-g-MA foram explicados como em função de:

- Maior grau de encapsulamento e desorientação dos cristais de talco pelo SEBS-g-MA. Em razão da interatividade alta entre talco/silano $\mathrm{NH}_{2}-\mathrm{MA}-$ SEBS, o elastômero SEBS-g-MA transfere-se da matriz de polipropileno para o interior do plano paralelo de cristais do talco, agindo como um amortecedor elástico entre camadas, promovendo absorção de impacto menor e o aumento no alongamento ao escoamento.

- Baixa massa molar do SEBS-g-MA (três vezes menor que a do SEBS).

Mae; Omiya; Kishimoto ${ }^{54}$ estudaram a deformação micro estrutural e o processo de evolução de micro defeitos em blendas ternárias de polipropileno (PP) com borracha de etileno-propileno (EPR) e talco. Os autores conduziram uma simulação, por meio de observações do processo de deformação micro estrutural in situ sob tensão, utilizando um microscópio de transmissão eletrônica (TEM) com o 
objetivo de melhorar a avaliação da evolução dos defeitos, etapa por etapa. Então, um modelo de simulação Dinâmica Molecular (MD) foi construído baseado nas análises morfológicas via TEM. A seguir, a tensão-deformação foi simulada pelo método de Dinâmica Molecular Coarse-Grained, e os resultados numéricos foram comparados com os dados experimentais. Os resultados experimentais evidenciaram que, inicialmente, o descolamento entre a matriz de polipropileno e 0 talco ocorreu principalmente por concentrações de tensão altas. A seguir, as partículas de EPR cavitaram e micro vazios foram formados, e, então, as fibrilas foram nucleadas na matriz de polipropileno. A mesma tendência foi obtida para 0 processo de simulação de evolução de micro defeitos por Dinâmica Molecular (MD). Com o intuito de investigar a importância da interface na melhoria da rigidez e da resistência, as forças interfaciais entre PP-EPR e entre PP-talco foram alteradas parametricamente, sendo analisado o efeito destas mudanças no processo micro estrutural de evolução de defeitos e nas propriedades mecânicas. Os autores concluíram que uma melhor interface entre PP-EPR é mais efetiva para o aumento da rigidez e a resistência do compósito, do que a melhor compatibilidade entre PP e talco. Além disso, para melhorar a ductilidade do material, também se torna importante aumentar a força interfacial entre o polipropileno e a borracha de etilenopropileno. Na figura 11 é mostrada a evolução de micro defeitos em compósitos com forças de interface normalizadas na seguinte ordem, sob determinado valor de tensão: $0,25 \mu_{0}$ (a); 1,0 $\mu_{0}$ (b) e 1,6 $\mu_{0}$ (c), em que $1 \mu_{0}$ corresponde a 2,091 x $10^{10}$ $\mathrm{J} / \mathrm{mol}$. Verifica-se na Figura 11 (c), que com o aumento da força interfacial entre PPEPR, ambas as fases de PP e EPR são fibriladas juntas nos mesmos feixes. Isto não acontece na Figura 11 (a), na qual, em função de uma interface baixa, somente a fase de EPR é fibrilada.

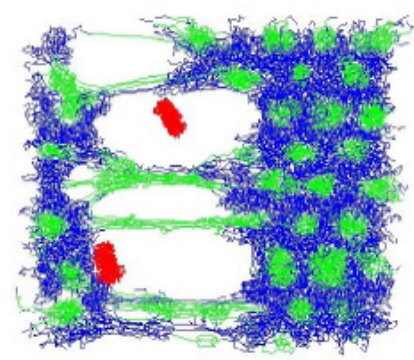

(a) 0.25

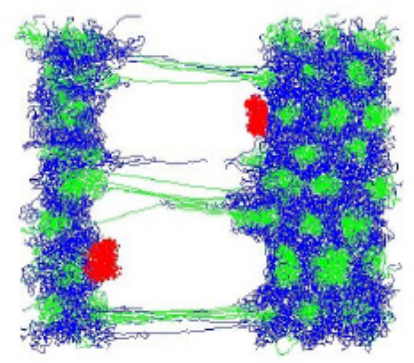

(b) 1.0

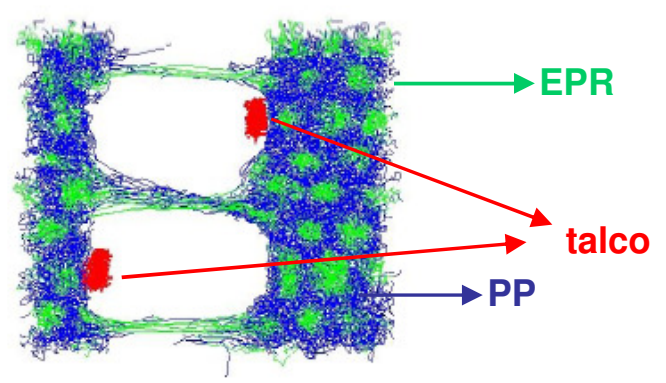

(c) 1.6

Figura 11 - Evolução de micro defeitos para várias forças interfaciais normalizadas entre PP e EPR, sob determinado valor de tensão ${ }^{54}$ 
Não só os mecanismos, mas também as propriedades mecânicas de compósitos de polipropileno tenacificados com elastômeros e reforçados com partículas minerais estão bem documentados na literatura. ${ }^{13,53,54,55,56}$ Quanto a fibras, os artigos citados ${ }^{40,52}$ nesta seção também mostram que a tenacidade de compósitos com este tipo de reforço pode ser influenciada por vários fatores. Evidencia-se a importância das concentrações da borracha e das fibras para as propriedades finais das formulações. Cita-se a relevância da adição de agentes compatibilizantes apropriados para a melhoria das propriedades mecânicas mediante o aumento de adesão interfacial entre polímero, fase elastomêrica e fibra. Esta pode ser alcançada por meio da funcionalização da matriz de polipropileno ou da fase elastomérica, ou de ambas. Além da melhor interação fibra-matriz e fibraborracha por tratamentos adequados das fibras. As deformações plásticas que ocorrem na interface fibra-matriz, assim como o arrancamento (pull out) das fibras constituem o processo primário de dissipação de energia durante um esforço de tensão ou de quebra por impacto. ${ }^{40}$

A morfologia dos tamanhos das partículas de borracha é outro fator importante relacionado às propriedades mecânicas dos compósitos. Além do tamanho e da forma, uma distribuição homogênea das partículas de borracha na matriz polimérica contribuem para o melhor comportamento de rigidez-tenacidade. ${ }^{57} \mathrm{Em}$ outro artigo analisado como complemento desta pesquisa, verificou-se que $\mathrm{Wu}^{58}$ estudou $\mathrm{o}$ efeito a tenacidade de compósitos de poliamida (PA) 6.6 e borracha, utilizando o critério de distância entre partículas de borracha. Os estudos do autor demonstraram que, para uma concentração constante de elastômero, a transição dúctil-frágil em misturas de PA 6.6 e borracha ocorre quando as partículas do elastômero estão separadas entre si por um determinado valor crítico, ou distância interpartículas $\left(T_{c}\right)$. Para que uma blenda apresente tenacidade adequada, além de uma forte adesão interfacial entre as fases é necessário que a distância interpartícula seja menor que o valor crítico. O diâmetro crítico de partícula $\left(d_{c}\right)$ é obtido pela eq. (2), na qual $\Phi_{\Gamma}$ é a fração de volume de borracha.

$$
d_{\mathrm{s}}=T_{\mathrm{s}}\left\{\left(\pi / 6 \Phi_{\mathrm{x}}\right)^{1 / 3}-1\right\}^{-1}
$$


Segundo $\mathrm{Wu}^{58}$, para as blendas de PA 6.6 / borracha, o mínimo de adesão requerida é obtida somente em misturas que apresentem adesão interfacial promovidas por interações do tipo van der Waals e não somente na presença de ligações covalentes.

\subsection{REQUISITOS ESPECÍFICOS PARA A INDÚSTRIA AUTOMOTIVA}

\subsubsection{Controle de emissões de voláteis}

O controle da qualidade do ar e dos odores presentes no interior dos automóveis é uma prática antiga para algumas indústrias automobilísticas, mas que vem se tornando cada vez mais importante e abrangente frente aos novos princípios de sustentabilidade. A cada projeto novo de um veículo, polímeros substituem metais pela busca da redução de peso e de custos. Por outro lado, o uso extensivo de polímeros eleva a percepção de odores no interior dos automóveis pela emissão de compostos orgânicos voláteis (VOCs).

O controle de emissões não é uma tarefa fácil em função da diversidade de materiais e do número de peças e componentes internos. Esta atividade inicia-se desde a escolha dos materiais até o monitoramento das condições e métodos de processamento de cada uma das peças e componentes.

Em controvérsia à sustentabilidade, segundo Xiang et al. $^{59}$, a maior preocupação no controle de emissões de compósitos de polipropileno é com respeito à utilização de reciclados. O reprocessamento de plásticos refugados pode gerar uma quantidade significativamente alta de VOCs, comparativamente a resinas "virgens". Isto porque os materiais reprocessados já foram mais térmica e mecanicamente expostos a condições ambientais adversas durante a sua vida útil, além disso, podem apresentar diversos tipos de contaminações. A emissão de compostos orgânicos voláteis em compósitos de polipropileno é oriunda da desvolatilização e degradação de aditivos presentes na formulação (plastificantes, estabilizantes, antioxidantes, entre outros), além da própria resina. A quantidade e os tipos de VOCs depende tanto do material como das condições de 
processamento. De acordo com o tipo de formulação de compósitos de polipropileno, as emissões podem conter substâncias de massa molar baixa como aldeídos, cetonas, alcoóis e ácidos carboxílicos (a maioria alifáticos), olefinas leves, éteres, ésteres, água e monóxido de carbono. Os mecanismos de degradação de poliolefinas, de modo geral, são muito complicados e dependentes das condições atmosféricas do processamento. Nos últimos anos, um grande número de pesquisas tem dado a sua contribuição para o difícil entendimento destas reações, bem como dos produtos ou substâncias resultantes. ${ }^{60}$

Durante o processamento de polipropileno, temperaturas acima de $200^{\circ} \mathrm{C}$ podem iniciar mecanismos de degradação termo-oxidativa, cuja intensidade dependerá da proteção proporcionada pelos aditivos presentes. Como resultados destes mecanismos se esperam alterações até mesmo estruturais (massa molar, reológicas, entre outras), com efeito em propriedades, como as mecânicas.

A necessidade de redução e minimização das emissões internas estimula o desenvolvimento de métodos sensitivos e instrumentais para a medição de odor. Bledzki; Kessler; Lieser ${ }^{61}$ descreveram uma técnica sensitiva (olfactometry) para a determinação de odor, visando à redução de emissões indesejáveis para plásticos, nos quais se incluem os empregados pela indústria automobilística. O método demonstrou uma detecção com reprodutibilidade alta para medições realizadas com o mesmo grupo de avaliadores, os quais devem ser selecionados a partir de requisitos como sensibilidade olfativa, ausência de resfriados, dentre outros. Guadarrama; Méndez; De Saja ${ }^{62}$ demonstraram o comportamento funcional de um "nariz eletrônico", ou seja, de um dispositivo formado por conjunto de sensores condutores com base polimérica para a distinção de odores de peças plásticas do interior de veículos. A capacidade de discriminação de odores foi melhorada pela utilização dos primeiros coeficientes da Transformada de Fourier, com curvas estabelecidas por variações quanto à análise dos componentes principais (PCA).

Não só os requisitos de odor e de emissão de carbono são relevados pela indústria automobilística na análise do comportamento a emissões. Os limites para emissões de formaldeído e para os constituintes condensáveis (fogging) também foram estabelecidos, além da proibição quanto à presença de substâncias simples, classificadas na legislação como cancerígenas. Mediante testes de medição de 
fogging, avalia-se a quantidade de compostos voláteis que podem condensar em áreas como o parabrisas, reduzindo a visão do condutor do veículo.

A investigação quanto às emissões internas, além de evitar exposições a substâncias que oferecem risco à saúde nos primeiros meses após a produção do veículo (os níveis de emissão são reduzidos em função do tempo), é também de extrema importância para a prevenção de eventuais efeitos que possam prejudicar a condução do automóvel pelo motorista (sonolência, desconforto, irritação da garganta, dores de cabeça, náuseas, dentre outros sintomas).

\subsubsection{Resistência a riscos}

Face ao bom desempenho, versatilidade e custo baixo, dentre outras razões já discutidas neste trabalho, os compósitos de polipropileno estão cada vez mais sendo utilizados em aplicações automotivas. Como consequência, aumenta-se o interesse pelo desenvolvimento de materiais que proporcionem uma melhor qualidade superficial, a qual está relacionada a fatores como tipo de textura, brilho baixo, isenção de marcas e linhas de fluxo (defeitos de processo), bem como quanto à resistência a riscos. O design de um painel de instrumentos, por exemplo, influencia a decisão de compra de um veículo. A presença de riscos na superfície desta peça, além de reduzir o apelo visual, aponta para fragilidade e para durabilidade baixa, mesmo que não haja o comprometimento funcional. A deformação causada por riscos na superfície do polipropileno se tornou um importante tema de pesquisas no campo da ciência dos materiais, principalmente em razão do efeito deletério proporcionado pela adição de alguns tipos de reforços, como o talco.

Pode-se definir, de modo simples, que o risco é uma marca que forma estrias visíveis e danos à superfície, entretanto, a resistência a riscos é muito mais abrangente do que parece. ${ }^{63}$ Os polímeros são materiais complexos em termos de características intrínsecas e de propriedades como a viscoelasticidade, viscoplasticidade, tensões de tenacidade e de rigidez, morfologia de superfície, dentre outras. Tais fatores são responsáveis pelo especial desafio na construção de um modelo teórico e no desenvolvimento de métodos de testes experimentais que 
possam prever ou interpretar o comportamento de um material frente às inúmeras formas de resposta às tensões geradas por um risco.

O comportamento de polímeros à resistência ao risco, ou à riscabilidade, tem sido analisado nos últimos cinquenta anos. Os primeiros registros datam de 1955 , onde os poliestirenos modificados foram testados neste requisito visando aplicação em carcaças de telefones. ${ }^{64}$ Um trabalho importante foi realizado por Briscoe et al. ${ }^{65}$, em 1996. Os autores construíram mapas de deformação para uma série de polímeros, como poli(metacrilato de metila), politetrafluoroetileno e polietileno de ultra alta massa molar, dentre outros. Os materiais foram submetidos a várias condições de reprodução de riscos, os quais foram produzidos por cones e esferas de vários tamanhos e sob diferentes condições de contato, como tensão, velocidade e cargas aplicadas. Imagens obtidas por microscopia eletrônica de varredura (SEM) e por perfilometria a laser foram utilizadas na análise dos resultados. O princípio utilizado pelos pesquisadores foi de que os mecanismos de deformação são originados a partir dos processos eficientes de dissipação de energia no ponto de contato entre o dispositivo de penetração (indentador) e o material e, portanto, o atrito de fricção medido corresponderia à resposta de energia dos materiais ao risco.

Inúmeros dispositivos de testes foram criados nos últimos anos para a avaliação da resistência a riscos. As dificuldades no desenvolvimento destes incluem aspectos como geometria e números de penetradores, coeficientes de fricção, definição de velocidade e pesos, quantidade de cargas e aditivos presentes na composição do material, dentre outros. Uma revisão quanto a dispositivos de destaque foi realizada por Wong et al. $^{63}$, os quais citam, dentre outros, o teste por lápis (Pencil test) e o dispositivo Five-Fingers, da Ford. O primeiro, considerado um dos mais simples, consistia na análise do risco proporcionado por um lápis em diferentes escalas de pressão proporcionada por uma mola interna. Entretanto, este método era muito dependente de fatores relacionados à forma de manipulação do lápis pelo analista, como o quão forte o dispositivo era pressionado contra a superfície, bem como, da sua inclinação e da velocidade imposta para a formação do risco. Dentre os dispositivos mais completos, o dispositivo Five-Fingers, mostrado na Figura 12, foi muito utilizado pela indústria automobilística para a avaliação de riscabilidade da superfície de peças presentes no interior e exterior do veículo. Neste dispositivo, o peso incidente sobre cada caneta tinha um valor fixo, o que resultava na flutuação da carga final aplicada em função da deformação induzida e 
descontínua pelo efeito de irregularidades na superfície do material. A viscoelasticidade do polímero também afetava a estabilidade dos parâmetros de teste. A explicação é que, comparativamente, entre um polímero rígido e um polímero mais flexível, a ponta de teste penetrava mais no flexível e, como consequência, este material resistia mais ao movimento do indentador. Tal fato proporcionava uma alteração da velocidade, tornando-a mais lenta no início do ensaio. Estas e outras instabilidades relativas ao método comprometiam a credibilidade dos resultados. ${ }^{64}$

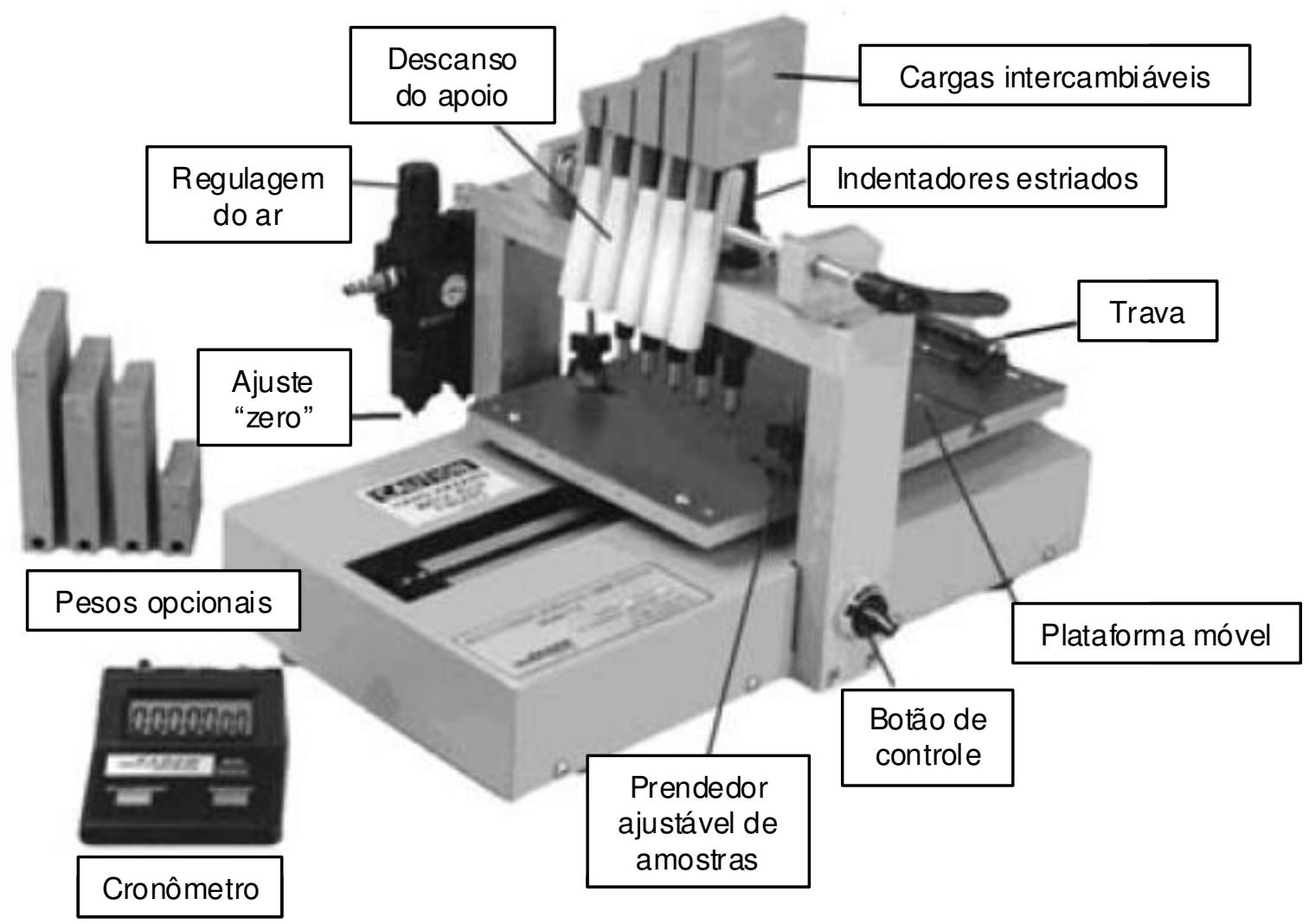

Figura 12 - Dispositivo de teste para resistência a riscos Multi-Finger Scratch (modelo 710), fabricado pela Taber $^{64}$

Não só o desenvolvimento apropriado dos dispositivos, mas também as interpretações dos resultados constituem um grande desafio. A interpretação da "visibilidade" de um risco por pesquisadores evoluiu de impressões visuais de um grupo de observadores, passando pela utilização de espectrofotômetros para a medição do espalhamento de luz incidente na superfície, até a análise digital de imagens por softwares adequados. ${ }^{64}$ Wong et al. $^{63}$ desenvolveram uma 
metodologia bastante robusta para a avaliação da riscabilidade mediante análises de imagens por microscopia e por métodos de elementos finitos (FEA). Os pesquisadores empregaram um dispositivo de teste, o qual foi construído com a capacidade de execução de riscos com vários indentadores, com a velocidade constante, carga constante sob velocidade constante, com variação linear da carga de acordo com velocidade, e capacidade de operar em várias temperaturas $\left(-50^{\circ} \mathrm{C}\right.$ a $+100^{\circ} \mathrm{C}$ ). Os testes poderiam ser conduzidos sob carga fixa ou por meio de um sistema de controle de carga por um sistema constituído por molas, prevenindo o problema de flutuação mencionado no dispositivo Five-Fingers. Por meio deste método, observações experimentais e resultados por FEM apresentaram uma boa correlação qualitativa.

Segundo Browning; Jiang; Sue ${ }^{64}$, pela evolução das pesquisas e estudos sobre o tema, como a de Wong et al..$^{63}$, um novo dispositivo de teste, como o mostrado na Figura 13, tem obtido bons resultados quanto à investigação da resistência a riscos.

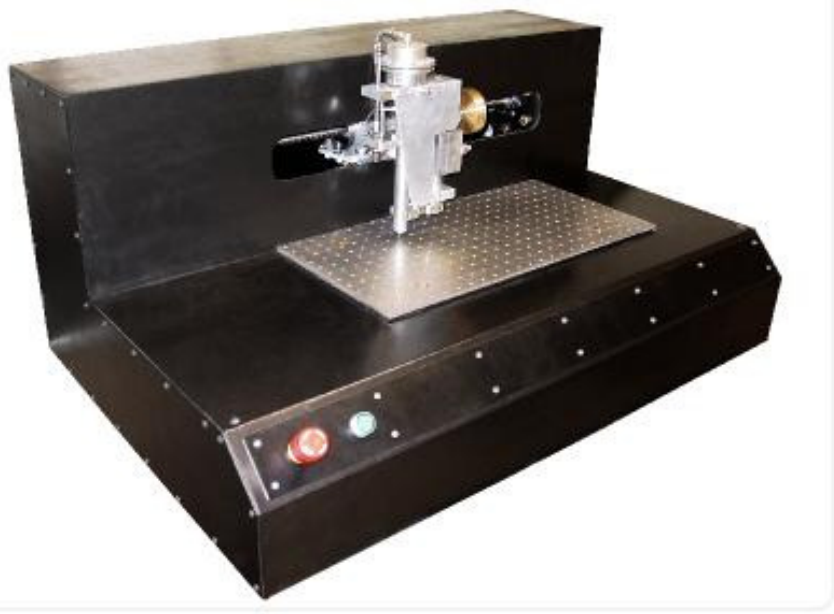

Figura 13 - Dispositivo para testes, conforme ASTM D 7027-05 e ISO 19252, Scratch 4 Machine ${ }^{\circledR}$, produzido pela empresa SMS ${ }^{66}$

Este equipamento conta com recursos como um servo motor para o deslocamento da ponta de teste (indentador), o qual permite um controle preciso da velocidade. Um sistema pneumático para aplicações de carga garante a linearidade desta durante a execução do risco, permitindo uma progressão contínua da deformação. Este dispositivo também pode ser equipado com sensores que detectam a aplicação normal e tangencial da carga, bem como, o deslocamento 
vertical e horizontal da ponta de teste. Estas informações são armazenadas para análise posterior. A norma ASTM D7027-05 cita esta metodologia, correlacionando os resultados obtidos com as análises via FEM.

No momento as indústrias automobilísticas utilizam diferentes métodos de teste para a avaliação da resistência a riscos. A "visibilidade" ou o esbranquiçamento por tensão ocasionada na superfície por um risco é uma característica relevante considerada em aplicações automotivas. ${ }^{67}$ Neste trabalho, o equipamento utilizado para os testes de riscabilidade será descrito no Capítulo 3. Este também dispõe de um controle de aplicação de carga, que é mantida constante ao longo da deformação, porém sem monitoramento por sensores. A "visibilidade" do risco é mensurada pela diferença da luz refletida entre superfície riscada e não riscada, mediante seus respectivos comprimentos de onda. A medida desta variação de luminosidade (claro / escuro), determinada por espectrofotômetro, apresenta uma boa correlação com a severidade da deformação observada.

Apesar dos avanços conquistados nos desenvolvimentos de métodos e modelos para a avaliação da riscabilidade, a complexidade deste tema ainda requer pesquisas e estudos que possam, um dia, prever com exatidão este comportamento para os polímeros.

\subsection{FIBRAS CURTAS DE SÍLICA AMORFA}

As fibras curtas de sílica, empregadas como agente de reforço neste trabalho, são provenientes do beneficiamento do minério espongilito, uma rocha formada por espículas silicosas, associadas à presença de carapaças de diatomáceas, grãos de areia, argila e matéria orgânica. ${ }^{8}$ As espículas silicosas constituem a estrutura inorgânica de suporte ou esqueletos dos copos das esponjas de água doce. ${ }^{11,12}$ Os depósitos geológicos de espongilitos no Brasil ocorrem no fundo de lagos e jazidas no sudoeste de Minas Gerais, sul de Goiás, nordeste do Mato Grosso do Sul, São Paulo e Bahia. ${ }^{8}$ As microfibras de sílica Silexil ${ }^{\circledR}$ são constituídas essencialmente por opala ou sílica biogênica, sendo este último um termo geral para descrever a forma 
amorfa da sílica. A opala, com composição química $\mathrm{SiO}_{2} \cdot \mathrm{nH}_{2} \mathrm{O}$, a partir de transformações físico-químicas, pode ser cristalizada na forma de quartzo. ${ }^{12}$

Com o formato tubular e com extremidades mais finas, parecido com o de uma agulha, as fibras curtas de sílica amorfa apresentam um orifício central ao longo do seu comprimento, o que the confere uma diminuição de densidade volumétrica. De acordo com as especificações do fabricante, estas apresentam comprimento médio (I) de $200 \mu \mathrm{m}$, diâmetro médio (d) de $10 \mu \mathrm{m}$, razão de aspecto média (I/d) de $15 \mathrm{e}$ área superficial média de $0,70 \mathrm{~m}^{2} \cdot \mathrm{g}^{-1}$ (por técnica de adsorção gasosa - método B.E.T.). A coloração varia de branco a bege claro.

$\mathrm{Na}$ Figura 14 é ilustrada a morfologia dessas fibras de sílica, as quais apresentam forma oca, com superfície basicamente lisa e contendo partículas depositadas sobre a mesma.

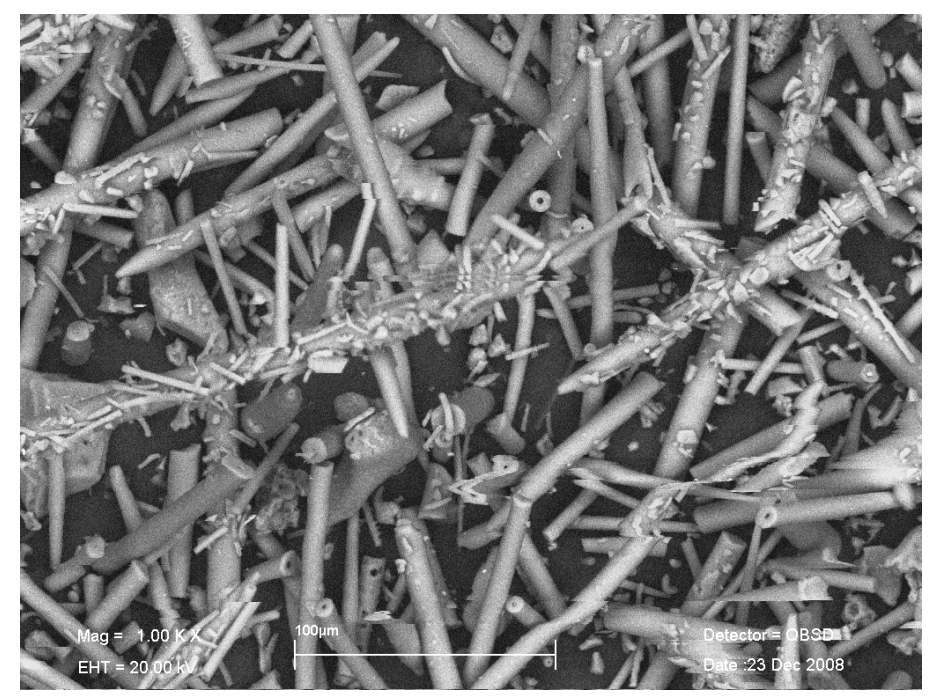

Figura 14 - Micrografia das fibras de sílica Silexil ${ }^{\circledR}$

Segatelli ${ }^{12}$ realizou análises de caracterização destas fibras, comprovando as informações especificadas pelo fabricante. Por meio da técnica de microscopia de varredura, a autora observou que as fibras possuem tamanhos muito variados, com dimensões médias de comprimento (I) e de diâmetro (d) de $150 \pm 83 \mu \mathrm{m}$ e $12 \pm 2$ $\mu \mathrm{m}$, respectivamente, com razão de aspecto (I/d) de aproximadamente 13. A partir da técnica B.E.T., constatou que as fibras de sílica possuem uma área superficial de $1,14 \mathrm{~m}^{2} \cdot \mathrm{g}^{-1}$, sugerindo a presença de poucos grupos silanóis na superfície. A característica amorfa das fibras foi confirmada por difratometria de raios $X(X R D)$. A composição química, obtida por espectrometria de fluorescência de raios $X(X R F)$, 
demonstrou que as fibras são constituídas basicamente de sílica, com concentração de $99,7 \%$ de $\mathrm{SiO}_{2}$. Análises de espectroscopia no infravermelho com transformada de Fourier (FTIR) por refletância difusa constataram o caráter hidrofílico das fibras pela presença de grupos hidroxila na superfície das mesmas.

O efeito da incorporação das fibras Silexil ${ }^{\circledR}$ nas propriedades de compósitos de poliuretano foi investigado por Sailba et al... ${ }^{8}$ Quanto aos ensaios de caracterização, os autores observaram comprimentos de fibras divergentes dos observados por Segatelli. ${ }^{12}$ Pela técnica de microscopia eletrônica de varredura (MEV), os autores identificaram fibras com variação de comprimento de 200 a $600 \mu \mathrm{m}$, sendo o comprimento médio (I) de $288 \mu \mathrm{m}$. 


\section{MATERIAIS E MÉTODOS}

Neste capítulo serão descritos os materiais e os procedimentos experimentais empregados no decorrer desta pesquisa, assim como as técnicas utilizadas para a caracterização das amostras deste trabalho.

\subsection{MATERIAIS}

\subsubsection{Compósitos de polipropileno homopolímero}

Foram utilizadas resinas de polipropileno homopolímero de fonte Quattor, de códigos comerciais HP 648S e HP 550K, com índices de fluidez (MFI) de $40 \mathrm{~g} / 10 \mathrm{~min}$ e 3,5 g/10 min., respectivamente, determinados pelo método ASTM D-1238 $\left(230^{\circ} \mathrm{C} /\right.$ 2,16 kg). Optou-se pelo emprego de duas resinas para um melhor controle do índice de fluidez do compósito final. As resinas foram estabilizadas termicamente pelo uso de um antioxidante de fenol estericamente impedido (Irganox ${ }^{\circledR} 1010$ - Basf) e de um antioxidante secundário (Cyanox® STDP - Cytec). Como agente dispersante foi empregado estearato de cálcio e, como agente facilitador de fluxo, a resina epóxi D.E.R. ${ }^{\mathrm{TM}} 663-\mathrm{A} 25$, fonte Dow.

O compatibilizante químico escolhido neste trabalho, para modificar as interações interfaciais entre fibras e polímero, foi o Bondyram ${ }^{\circledR} 1001$, fonte Polyram, à base de polipropileno homopolímero funcionalizado com anidrido maleico (PP-gMAH), o qual apresenta índice de fluidez de $100 \mathrm{~g} / 10 \mathrm{~min}$, determinado pelo método ISO $1133\left(190^{\circ} \mathrm{C} / 2,16 \mathrm{~kg}\right)$, e concentração de MAH de $1 \%$ em peso.

$\mathrm{Na}$ preparação dos compósitos, a carga mineral empregada foi o talco TALMAG $^{\circledR}$ GM20, fonte Magnesita, que é um tipo lamelar, micronizado, de brancura e pureza alta, com tamanho de partícula médio $d_{50}=3,5 \mu \mathrm{m}$, medido por serigrafia, e área superficial de $7 \mathrm{~m}^{2} \cdot \mathrm{g}^{-1}$ determinada pela técnica B.E.T. As fibras de sílica 
Silexilß, usadas como agente de reforço, foram fornecidas pela empresa Magnesita e descritas no capítulo 2 deste trabalho.

Os valores das propriedades mencionadas para os componentes de formulação descritos neste item foram obtidos por meio das especificações dos respectivos fabricantes.

\subsubsection{Compósitos de polipropileno copolímero modificados com POE}

A resina de polipropileno copolímero heterofásico escolhida foi a de fonte Braskem, código comercial CP 286, com índice de fluidez de 18 g/10min, determinado pelo método ASTM D-1238 $\left(230^{\circ} \mathrm{C} / 2,16 \mathrm{~kg}\right)$. O polímero com características elastoméricas utilizados para melhorar a tenacidade final das composições foi o copolímero etileno e 1-octeno (POE), que é comercializado pela Dow, código ENGAGE ${ }^{\mathrm{TM}}$ 8100, com conteúdo de 1-octeno de $38 \%$ e índice de fluidez (MFI) de 1,0 g/10 min, também determinado pelo método ASTM D-1238 $\left(190^{\circ} \mathrm{C} / 2,16 \mathrm{~kg}\right)$. O POE, que também pertence à família dos copolímeros etileno- $\alpha-$ olefina, é um copolímero que possui ramificações curtas hexílicas (seis carbonos). Em todas as misturas foram adicionados um antioxidante de fenol estericamente impedido (Irganox ${ }^{\circledR} 1010$ - Basf) e um antioxidante secundário (Irganox $®$ B215 Basf) composto de uma blenda base fenólico / organofosfato. O compatibilizante químico, o talco, bem como, as fibras curtas de sílica, são os mesmos utilizados para os compósitos de polipropileno homopolímero e descritos anteriormente. As formulações foram pigmentadas utilizando-se masterbatch preto, em concentração de $1,80 \%$ em peso.

Os valores das propriedades mencionadas para os componentes de formulação descritos neste item foram obtidos por meio das especificações dos respectivos fabricantes. 


\subsection{MÉTODOS}

\subsubsection{Preparação dos compósitos}

A preparação dos compósitos foi realizada na empresa Basell Poliolefinas, utiizando uma extrusora dupla rosca co-rotacional ZSK25 Super Compounder, da Werner \& Pfleider, com rosca de $25 \mathrm{~mm}$ de diâmetro, com perfil de cisalhamento baixo, relação $L / D=44$. A resina e os aditivos foram misturados previamente em um equipamento do tipo Ribbon-blender. A alimentação da pré-mistura e da carga foi efetuada por dosadores gravimétricos Brabender. $O$ resfriamento, para posterior granulação, foi realizado pelo acessório tipo "banheira". As misturas foram preparadas com vazão de $10 \mathrm{~kg} / \mathrm{h}$, com velocidade de rotação da rosca de $500 \mathrm{rpm}$ e com um perfil de temperaturas ao longo do barril de 200 a $260^{\circ} \mathrm{C}$.

\subsubsection{Injeção dos corpos de prova}

Inicialmente, os materiais foram secados em estufa com circulação forçada de ar, modelo Heraeus BUT 5050 , a $120^{\circ} \mathrm{C}$ por 2 horas. A conformação dos corpos de prova foi realizada em uma injetora Battenfeld, modelo TM 130/525, com força de fechamento de $1310 \mathrm{kN}$, também na empresa Basell. Os parâmetros de processo estão descritos a seguir:

- Temperaturas das zonas: 185 a $215^{\circ} \mathrm{C}$.

- Temperatura do molde: $(25 \pm 5)^{\circ} \mathrm{C}$

- Tempo de injeção: $20 \mathrm{~s}$

-Pressão de injeção: 20 bar 


\subsubsection{Composição das amostras}

O teor de reforço escolhido para os compósitos foi de $20 \%$, o qual é de grande aplicação em peças automotivas, tanto para compósitos com talco, como com fibras de vidro. A composição das amostras dos compósitos de polipropileno homopolímero (PP homo), bem como a dos compósitos de polipropileno copolímero (PP copo) modificados com 5\% de POE em peso, estão apresentadas nas Tabelas 1 e 2 , respectivamente.

Tabela 1 - Composição das amostras de PP homopolímero, em peso

\begin{tabular}{cl}
\hline Amostra & \multicolumn{1}{c}{ Composição } \\
\hline PP homo & PP homopolímero puro \\
$20 T$ & PP homo, 20\% de talco \\
10T/10S & PP homo, 10\% de talco, 10\% de fibra de sílica, sem PP-g-MAH \\
$10 T / 10 S-2$ & PP homo, 10\% de talco, 10\% de fibra de sílica, 2\% de PP-g-MAH \\
$20 S$ & PP homo, 20\% de fibra de sílica, sem PP-g-MAH \\
$20 S-1$ & PP homo, 20\% de fibra de sílica, 1\% de PP-g-MAH \\
20 S-2 & PP homo, 20\% de fibra de sílica, 2\% de PP-g-MAH \\
20 - -4 & PP homo, 20\% de fibra de sílica, 4\% de PP-g-MAH \\
\hline
\end{tabular}

Tabela 2 - Composição as amostras de PP copolímero/POE, em peso

\begin{tabular}{cc}
\hline Amostra & Composição \\
\hline E/P - 20T & PP copo/POE, 20\% de talco, 2\% de PP-g-MAH \\
E/P - 20S & PP copo/POE, 20\% de fibra de sílica, 2\% de PP-g-MAH \\
E/P - 10T/10S & PP copo/POE, 10\% de fibra de sílica, 10\% de talco, 2\% PP-g-MAH \\
\hline
\end{tabular}

\subsubsection{Caracterização das amostras}

\subsubsection{Distribuição e comprimento das fibras antes e após moldagem}

A análise da distribuição e dos comprimentos das fibras curta de sílica, antes e após moldagem, foram efetuadas por microscopia óptica (OM), utilizando-se o 
microscópio óptico Olympus modelo SZX10 (aumento de 126x) e uma câmera Olympus modelo U-TV0.5X3. As medidas dos comprimentos foram determinadas com o auxílio do Software AnalySIS. Antes da moldagem ou preparação dos compósitos, as fibras foram avaliadas diretamente no estado de recebimento. Após a moldagem por injeção, os compósitos foram calcinados em forno tipo mufla a $(600 \pm 10)^{\circ} \mathrm{C}$ e, após resfriamento à temperatura ambiente, as fibras foram submetidas à análise por $\mathrm{OM}$.

\subsubsection{Densidade dos compósitos}

As densidades de cada uma das formulações foram determinadas conforme a metodologia DIN EN ISO 1183-1, método A - imersão, com o auxílio de uma balança marca Mirage modelo SD-120L 120g e dispositivo específico.

\subsubsection{Propriedades mecânicas dos compósitos}

Antes dos ensaios, os corpos de prova moldados foram condicionados em laboratório por, no mínimo, 48 horas em clima padrão DIN 50014-23/50-2.

Dez corpos de prova definidos pela norma DIN EN ISO 527-2, tipo 1B, foram submetidos a ensaios de tração e alongamento conforme a norma DIN EN ISO 5271 , velocidade de ensaio de $(50 \pm 5) \mathrm{mm} / \mathrm{min}$., utilizando-se uma máquina de ensaio universal marca Instron, modelo 5566. Este equipamento também foi usado para a determinação das propriedades de módulo e de resistência à flexão, a $23^{\circ} \mathrm{C}$, de acordo com os requisitos da norma DIN EN ISO 178, porém com dez corpos de prova com comprimento de $(50 \pm 1) \mathrm{mm}$, largura de $(6 \pm 0,2) \mathrm{mm}$ e espessura de 4 $\mathrm{mm}$, distância de apoio de $40 \mathrm{~mm}$, raio de apoio de 1,0 até 1,2 $\mathrm{mm}$ e velocidade de ensaio de $(14 \pm 1) \mathrm{mm} / \mathrm{min}$.

Os ensaios de resistência ao impacto Charpy, com e sem entalhe, foram realizados em dez corpos de prova com as mesmas dimensões dos citados para os 
ensaios de flexão, segundo a norma DIN EN ISO 179-1, porém com distância de apoio de $40 \mathrm{~mm}$ e tipo de entalhe na forma de "U" de 0,8 $\mathrm{mm}$ de largura (profundidade do entalhe $=1 / 3$ da espessura e com cantos que limitam o fundo do entalhe com raio de arredondamento $<0,1 \mathrm{~mm}$ ). $\mathrm{O}$ dispositivo utilizado para os testes de impacto à temperatura ambiente foi o de modelo Resil 5.5, marca Ceast, com pêndulo de 4 Joules. Os entalhes foram confeccionados com o auxílio do dispositivo TMI Notching Cutter modelo 22-05-03-0002. Para os testes em temperatura baixa $\left(-30^{\circ} \mathrm{C}\right)$ utilizaram-se os equipamentos Ceast modelo Resil 25, Ray-Ran modelo RR 3700 (para o entalhe) e a câmara Ceast Cryodispenser 684.800 .

\subsubsection{Propriedades térmicas dos compósitos}

Cinco corpos de prova, com espessura mínima de $3 \mathrm{~mm}$ e máxima de 6,5 mm, com área aproximada de $(1 \times 10) \mathrm{mm}^{2}$, foram avaliados com relação à propriedade de temperatura de amolecimento, segundo VICAT, conforme procedimentos da norma DIN EN ISO 306 (método A50, aplicação de $10 \mathrm{~N}$ de carga, taxa de aquecimento de $50^{\circ} \mathrm{C} /$ hora).

Para determinar a cristalinidade das amostras foi utilizada a técnica de calorimetria diferencial de varredura (DSC), por meio do equipamento DP Union, modelo Q20. Amostras de, aproximadamente, $10 \mathrm{mg}$ foram aquecidas na faixa de temperatura de $40^{\circ} \mathrm{C}$ a $220^{\circ} \mathrm{C}$, sob taxa de aquecimento de $5^{\circ} \mathrm{C} \cdot \mathrm{min}^{-1}$ e atmosfera inerte de nitrogênio. Ao atingir a temperatura de $200^{\circ} \mathrm{C}$, as amostras foram mantidas em isometria de 5 minutos e depois resfriadas novamente até $40^{\circ} \mathrm{C}$, sob a taxa de $5^{\circ} \mathrm{C} \cdot \mathrm{min}^{-1}$. Foram obtidos os valores de temperatura de cristalização $\left(T_{c}\right)$, temperatura de fusão $\left(T_{m}\right)$, entalpia de fusão $\left(\Delta H_{m}\right)$ e grau de cristalinidade $\left(X_{c}\right)$. $O$ grau de cristalinidade, em porcentagem, foi calculado pela eq. (3):

$$
\mathrm{X}_{\mathrm{c}}=\left(\Delta \mathrm{H}_{\mathrm{m}} / \Delta \mathrm{H}_{100}\right) \times 100
$$


em que, $\Delta \mathrm{H}_{\mathrm{m}}$ é um valor de referência que representa a entalpia de fusão para um polipropileno $100 \%$ cristalino, que neste caso é tomado como $209 \mathrm{~J} / \mathrm{g}$.

\subsubsection{Anisotropia}

A anisotropia foi calculada pela razão da contração longitudinal e transversal dos corpos de prova. O corpo de prova utilizado foi uma placa injetada em molde com dimensões 194,98 mm por 99,97 mm e 2,5 mm de espessura. Na Figura 15 é mostrado um esquema da medição da contração diferencial, em que os valores de T1, T2 e L1 são obtidos por meio de relógios comparadores.

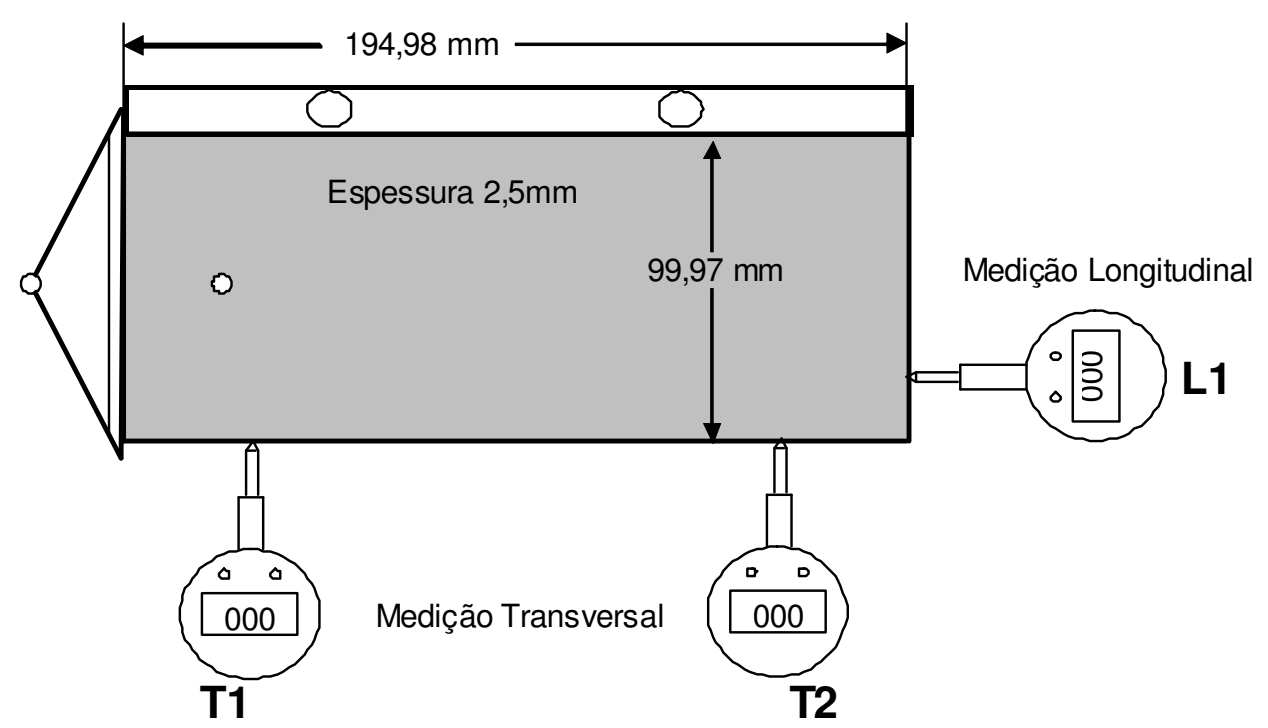

Figura 15- Esquema do método de medição da contração diferencial (anisotropia) do material

\subsubsection{Caracterização morfológica}

A morfologia dos compósitos foi analisada utilizando-se os seguintes microscópios eletrônicos de varredura: 
- JEOL, modelo JSM 7500 F (Field Emission Microscope), tensão para aceleração do feixe de $1 \mathrm{keV}$ e distância de trabalho de $18 \mathrm{~mm}$.. Os corpos de prova foram recobertos com carbono, sob base de alumínio, e aderidos com resina epóxi condutora.

- LEO, modelo VP435i. Amostras recobertas por "xputtering"; fixação em suportes com fita adesiva de carbono dupla-face; tensão para aceleração do feixe de 20 $\mathrm{keV}$, distância de trabalho de $19 \mathrm{~mm}$.

Para a análise foram utilizados os mesmos corpos de prova injetados para os ensaios de resistência ao impacto Charpy, os quais foram fraturados na direção perpendicular ao fluxo de injeção, em temperatura baixa.

\subsubsection{Caracterização de propriedades específicas - comportamento a emissões}

\subsection{Emissão total de compósitos orgânicos}

Cinco amostras (em grãos - pellets) de $(1,000 \pm 0,001) \mathrm{g}$ foram pesadas $\mathrm{e}$ colocadas em frascos tipo head-space, os quais foram hermeticamente fechados e climatizados no emissor de ensaio head-space a $(120 \pm 1)^{\circ} \mathrm{C}$ durante $5 \mathrm{~h} \pm 5 \mathrm{~min}$ e, em seguida, analisados com $\mathrm{o}$ auxílio do mesmo. O coeficiente reativo foi determinado pela formação do valor médio dos valores sinalizados resultantes de, no mínimo, cinco medições com frascos vazios. Para a determinação quantitativa da emissão total de carbono foram estabelecidas curvas de calibração, utilizando acetona de pureza alta, segundo o método de padrão externo. A avaliação foi efetuada a partir dos dados registrados pelo cromatógrafo para a fase gasosa, sendo obtidos os valores das áreas de pico total, cujo cálculo considerou somente os picos com altura superior ao triplo do ruído da linha básica, bem como com área maior que $10 \%$ da área do pico de acetona na solução de calibração com concentração de $0,5 \mathrm{~g} / \mathrm{l}$. $O$ valor de emissão total $\left(E_{T}\right)$ foi obtido a partir da área total de pico $\left(A_{P}\right)$, resultante da análise do material de ensaio, do fator de calibração $(k)$ e da área de pico do componente reativo $\left(A_{R}\right)$, segundo a eq. (4). 


$$
E_{T}=\left(A_{P}-A_{R} / k\right) \times 2 \times 0,6204
$$

O fator 0,6204 representa o índice de massa do carbono presente na acetona. $O$ cromatógrafo utilizado foi GC-3800 - Varian, para fase gasosa para operação de adsorção por coluna capilar, com emissor de ensaio head-space Autosampler Modelo 7000 - Tekmar, detector de ionização térmica (FID) e computador/integrador, coluna separadora capilar WCOT (tipo Wax, 0,25 \$mm int., 0,25 $\mu \mathrm{m}$ espessura de película, $30 \mathrm{~m}$ de comprimento). Na Figura 16 é mostrada uma representação do princípio da medição de emissões totais, por meio de frascos tipo head-space.

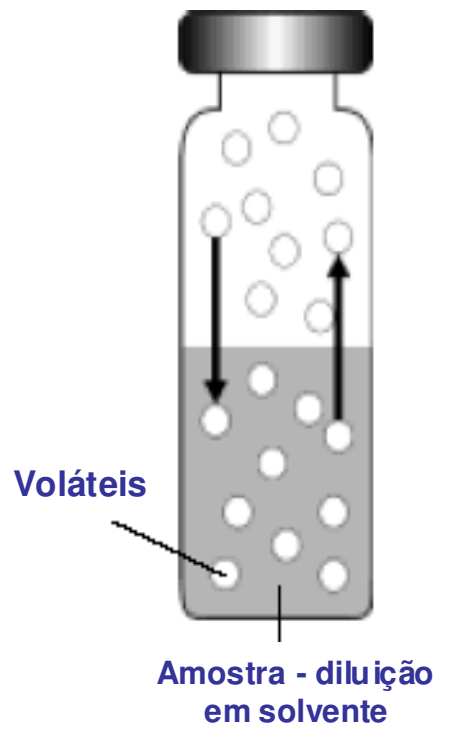

Figura 16 - Representação do princípio de medição de emissões totais de compósitos orgânicos, por meio de frascos tipo head-space

\subsection{Teste de Odor}

Placas injetadas dos compósitos de PP homopolímero foram recortadas para se obter $(50 \pm 5) \mathrm{cm}^{3}$ de amostra por tipo de formulação. Estas foram colocadas em frascos de 1,0 litro, cada um com tampa e com vedação apropriada. Os frascos foram limpos previamente, conforme procedimento adequado, para que ficassem 
totalmente isentos de qualquer tipo de odor. Os recipientes com as amostras, devidamente fechados, foram submetidos à temperatura de $(80 \pm 2)^{\circ} \mathrm{C}$ por $2 \mathrm{~h} \pm 10$ min, em estufa de circulação forçada de ar, marca Heraus, sendo posteriormente resfriados até $(60 \pm 5)^{\circ} \mathrm{C}$ em temperatura ambiente e, a seguir, abertos rapidamente para a análise de cada um dos analistas. Na Figura 17 é mostrado o tipo de frasco empregado para os testes de odor.

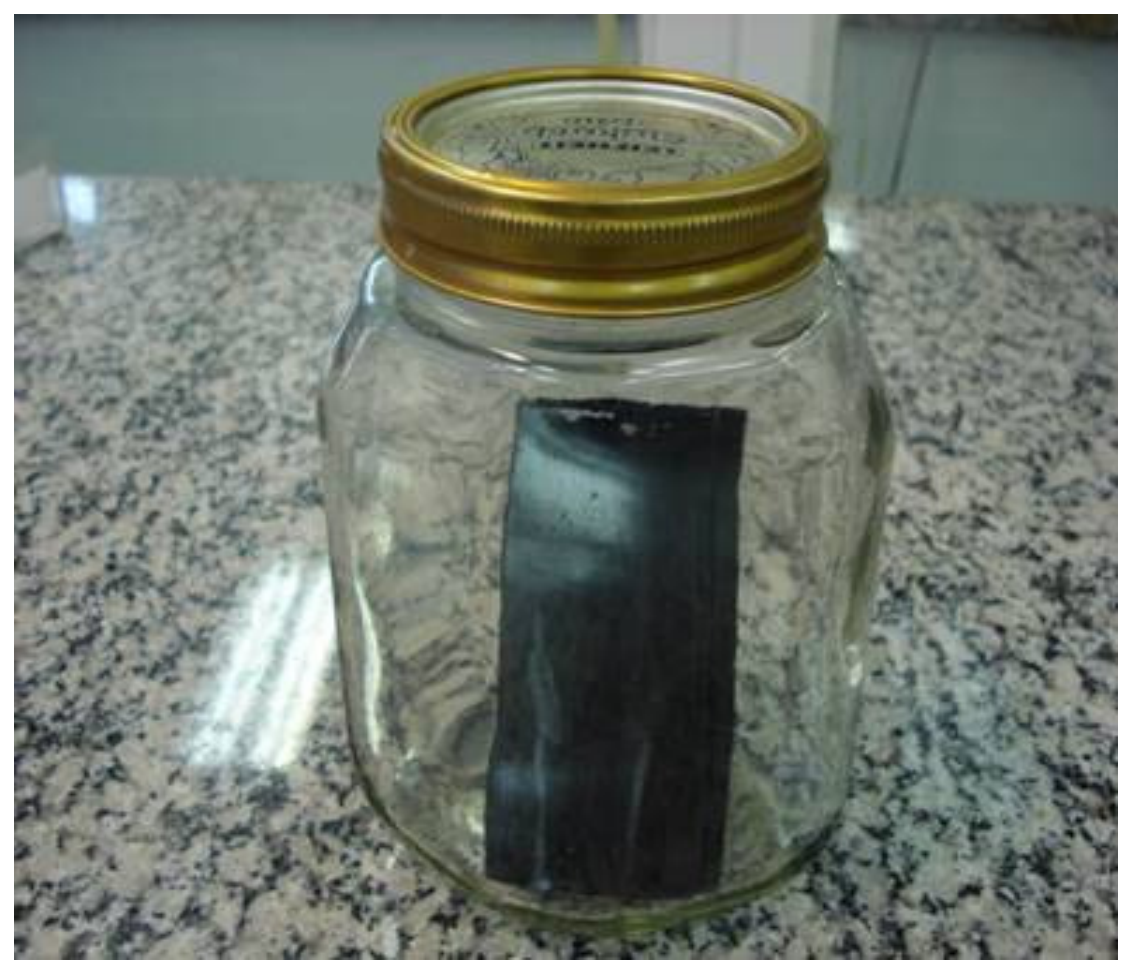

Figura 17 - Frasco para determinação de odor

\subsubsection{Teste de resistência a riscos}

Os ensaios de resistência a riscos foram efetuados apenas para os compósitos de polipropileno copolímeros modificados com POE. Cinco placas planas com aplicação de textura, injetadas para cada uma das formulações, constituíram os corpos de prova avaliados pela metodologia descrita a seguir.

Um dispositivo com uma ponta esférica de metal duro, com diâmetro de $1 \mathrm{~mm}$, é guiado através do equipamento Erichsen, modelo 430P (mostrado na Figura 18), traçando riscos na superfície da amostra, sob um peso de $10 \mathrm{~N}$ e com velocidade de 
$1,00 \mathrm{~mm} / \mathrm{min}$. Forma-se uma grade de riscos, com vinte linhas, sendo cada uma produzida em um só movimento. Dez linhas são efetuadas em uma direção e mais dez linhas em direção perpendicular as primeiras, com distância de, aproximadamente, 2 mm. Um espectrofotômetro Minolta, modelo CM-2500, com ângulo de medição de $45^{\circ} / 0^{\circ}$ - D65, é então utilizado para determinar a diferença de luminosidade $\left(\Delta L^{*}\right.$ - Codificação CieLab) entre a superfície riscada e não riscada.

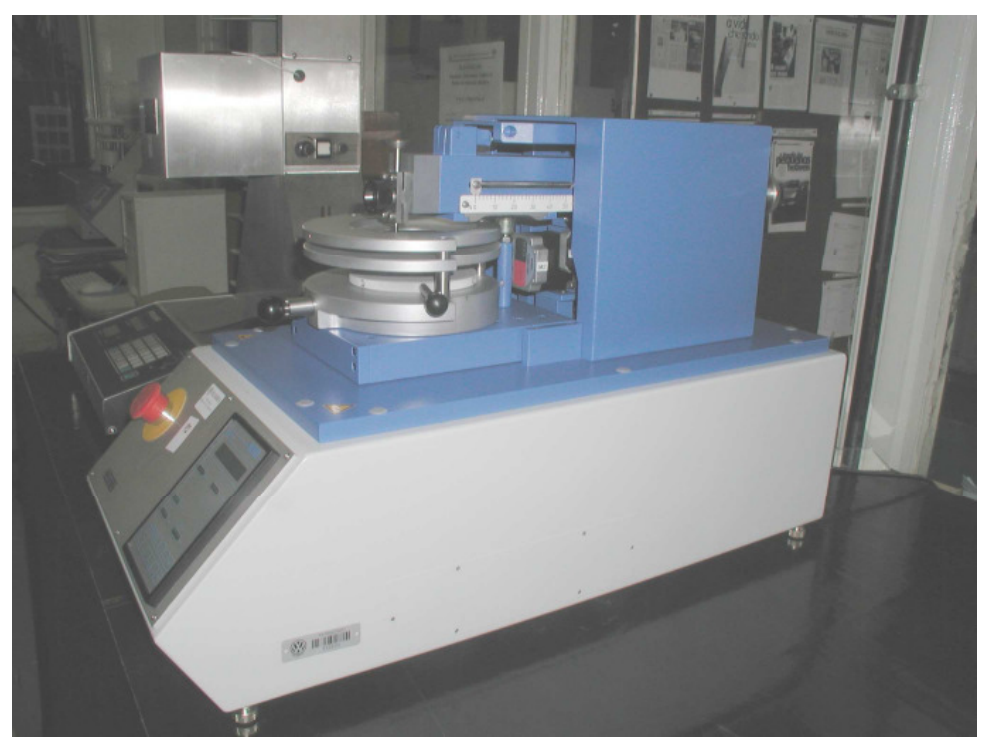

Figura 18 - Equipamento Erichsen, modelo 430P 


\section{RESULTADOS E DISCUSSÃO}

Este capítulo está divido em dois tópicos. Primeiramente serão apresentados e discutidos os resultados obtidos na caracterização e análise dos compósitos de polipropileno homopolímero, com ênfase no aumento da afinidade entre as fibras curtas de sílica e a matriz, por meio da variação de concentrações de polipropileno funcionalizado com anidrido maleico (PP-g-MAH). Posteriormente, será avaliado o efeito da incorporação das fibras em compósitos de polipropileno copolímero modificados com POE (copolímero de etileno e 1-octeno), mantendo-se constante o teor do agente compatibilizante. Para os dois casos citados será investigada a influência da adição de talco quanto à otimização de propriedades finais dos compósitos híbridos.

\subsection{COMPÓSITOS DE POLIPROPILENO HOMOPOLÍMERO}

\subsubsection{Distribuição e comprimentos das fibras antes e após moldagem}

Visando-se verificar a influência das condições de processamento para a integridade das fibras de sílica, foram avaliadas as distribuições de comprimento destas, antes (estado de recebimento) e após moldagem (somente para os compósitos 10T/10S-2 e 20S-2). As fibras foram observadas por meio de microscópio óptico, sendo efetuada uma contagem de 300 fibras. Os resultados estão mostrados nas Figuras 19, 20 e 21. 


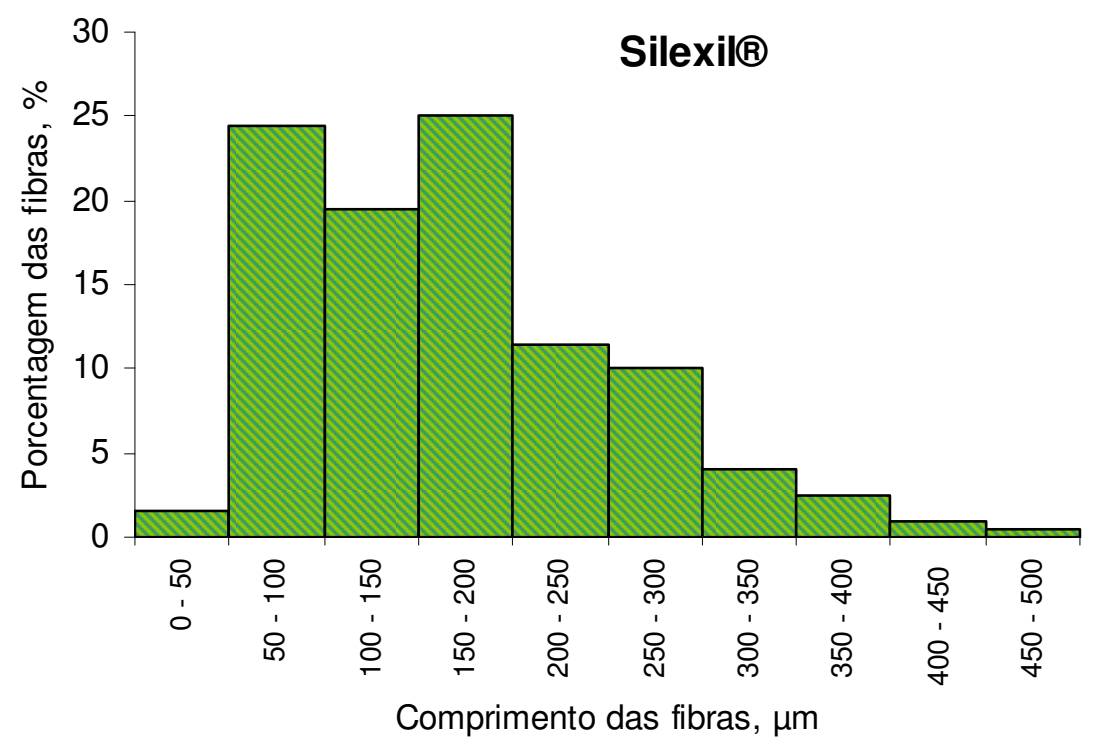

Figura 19 - Distribuição dos comprimentos das fibras de sílica (estado de recebimento)

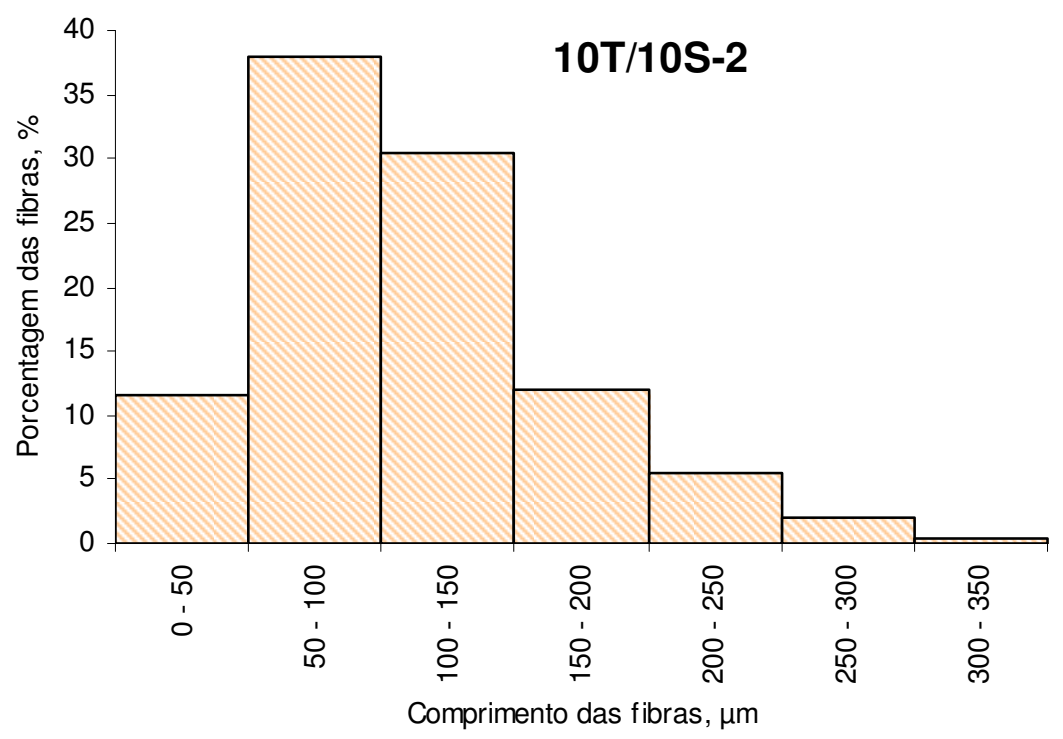

Figura 20 - Distribuição dos comprimentos das fibras após moldagem do compósito com $10 \%$ de talco, $10 \%$ de sílica e $2 \%$ de agente compatibilizante 


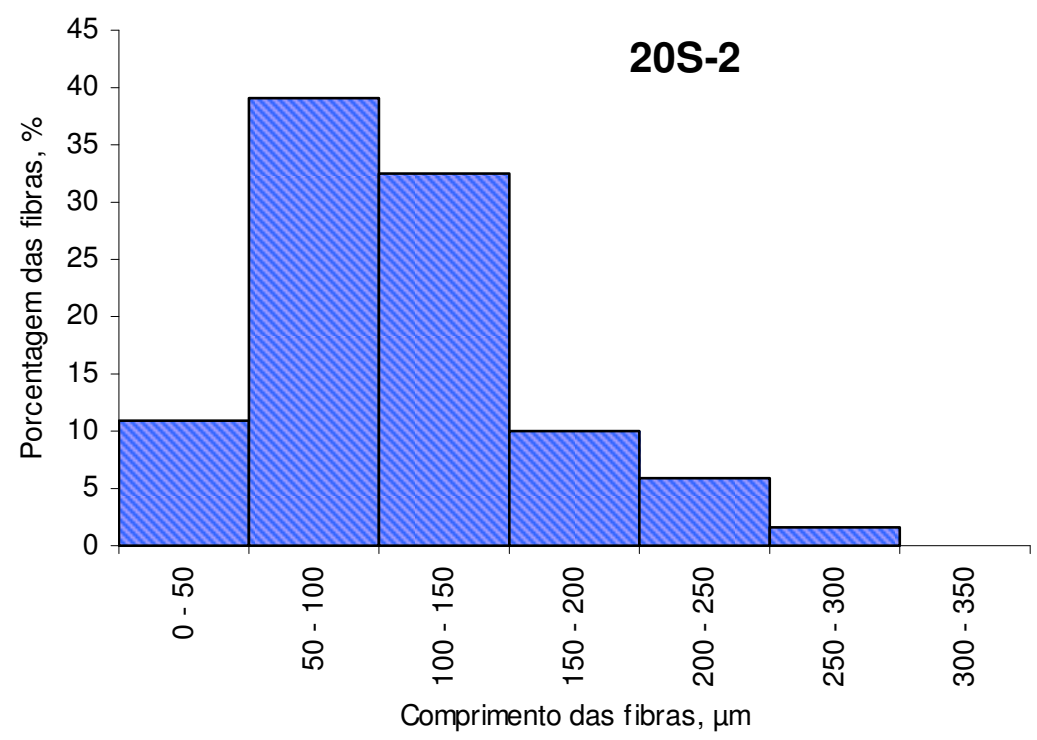

Figura 21 - Distribuição dos comprimentos das fibras após moldagem do compósito com $20 \%$ de sílica e $2 \%$ de agente compatibilizante

A partir das análises efetuadas, verificou-se que as fibras de sílica, no seu estado de recebimento, apresentaram dimensões médias de comprimento de $169 \pm$ $84 \mu \mathrm{m}$. Após processamento, os valores médios observados para os compósitos 10T/10S-2 e 20S-2 foram de $111 \pm 57 \mu \mathrm{m}$ e de $109 \pm 57 \mu \mathrm{m}$, respectivamente. Os resultados demonstraram que as fibras originais apresentaram uma distribuição mais ampla de comprimentos, a qual se tornou mais estreita, com a diminuição aproximada de $35 \%$ em relação ao tamanho médio inicial. A preservação das fibras depende da influência das variáveis relacionadas não só às condições de processo, como temperatura, rotação, configuração da rosca, entre outras, mas também de fatores relacionados aos materiais, como viscosidade, presença de agentes compatibilizantes, dentre outros. $^{28}$ Comparativamente, não foram observadas diferenças significativas entre os compósitos 10T/10S-2 e 20S-2. A distribuição mais estreita de comprimentos médios observada para estes materiais indicou uma provável mistura mais dispersiva e distributiva, favorecida pela melhor redução da tensão interfacial entre as fases, promovida pela presença do aminossilano e do anidrido maleico. 


\subsubsection{Densidade dos compósitos}

As densidades dos diversos compósitos formulados utilizando-se matriz de polipropileno homopolímero estão apresentadas na Tabela 3. Como esperado, em função do peso específico baixo das fibras, todos os compostos com fibra de sílica apresentaram valores menores para esta propriedade comparativamente ao compósito 20T, o qual é muito utilizado em aplicações automotivas.

Tabela 3 - Densidade dos compósitos, $\mathrm{g} / \mathrm{cm}^{3}(23 \pm 1)^{\circ} \mathrm{C}$

\begin{tabular}{cccccccc}
\hline PP homo & 20T & 10T/10S & 10T/10S-2 & 20S & 20S-1 & 20S-2 & 20S-4 \\
\hline 0,902 & 1,065 & 1,024 & 1,018 & 1,006 & 1,006 & 0,999 & 0,995 \\
\hline
\end{tabular}

Observa-se que os valores de densidade para os compósitos com $20 \%$ de fibras de sílica diminuem gradativamente com o aumento da concentração do agente compatibilizante. Esta ligeira redução dos valores pode ser decorrente da melhor molhabilidade das fibras proporcionada pelo compatibilizante, ocasionando um maior contato entre fibra e matriz e diminuindo a presença de vazios entre ambos.

\subsubsection{Propriedades mecânicas}

Na Figura 22 é mostrado o comportamento dos diversos compósitos, de forma comparativa, obtidos nos ensaios de resistência à tração no escoamento. Pode-se observar que as amostras $20 \mathrm{~S}$ (com 20\% de fibra de sílica) e 10T/10S (compósito híbrido contendo $10 \%$ de talco e $10 \%$ de fibra de sílica), sem a adição do compatibilizante, apresentaram valores de tensão menores que os valores obtidos para o homopolímero puro (PP homo), bem como os que da amostra 20T, com $20 \%$ de talco. Entretanto, as amostras 10T/10S-2, 20S-1, 20S-2 e 20S-4, nas quais se adicionou o compatibilizante anidrido maleico, apresentaram uma melhor interação 
polímero-fibra, evidenciando a melhor eficiência de reforço proporcionada pela fibra de sílica.

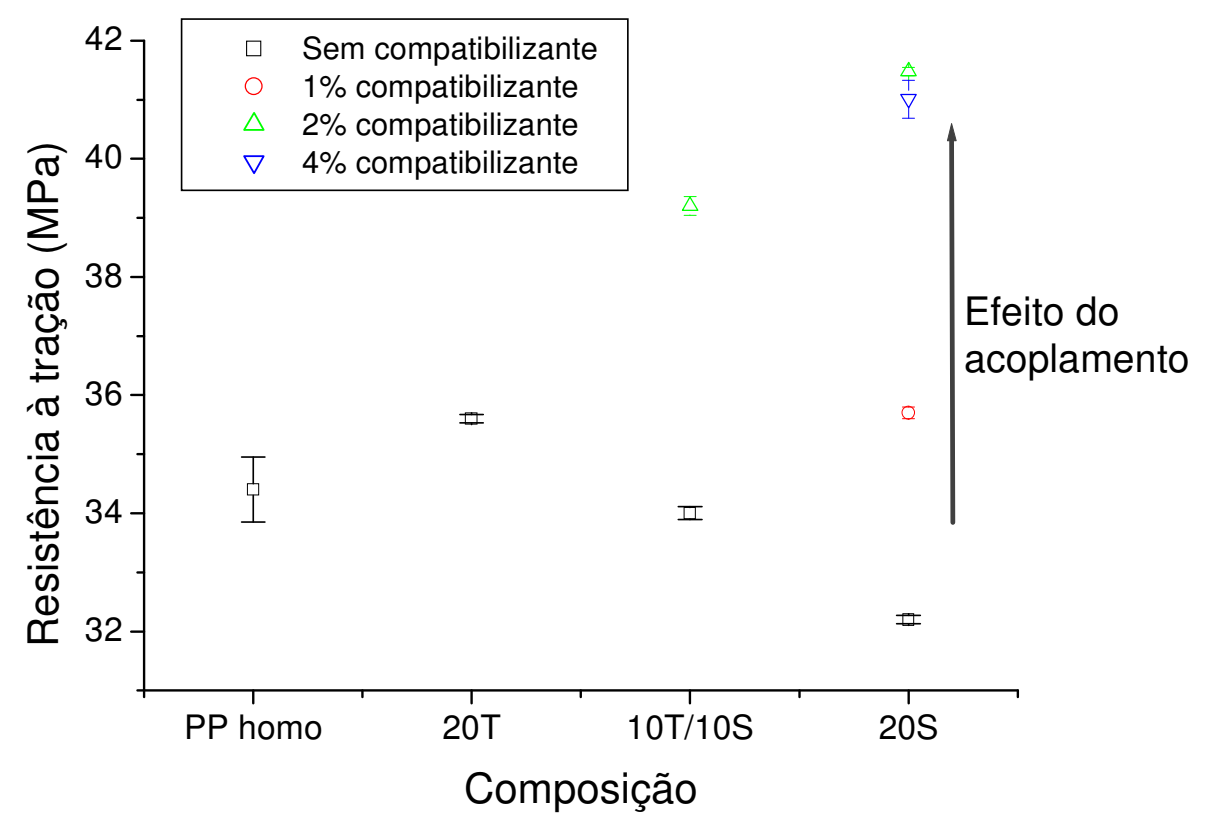

Figura 22 - Valores comparativos entre os diversos compósitos, obtidos para a propriedade de resistência à tração

O comportamento dos compósitos com $20 \%$ de sílica, com variação do teor de PP-g-MAH (0, 1\%, 2\% e 4\%, em peso) está representado isoladamente na Figura 23. O valor médio resistência à tração no escoamento obtido para o compósito 20S2, com $20 \%$ de fibras curtas de sílica e $2 \%$ de compatibilizante, é $28,5 \%$ maior que o valor médio obtido para o compósito $20 \mathrm{~S}$, também com $20 \%$ de fibras de sílica, porém sem a adição do anidrido maleico. Observa-se que há uma ligeira queda desta propriedade para o compósito $20 \mathrm{~S}-4$, com teor de $4 \%$. 


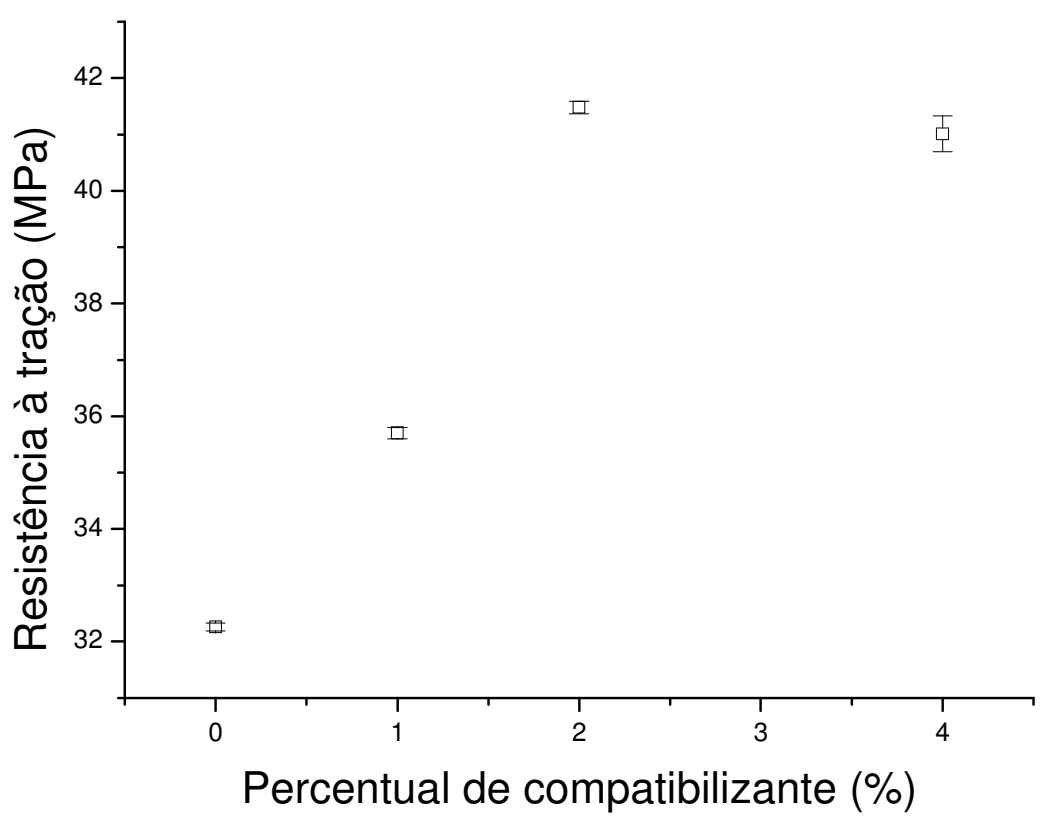

Figura 23 - Variação da resistência à tração em função do percentual de compatibilizante

O alongamento na ruptura é drasticamente menor para os compósitos com fibras de sílica quando comparados ao polímero puro, conforme mostrado na Figura 24. A amostra PP homo apresentou um valor médio de 339\%, o qual diminui para $7 \%$ para o compósito $20 \mathrm{~S}-2$, de melhor adesão interfacial. Por outro lado, não existem diferenças significativas entre os compósitos com variações do teor do agente compatibilizante e o compósito $20 \mathrm{~T}$, com $20 \%$ de talco. Este comportamento é esperado para compósitos poliméricos reforçados com fibras ou partículas rígidas, as quais restringem a mobilidade da cadeia molecular do polímero., ${ }^{4,68} \mathrm{O}$ efeito proporcionado pela variação da concentração do agente compatibilizante é mostrado na Figura 25 para a propriedade de alongamento na ruptura dos compósitos 20S, 20S-1, 20S-2 e 20S-4. Há uma redução brusca dos valores obtidos até a concentração de $2 \%$ de PP-g-MAH, acima da qual se observa um ligeiro aumento do alongamento, o qual pode ser atribuído à presença em excesso deste aditivo. 


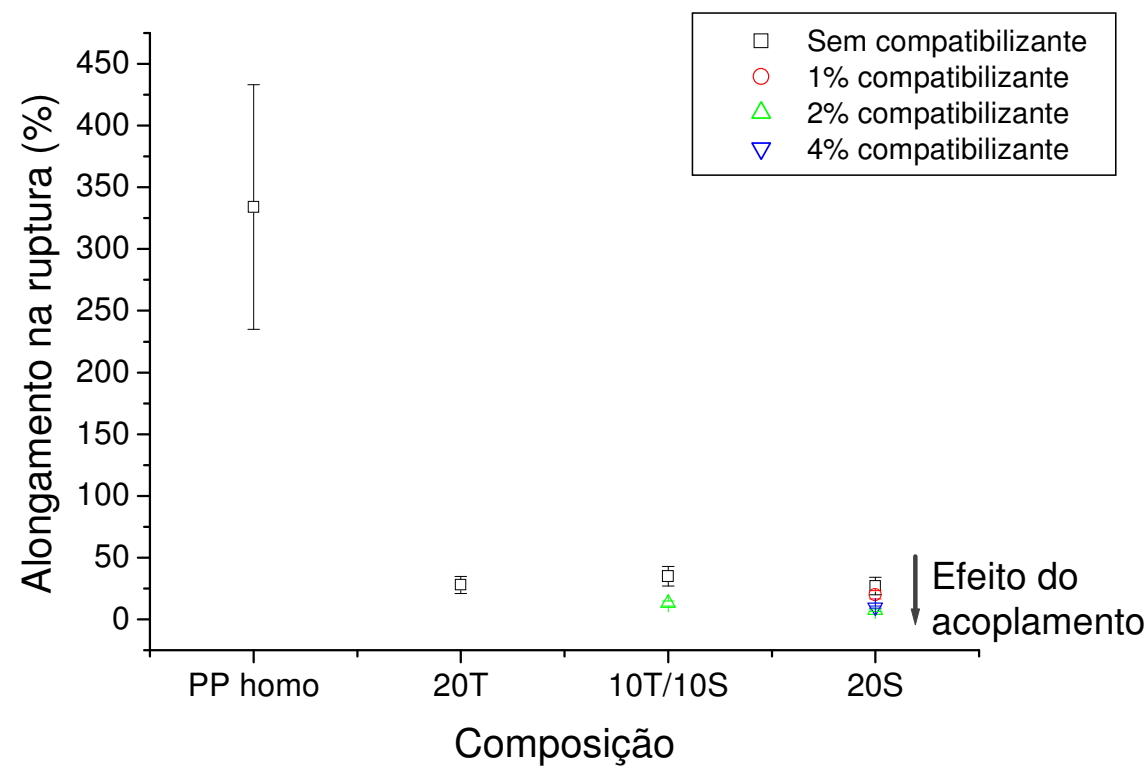

Figura 24 - Valores comparativos entre os diversos compósitos, obtidos para a propriedade de alongamento na ruptura

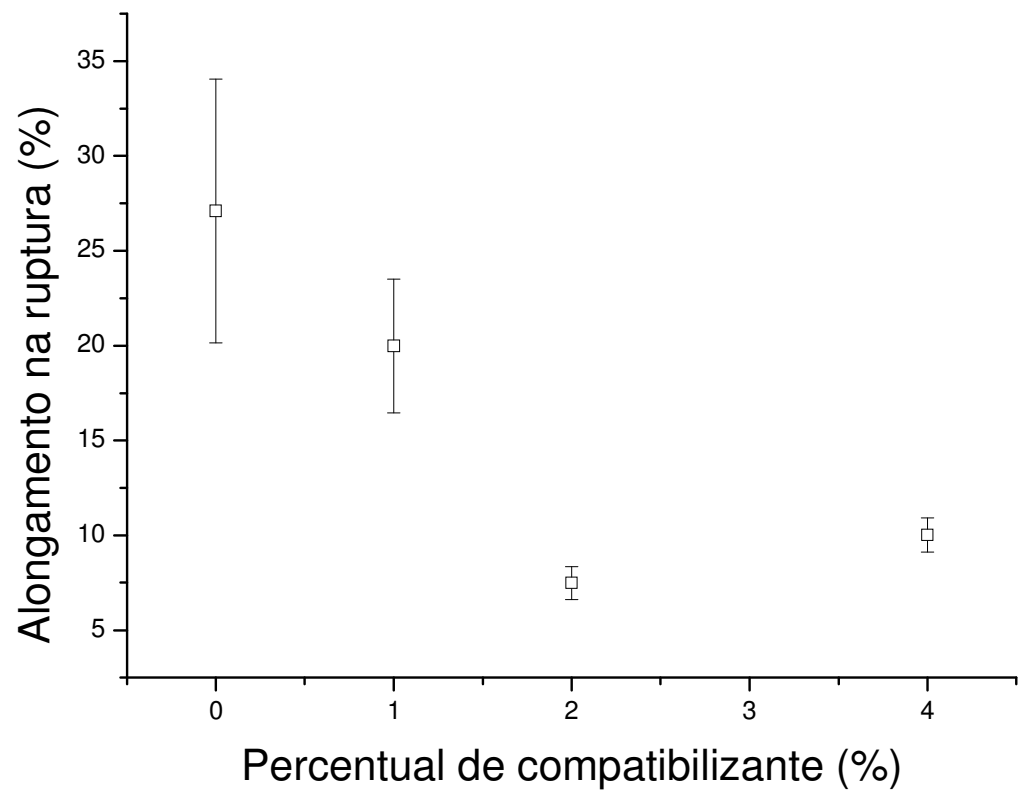

Figura 25 - Variação do alongamento na ruptura em função do percentual de compatibilizante

Há um número significativo de trabalhos publicados que tratam a compatibilização interfacial e a sua influência nas propriedades de compósitos de polipropileno reforçados com diversos tipos de cargas e fibras (de vidro e naturais). Algumas destas publicações estão comentadas na seção 2.4.1 deste trabalho. A 
sílica é classificada como uma fibra polar, altamente reativa, de caráter hidrofílico e que contém uma grande quantidade de grupos silanóis $(\mathrm{Si}-\mathrm{OH})$ em sua superfície. A presença destes grupos induz a uma interação fibra-fibra, que aumenta a tendência das fibras a se aglomerarem na matriz polimérica e, consequentemente, dificulta o processo de dispersão e processamento. ${ }^{43-46,69}$ As fibras de sílica Silexil ${ }^{\circledR}$, foram tratadas com o agente 3-aminopropil-trietoxissilano, $\mathrm{H}_{2} \mathrm{~N}-\left(\mathrm{CH}_{2}\right)_{3}-\mathrm{Si}\left(\mathrm{OC}_{2} \mathrm{H}_{5}\right)_{3}$, código comercial, Dynasylan ${ }^{\circledR}$ AMEO, fonte Evonik, o qual proporcionou um maior grau de molhabilidade. Na Figura 26 é mostrado o mecanismo desta reação. A adesão interfacial proporcionada por esse tratamento foi otimizada pelo uso de polipropileno funcionalizado com anidrido maleico (PP-g-MAH), cujos grupos reativos de ácidos carboxílicos reagem com os grupos básicos amina do silano, formando um copolímero grafitizado de PP-co-siloxano. Este último atuou como um compatibilizante interfacial, melhorando as propriedades do material por meio de uma melhor transferência de tensões entre fibra e matriz ${ }^{31,41}$, como observado para as amostras 10T/10S-2, 20S-1, 20S-2 e 20S-4.<smiles>CCO[Si](CN)(OCC)OCC</smiles>
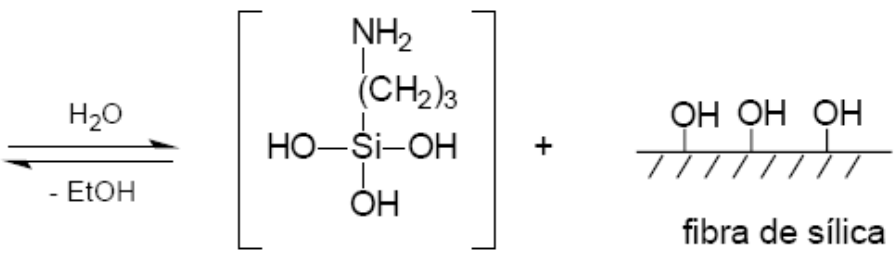

aminopropiltrietoxissilano

silanol
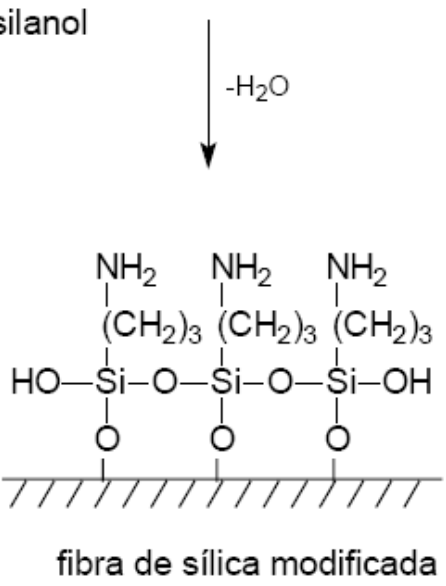

Figura 26 - Mecanismo de reação entre a superfície da fibra de sílica e o agente de acoplamento aminossilano ${ }^{12}$ 
Nas Figuras 27 e 28 são mostrados os valores obtidos referentes às propriedades de resistência e módulo à flexão, respectivamente, para os diversos compósitos, os quais confirmam a melhoria da resistência mecânica proporcionada pela adição de fibras de sílica, aliada à melhoria da adesão interfacial por meio da utilização do agente compatibilizante.

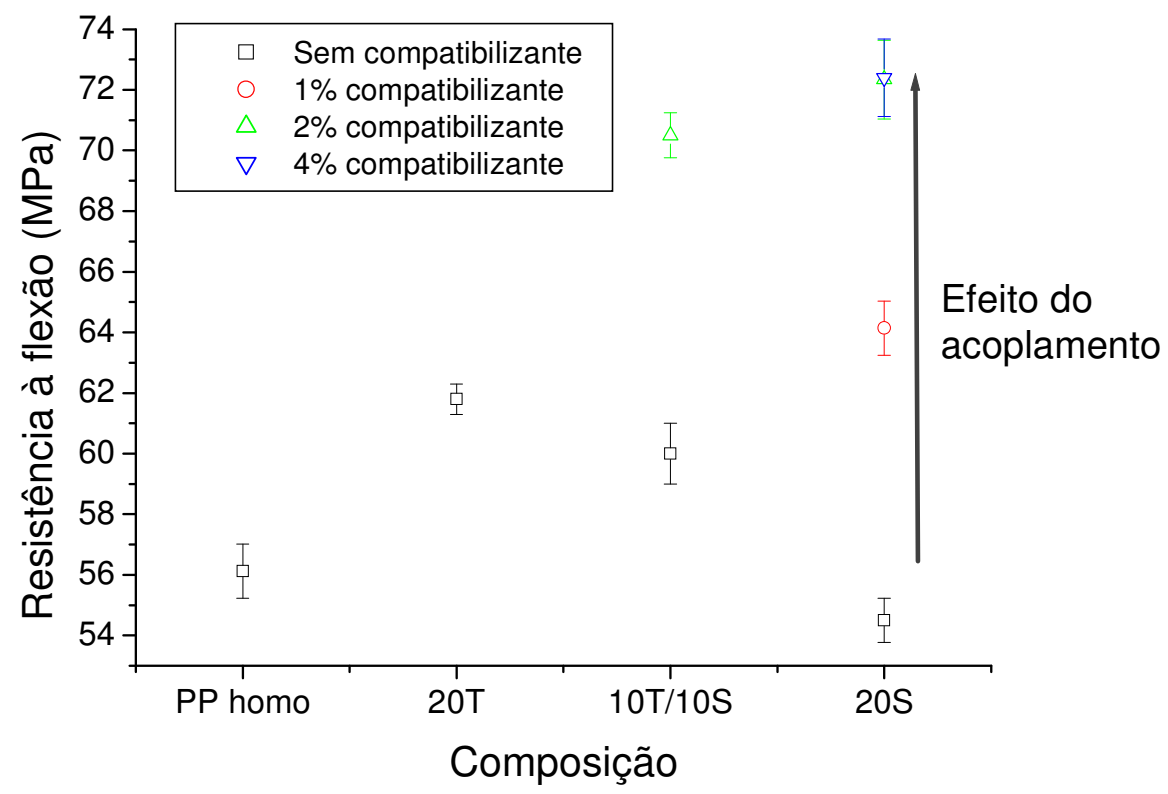

Figura 27 - Valores comparativos entre os diversos compósitos, obtidos para a propriedade de resistência à flexão

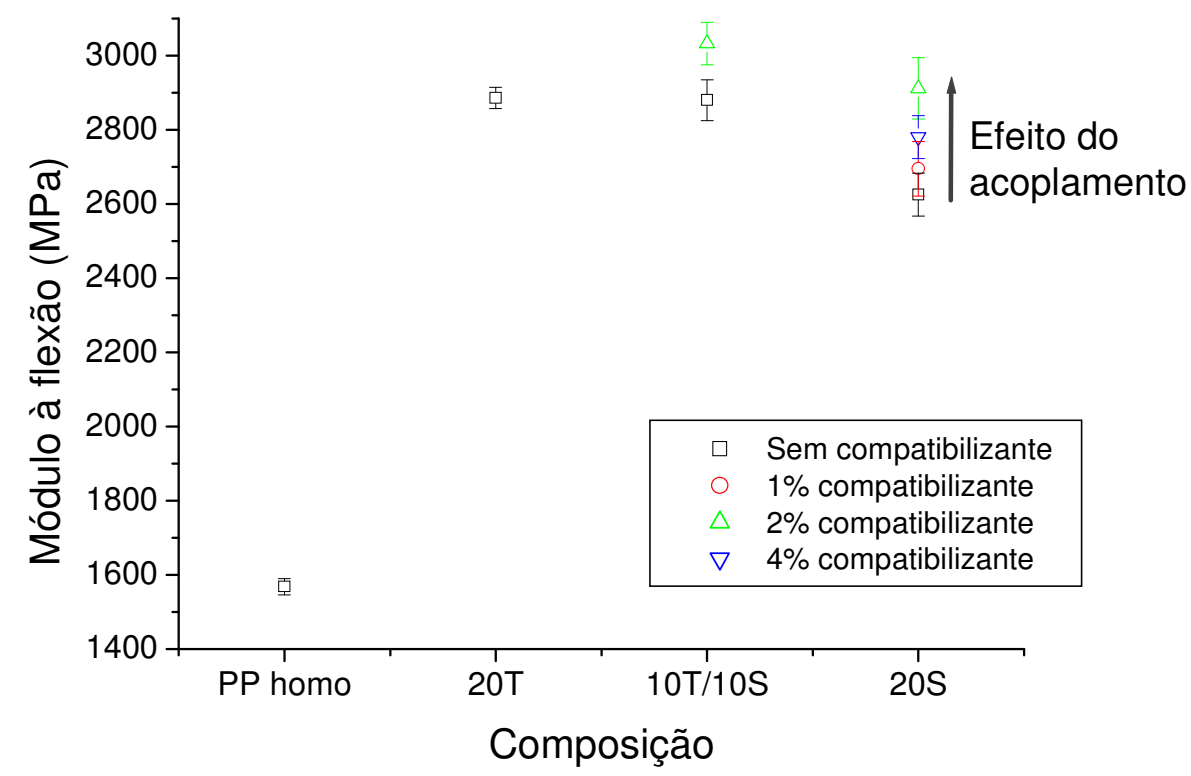

Figura 28 - Valores comparativos entre os diversos compósitos, obtidos para a propriedade de módulo à flexão 
A mesma tendência de comportamento obtida para a tensão de alongamento, com relação à variação do teor do compatibilizante, foi observada para a resistência e para o módulo de flexão, conforme é mostrada nas Figuras 29 e 30, sendo também constado um aumento gradual destas propriedades até a concentração de $2 \%$.

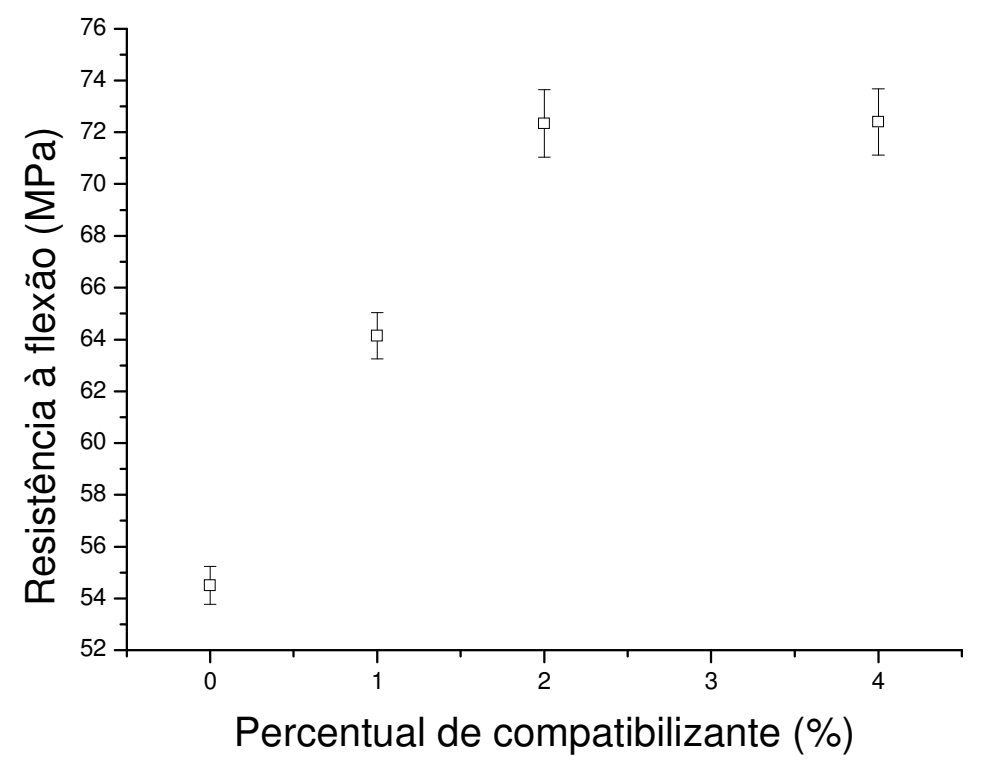

Figura 29 - Variação a resistência à flexão em função do percentual de compatibilizante

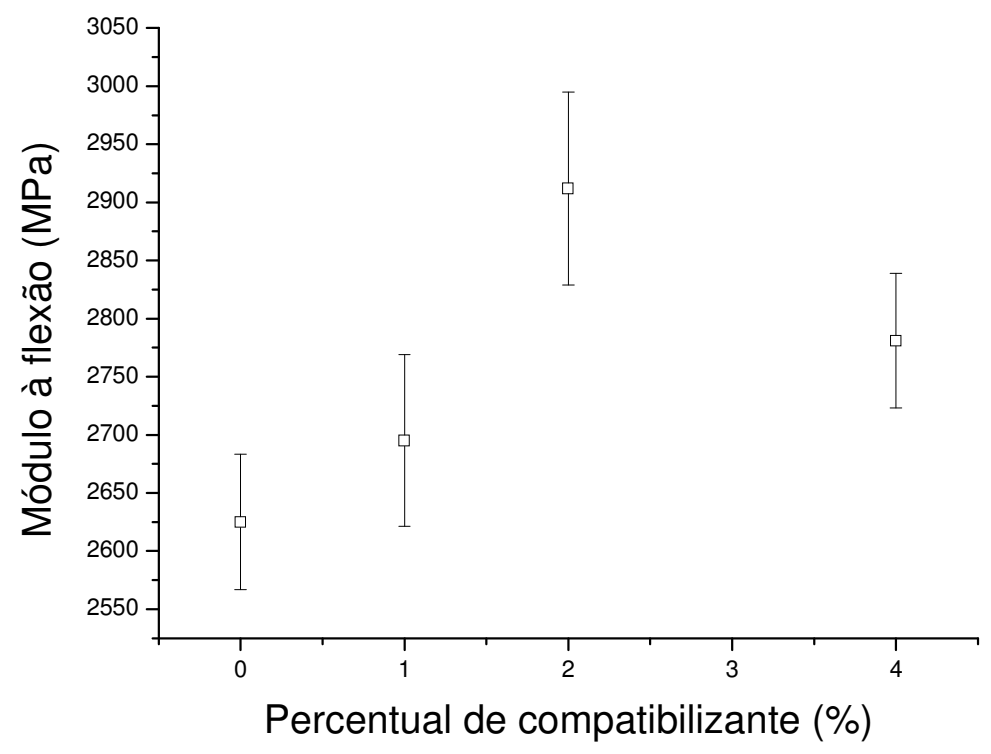

Figura 30 - Variação do módulo à flexão em função do percentual de compatibilizante 
O reforço nas propriedades mecânicas depende também do efeito combinado do comprimento e da razão de aspecto das fibras, bem como do arranjo (distribuição e orientação) das mesmas na matriz polimérica. ${ }^{28}$ Por meio da avaliação do comprimento das fibras antes e após o processamento para os compósitos 10T/10S-2 e 20S-2, mencionada na seção 4.1.1 deste trabalho, verificou-se que houve uma redução no tamanho médio das fibras. Após injeção, os compósitos apresentaram um comprimento médio de $100 \mu \mathrm{m}$ para as fibras de sílica. Face aos resultados de rigidez obtidos, este comprimento é provavelmente maior que o comprimento crítico necessário ao não comprometimento da eficiência de transferência de tensões de cisalhamento, as quais são geradas durante a solicitação mecânica do compósito.

Por outro lado, os resultados da análise morfológica das fibras dos compósitos 10T/10S-2 e 20S-2, por MEV, mostrados a seguir na seção 4.1.7, indicam ainda a presença de algumas fibras desacopladas pela falta de molhamento e de adesão da matriz de polipropileno sobre a fibra de sílica. Apesar da incidência baixa de desacoplamento e da satisfatória deformação plástica ocorrida para a matriz de polipropileno, há um comprometimento da eficiência da resistência mecânica e da rigidez que poderia ser proporcionada pelas fibras em uma condição ideal de interação entre as fases. Os menores valores do módulo à flexão obtidos para o compósito 20S-2 em relação aos compósitos 20T e 10T/10S-2, comprovam as observações morfológicas. Os possíveis fatores relacionados a este comportamento serão discutidos na seção 4.1.7.

Na Figura 31 são mostrados os valores obtidos para a resistência ao impacto Charpy sem entalhe e em temperatura ambiente. 


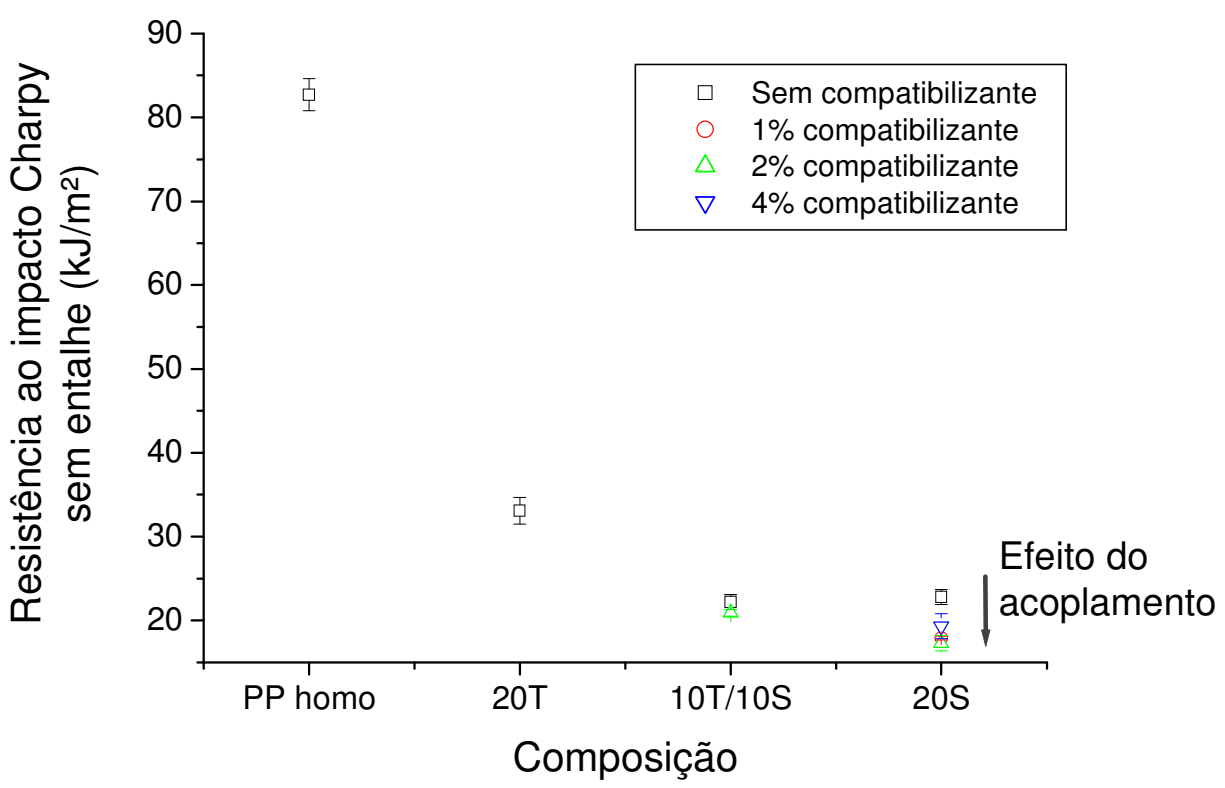

Figura 31 - Valores comparativos entre os diversos compósitos, obtidos para a propriedade de resistência ao impacto Charpy sem entalhe

Promover a rigidez sem detrimento à tenacidade é um dos principais desafios durante o desenvolvimento de compósitos reforçados. A resistência ao impacto de compósitos reforçados por fibras curtas é função da energia absorvida ou dissipada durante a propagação de uma fratura. ${ }^{4}$ As características da interface são determinantes neste processo, ou seja, uma trinca pode ser propagada por impacto frente à baixa interação interfacial. Por outro lado, caso a interação interfacial for muito alta, as fibras irão restringir a mobilidade molecular do polímero. Nos dois casos pode haver uma redução da resistência ao impacto. ${ }^{4,28}$ É conhecido que compósitos mais rígidos apresentam baixa resistência ao impacto devido à melhor transferência de tensões da matriz para a fibra. Considerando-se este último aspecto, seria esperada a diminuição gradual da resistência ao impacto com a adição do agente compatibilizante, principalmente para o compósito 20S-2, o qual mostrou os melhores valores de rigidez. Por outro lado, os compósitos 20S e 20S-1, os quais apresentam interação interfacial baixa e ineficiente transferência de esforços da matriz para as fibras, mostraram valores de resistência ao impacto mais altos, como mostrado na Figura 32. Este comportamento pode ser atribuído à energia gasta no descolamento da fraca interface e na ramificação da trinca, bem 
como no atrito promovido pelo arrancamento da fibra por meio do mecanismo conhecido como pull out.

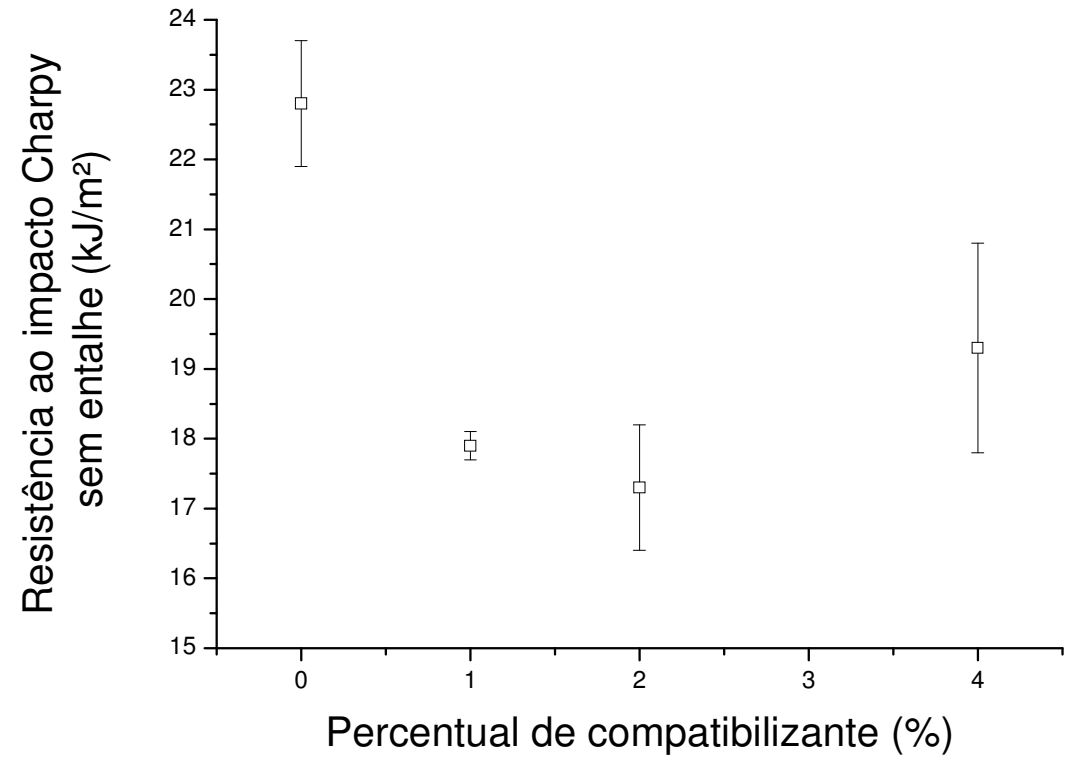

Figura 32 - Variação da resistência ao impacto Charpy, sem entalhe, em função do percentual de compatibilizante

A quantidade de energia necessária para iniciar uma fratura em corpos de prova com entalhe é menor do que a requerida para amostras sem entalhe. Os valores de resistência ao impacto com entalhe geralmente refletem a energia requerida para propagar uma trinca já existente através da amostra, bem como é controlada por sítios de concentração de tensões na região do entalhe. Já os valores referentes ao impacto sem entalhe são dependentes tanto da energia de propagação, quanto da energia de iniciação da trinca. Desta forma, vários mecanismos de dissipação de energia podem estar envolvidos em uma ruptura por impacto de corpos de prova com entalhe. ${ }^{70} \mathrm{~A}$ carga aplicada pode exceder a resistência da interface fibra-matriz. As fibras podem fraturar se o nível de tensões na região do entalhe for maior que a resistência das mesmas. Na Figura 33 são mostrados os valores obtidos para a resistência ao impacto Charpy, com entalhe e em temperatura ambiente. Para todas as formulações estudadas, independente do tipo de reforço utilizado, não houve um comprometimento significativo à resistência ao impacto com entalhe frente à obtida para o polímero puro. A energia absorvida para a propagação das trincas em todos os compósitos foi baixa em função da característica frágil do polipropileno homopolímero, não havendo diferenças 
significativas de valores mesmo com a melhor interação fibra-matriz e independentemente do mecanismo envolvido no processo.

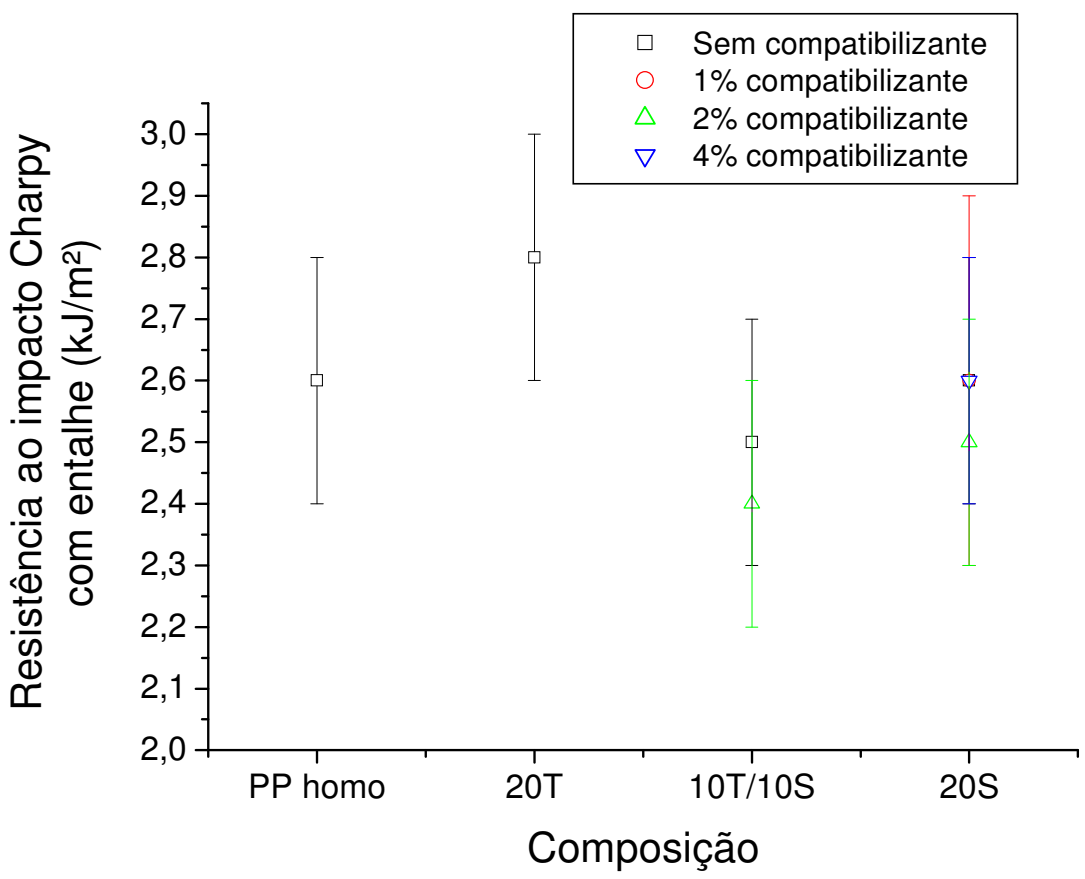

Figura 33 - Valores comparativos entre os diversos compósitos, obtidos para a propriedade de resistência ao impacto Charpy com entalhe

Pelas propriedades investigadas neste trabalho sugere-se que a concentração ótima de PP-g-MAH, a qual corresponde ao ponto de melhor equilíbrio das propriedades de rigidez e tenacidade, é de $2 \%$ em peso. Esta concentração pode corresponder ao ponto de saturação da interface fibra-polímero, conforme observado por Lopes e Sousa. ${ }^{28,41}$ Eles citam a hipótese de formação de uma camada interfacial com alta resistência ao cisalhamento, porém mais deformável, sendo constituída de PP-co-siloxano. Esta permite uma melhor transferência de tensões entre fibra e matriz e maximiza a relação "resistência - rigidez- tenacidade". Acredita-se que acima da concentração ótima há a formação da camada de interface com uma espessura contendo essencialmente o copolímero polar PP-cosiloxano. Esta contribui para uma redução gradual para as propriedades relacionadas à rigidez dos compósitos, sendo também suscetível a degradações. ${ }^{42}$ 


\subsubsection{Propriedades térmicas}

A temperatura de amolecimento, segundo Vicat, é um dos indicativos qualitativos do desempenho termo-mecânico de um material, ou seja, da capacidade de resistir a temperaturas altas sem sofrer deformações. Na Figura 34 é mostrado que a fibra de sílica aumentou a resistência térmica dos compósitos, e que a adição do compatibilizante interfacial contribuiu ainda mais para a elevação da temperatura Vicat. Em termos comparativos, a temperatura Vicat para o compósito 20 S-2 com $2 \%$ foi de, aproximadamente, $20 \%$, superior à do compósito puro devido à melhoria da rigidez mecânica proporcionada pela melhor interação fibra-polímero. Resultado divergente foi observado por Sato ${ }^{11}$, o qual verificou que os compósitos híbridos de polipropileno com fibras curtas de sílica e fibras de madeira mostraram valores superiores a compósitos somente com a incorporação de fibras de sílica, entretanto, sem diferenças significativas entre os compósitos com e sem compatibilizante interfacial.

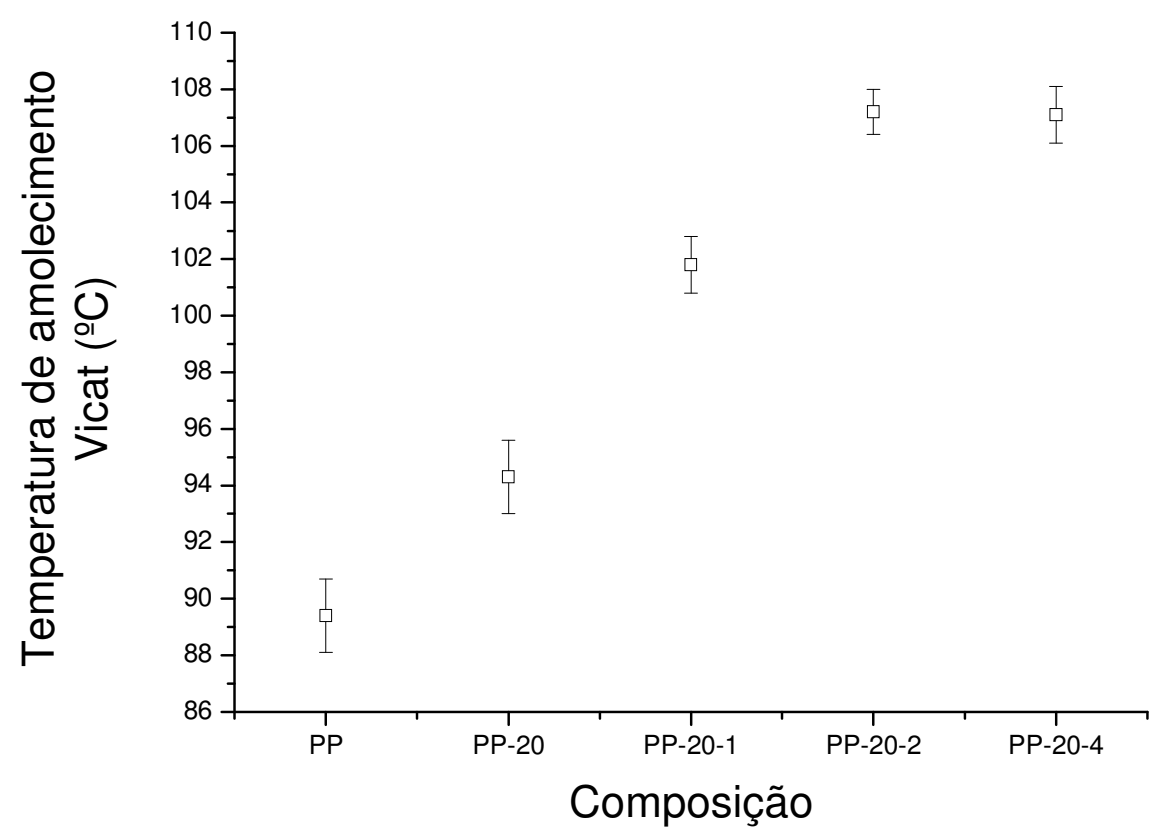

Figura 34 - Variação da temperatura de amolecimento Vicat, em função do percentual de compatibilizante, para os diversos compósitos 
Na Tabela 4 são apresentados os valores de temperatura de cristalização $\left(T_{c}\right)$, temperatura de fusão $\left(T_{m}\right)$, entalpia de fusão $\left(\Delta H_{m}\right)$ e grau de cristalinidade $\left(X_{c}\right)$ para os diversos compósitos estudados.

Tabela 4 - Temperatura de cristalização $\left(T_{c}\right)$, temperatura de fusão $\left(T_{m}\right)$, entalpia de fusão $\left(\Delta \mathrm{H}_{\mathrm{m}}\right)$ e grau de cristalinidade $\left(\mathrm{X}_{\mathrm{c}}\right)$ para os diversos compósitos estudados

\begin{tabular}{ccccc}
\hline Amostra & $\mathrm{T}_{\mathrm{c}}\left({ }^{\circ} \mathrm{C}\right)$ & $\mathrm{T}_{\mathrm{m}}\left({ }^{\circ} \mathrm{C}\right)$ & $\Delta \mathrm{H}_{\mathrm{m}}(\mathrm{J} / \mathrm{g})$ & $\mathrm{X}_{\mathrm{c}}(\%)$ \\
\hline PP homo & 124 & 169 & 60 & 29 \\
$20 \mathrm{~T}$ & 130 & 168 & 42 & 20 \\
$10 \mathrm{~T} / 10 \mathrm{~S}$ & 128 & 169 & 44 & 21 \\
$10 \mathrm{~T} / 10 \mathrm{~S}-2$ & 133 & 168 & 50 & 24 \\
$20 \mathrm{~S}$ & 123 & 168 & 52 & 25 \\
$20 \mathrm{~S}-1$ & 125 & 169 & 48 & 23 \\
$20 \mathrm{~S}-2$ & 127 & 168 & 56 & 27 \\
$20 \mathrm{~S}-4$ & 127 & 169 & 45 & 21 \\
\hline
\end{tabular}

As análises, por intermédio da técnica DSC, indicaram que a presença do agente compatibilizante diminuiu a cristalinidade do polipropileno, que foi parcialmente recuperada com a adição das fibras de sílica e com a melhor interação fibra-polímero. Observa-se que, entre o compósito 20S-2 e o polímero puro, houve um ganho de $3^{\circ} \mathrm{C}$ para a temperatura de cristalização. Assim como o efeito nucleante do talco, o efeito nucleante da sílica para o polipropileno também foi observado em pesquisas ${ }^{7,13,44,45}$ mencionadas neste trabalho. $O$ aumento da $T_{c}$ pode ser atribuído à formação de núcleos em um estágio primário e em temperatura alta, durante o processo de resfriamento. ${ }^{7}$ Zoukrami et al. ${ }^{44}$ propõem que, quando as cadeias do polipropileno são adsorvidas na superfície da sílica, a entropia configuracional da cadeia completa diminui, ajudando a atingir um volume de núcleo crítico e que este efeito de nucleação não é prejudicado na presença do compatibilizante PP-g-MAH, a não ser que este esteja presente em excesso. Esta observação é comprovada apenas parcialmente neste trabalho. Os resultados obtidos para o compósito 20S-2 mostram que o PP-g-MAH favoreceu o efeito de nucleação da fibra de sílica. Todavia, o grau de cristalinidade do compósito 20S-4, com maior teor de compatibilizante, foi menor que o obtido para o compósito $20 \mathrm{~S}-2$. 


\subsubsection{Anisotropia}

A análise dos dados apresentados na Tabela 5, indica que, para o compósito 10T/10S-2, os efeitos da anisotropia são minimizados pela adição de talco.

Tabela 5 - Resultados obtidos para as propriedades de contração longitudinal, transversal e anisotropia para os compósitos 20T, 10T/10S-2, 20S-2 e 20S-4

\begin{tabular}{cccc}
\hline Amostra & $\begin{array}{c}\text { Contração } \\
\text { Longitudinal (\%) }\end{array}$ & $\begin{array}{c}\text { Contração } \\
\text { Transversal (\%) }\end{array}$ & Anisotropia \\
\hline 20T & $1,09 \pm 0,01$ & $1,31 \pm 0,01$ & $1,20 \pm 0,01$ \\
$10 T / 10 S-2$ & $1,34 \pm 0,01$ & $1,13 \pm 0,01$ & $1,19 \pm 0,01$ \\
$20 S-2$ & $1,40 \pm 0,02$ & $0,89 \pm 0,02$ & $1,57 \pm 0,02$ \\
$20 S-4$ & $1,70 \pm 0,08$ & $1,15 \pm 0,03$ & $1,48 \pm 0,06$ \\
\hline
\end{tabular}

A presença de fibras contribui para uma elevada anisotropia de propriedades físicas e mecânicas em razão do grau de orientação adquirido pelas mesmas na direção do fluxo de injeção. A combinação ou hibridização de cargas, com a adição de talco, permite a obtenção de compósitos com anisotropia baixa em virtude do formato lamelar e à razão de aspecto baixa das partículas deste mineral, os quais irão contribuir para uma redução no grau de orientação preferencial do reforço. A considerável redução de anisotropia é uma vantagem significativa para a prevenção de problemas relacionados ao processamento, como o encolhimento diferencial que gera o empenamento de peças. ${ }^{9}$

Os resultados obtidos para o compósito 10T/10S-2 confirmam a tendência de que a combinação de fibras curtas e partículas minerais, como reforço de compósitos termoplásticos, é também uma interessante proposta para se obter um adequado balanço de propriedades mecânicas. Este compósito demonstrou resultados intermediários com relação aos compósitos com talco (20T) e com fibra de sílica (20S-2) para as propriedades mecânicas avaliadas, como demonstrado no item 4.1.3 deste trabalho. O valor alto obtido para a temperatura de cristalização $\left(T_{c}\right)$ indica um possível efeito sinérgico proporcionado pela hibridização. Os valores obtidos para o comprimento médio das fibras de sílica (item 4.1.1) sugerem que o provável aumento da viscosidade pela presença do talco não causou a quebra ou a diminuição do comprimento das fibras de sílica. 


\subsubsection{Propriedades específicas - comportamento a emissões}

O efeito dos aditivos e substâncias presentes na formulação dos compósitos de melhor desempenho mecânico, 10T/10S-2 e 20S-2, foram investigados frente ao comportamento a emissões pelos métodos instrumental (cromatografia) e sensorial (odor). Os resultados obtidos estão apresentados na Tabela 6 e demonstram que ambas as formulações atendem aos valores especificados por uma indústria automobilística. Quanto ao odor, os mesmos foram percebidos como "olefínicos", ou seja, característicos do tipo de polímero avaliado. Não houve percepção de quaisquer substâncias incômodas ou prejudiciais à saúde.

Tabela 6 - Resultados obtidos para as propriedades de emissão de carbono e de odor dos compósitos 10T/10S-2 e 20S-2

\begin{tabular}{llcc}
\hline \multicolumn{1}{c}{ Propriedade } & Requisito & $\mathbf{1 0 T} / \mathbf{1 0 S - 2}$ & 20S-2 \\
\hline 1. Emissão total de carbono $\left(\mathrm{E}_{\mathrm{T}}\right), \mu \mathrm{gC} / \mathrm{g}$. & $\leq 50$ & $1,02 \pm 0,07$ & $1,04 \pm 0,08$ \\
2. Odor - variante $\mathrm{C}\left(80^{\circ} \mathrm{C}\right)$ & $\leq$ nota 3,5 & 3,5 & 3,5 \\
\hline
\end{tabular}

A emissão total de compósitos orgânicos $\left(E_{T}\right)$ corresponde à soma de todos os valores resultantes das substâncias, emitidas após uma desagregação cromatográfica em fase gasosa. $O$ valor da $E_{T}$ não deve exceder $50 \mu \mathrm{gC} / \mathrm{g}$. A definição deste limite considerou aspectos como volume, características e tipos de materiais (polímeros, tecidos, couros, dentre outros) presentes no interior do veículo.

$O$ teste de odor estabelece uma maneira de se determinar a impressão sensorial proporcionada por materiais utilizados no compartimento de passageiros. Os resultados obtidos não são base para determinação quantitativa de substâncias orgânicas por eles emitidas, mas representam uma identificação inicial da presença das mesmas. O odor é avaliado por cinco analistas, os quais atribuem notas em escala de 1 a 6 , sendo nota 1 quanto o odor é imperceptível, e nota 6 quando é insuportável. $O$ analista também identifica o odor relacionando-o com as substâncias conhecidas e presentes em sua "memória olfativa". Se a nota entre os analistas diferir mais que dois pontos, as avaliações deverão ser repetidas. A nota final será a 
média aritmética das cinco determinações. A condição de ensaio avaliada neste trabalho é classificada como Variante $\mathrm{C}$, e é correlacionada com as condições de aplicação prováveis para os compósitos em estudo. A nota especificada deve ser menor ou igual a 3,5. O valor corresponde a um odor perceptível, porém, não ofensivo ou irritante.

A escolha dos tipos e teores de resinas e dos aditivos (antioxidantes primários e secundários, compatibilizantes, agentes dispersantes e facilitadores de fluxo) para as formulações desenvolvidas neste trabalho teve como objetivo inicial a obtenção de compósitos com um bom balanço de propriedades. Por outro lado, os resultados satisfatórios de emissões e de odor permitem verificar que o sistema de estabilização escolhido mostrou-se eficiente quanto à inibição dos mecanismos de degradação termo-oxidativa. Além disso, as substâncias utilizadas não contribuíram para a percepção de odores fortes e desagradáveis. Os níveis baixos de emissões de carbono também são valores indicativos de condições adequadas de processamento, apesar das condições adversas proporcionada pela rigidez e pela abrasividade das fibras de sílica.

\subsubsection{Caracterização morfológica (MEV)}

As micrografias eletrônicas de varredura das superfícies de fratura à temperatura baixa evidenciaram que a adição do compatibilizante interfacial, melhora a interface entre a fibra e a matriz para os compósitos 10S/10T-2, 20S-2 e 20S-4, confirmando os resultados bons obtidos para a rigidez destes compósitos.

$\mathrm{Na}$ Figura 35 são monstradas as micrografias obtidas para os compósitos híbridos 10T/10S, sem (a) e com (b) a presença do agente compatibilizante anidrido maleico. 


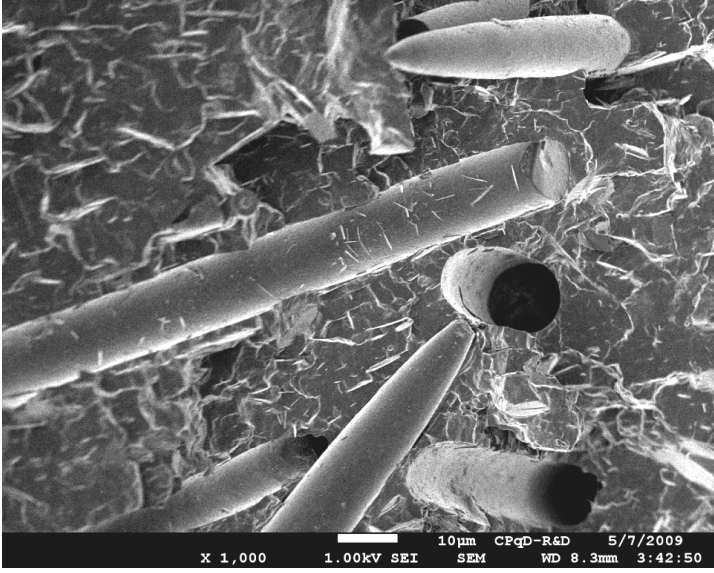

(a)

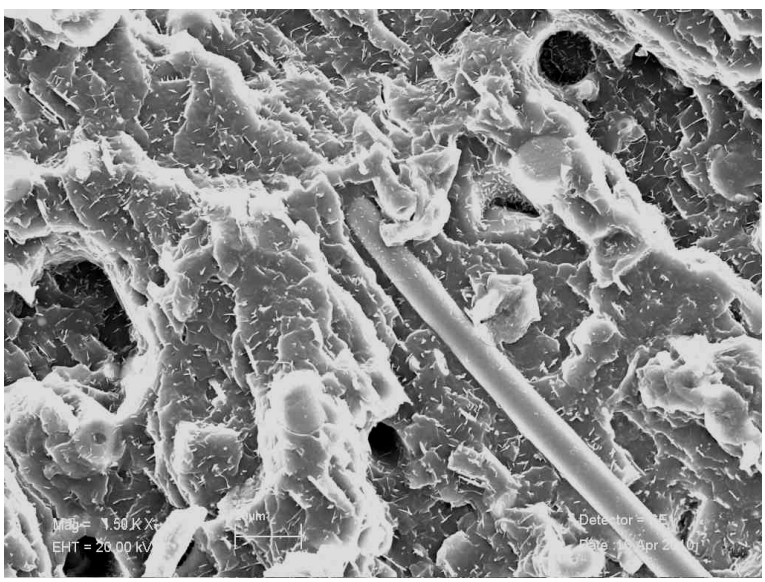

(b)

Figura 35 - Micrografias obtidas por microscópio eletrônico de varredura de superfície de fratura de amostras: 10T/10S (a), 10T/10S-2 (b)

Para o compósito 10T/10S-2 (Figura 34(b)), apesar da boa interface e da molhabilidade das fibras pelo polímero com a adição do PP-g-MAH, verifica-se que, após fratura, algumas fibras foram arrancadas da matriz, cujo efeito é chamado de pull out. Também foi notada a presença de uma ou outra fibra não aderida à matriz, para as quais a modificação da superfície da fibra empregando 3aminopropil-trietoxissilano não foi efetiva. Neste compósito as fibras não estão orientadas em uma direção preferencial. As partículas lamelares do talco estão bem incorporadas ao polímero. Este mineral, sendo hidrofóbico e inerte, apresenta uma excelente interface com a matriz, e a interação da superfície desta partícula com o grupo metil do polipropileno ocorre através de ligações de hidrogênio.

Na Figura 36 são apresentadas as micrografias (a e b) do compósito 20S-1, para o qual a concentração do agente compatibilizante não foi suficiente para permitir uma eficiente transferência de tensões fibra-matriz. Além disso, verificam-se pontos de aglomeração de partículas e má homogeneização. 


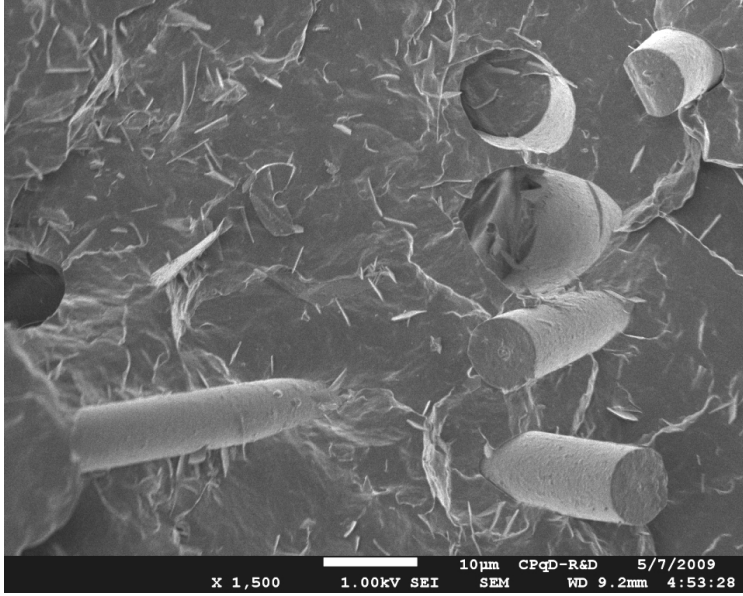

(a)

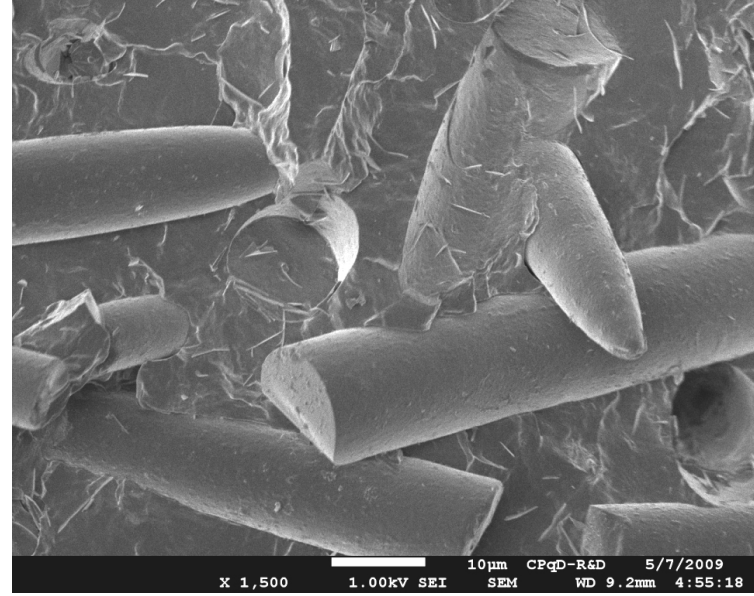

(b)

Figura 36 - Micrografias obtidas por microscópio eletrônico de varredura de superfície de fratura de amostras (a e b) obtidas para o compósito 20S-1

As micrografias mostradas na Figura 37 dos compósitos com 20\% de fibra de sílica, 20S-2 (c) e 20S-4 (d), contendo $2 \%$ e $4 \%$ de teor de compatibilizante em peso, respectivamente, demonstraram a melhoria da adesão interfacial em comparação ao compósito 20 S (Figuras 37 (a) e (b)), o qual não contém anidrido maleico. Para os compósitos 20S-2 e 20S-4, observa-se uma aleatoriedade parcial na orientação das fibras de sílica, ao menos na superfície. Observa-se claramente o efeito de uma molhabilidade satisfatória das fibras pela adição do PP-g-MAH. Acredita-se que a adesão interfacial é promovida pela presença de uma camada espessa da interfase de PP-co-siloxano, a qual é obtida pela interação química e física com os grupos amina presentes na superfície das fibras. ${ }^{28,41}$

Por outro lado, para os dois compósitos existem algumas fibras desacopladas, com pouca molhabilidade e adesão à matriz. A exemplo do compósito 10T/10S-2, sugere-se que o tratamento das fibras com o agente aminossilano não foi eficiente, provavelmente em razão do rendimento baixo da reação para a hidrofobização da superfície da fibra de sílica. Em seu estudo quanto à incorporação de Silexil ${ }^{\circledR}$ em compósitos de poliamida, Segatelli ${ }^{12}$ observou que a modificação desta fibra com o agente aminopropiltrietoxissilano (ATPS) não se mostrou efetiva, apesar das análises morfológicas demonstrarem a adesão das fibras à matriz. A autora atribuiu este aspecto à área superficial baixa obtida para as fibras, a qual indica que estas possuem poucos pontos de ancoragem do silano, em grupos silanóis presentes em sua superfície. 


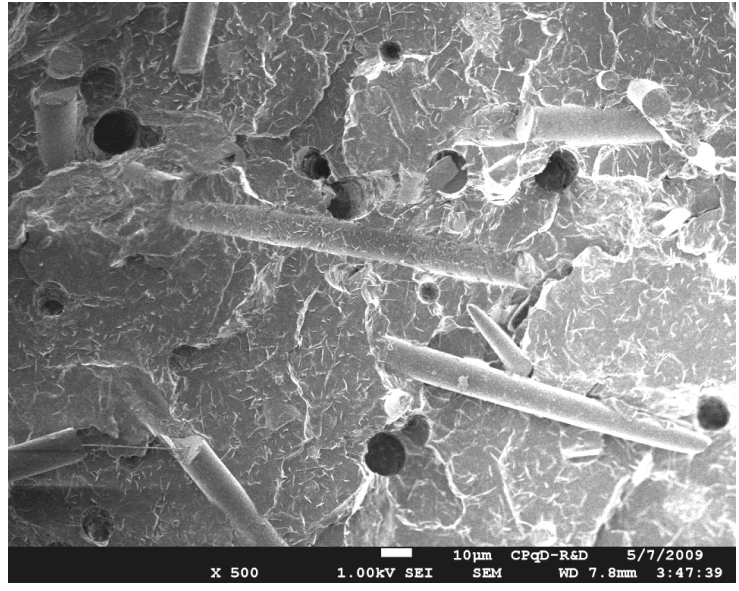

(a)

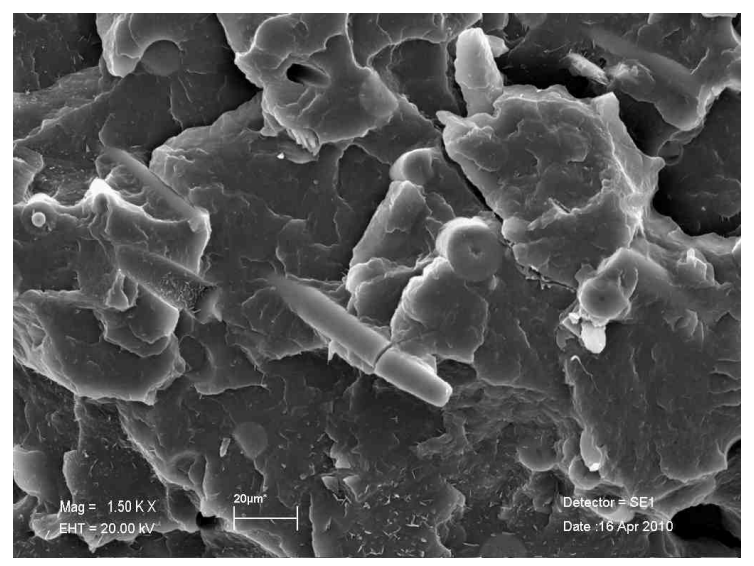

(c)

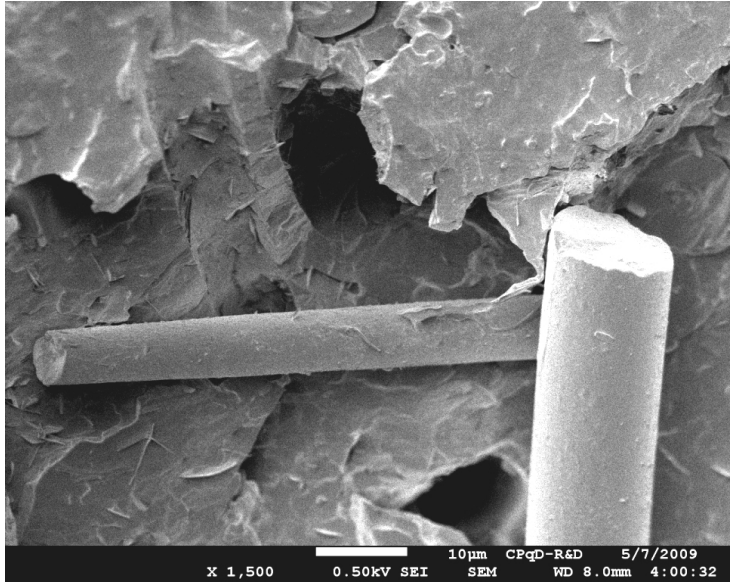

(b)

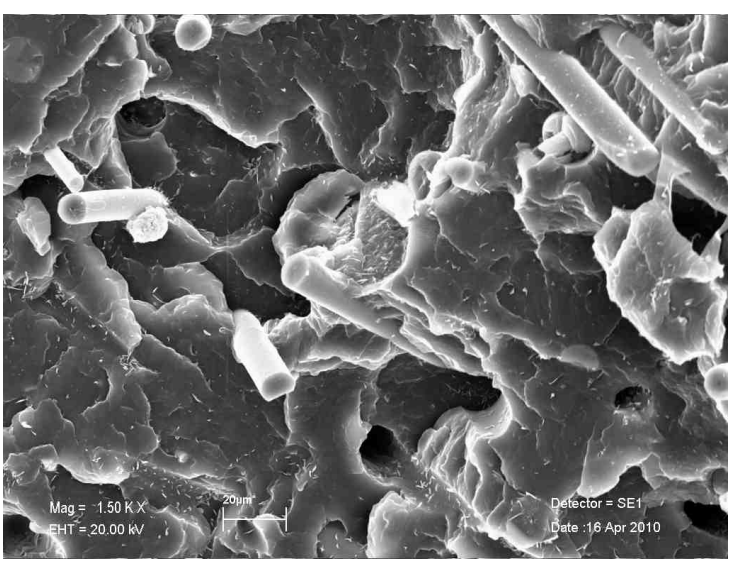

(d)

Figura 37 - Micrografias obtidas por microscópio eletrônico de varredura de superfície de fratura das amostras: 20S (a), 20S (b), 20S-2 (c) e 20S-4 (d)

Nas seções 2.4.1 e 2.4.3 deste trabalho, foram relacionadas pesquisas ${ }^{44,46,52}$ sobre o efeito do tratamento químico de fibras e partículas com diferentes silanos de diferentes grupos funcionais, bem como agentes compatibilizantes distintos, com 0 objetivo de melhoria da interação interfacial. A análise destes diferentes tratamentos seria uma sugestão para trabalhos futuros de otimização das formulações e melhoria das propriedades de compósitos de polipropileno homopolímero reforçados com fibras curtas amorfas de sílica. 


\subsection{COMPÓSITOS DE POLIPROPILENO MODIFICADOS COM POE}

A partir dos resultados experimentais obtidos para os compósitos de polipropileno homopolímero, foi possível verificar que as fibras de sílica mostram-se eficazes para atuar como reforço, considerando-se que os valores das propriedades relacionadas à resistência mecânica e à rigidez foram sempre superiores ao do polímero puro e a de compósitos reforçados com talco. Entretanto, visando o uso da fibra de sílica para aplicações automotivas que requerem maior tenacidade e melhor resistência ao impacto em temperaturas baixas, formulações novas foram preparadas alterando-se a matriz polimérica para um polipropileno copolímero heterofásico e adicionando-se $5 \%$ do copolímero etileno e 1-octeno (POE), em peso. Esta concentração foi escolhida com base em pesquisas presentes na literatura $^{40,71}$, procurando-se utilizar a quantidade mínima necessária para se obter o melhor balanço possível entre rigidez e impacto do sistema.

Os compósitos foram avaliados quanto à morfologia, às propriedades mecânicas, às térmicas, à anisotropia e à resistência a riscos. Sendo o comportamento nesta última propriedade um dos requisitos determinantes para a aplicação do compósito em revestimentos do interior de automóveis, onde a qualidade do acabamento superficial é primordial.

Procurando-se promover a interação interfacial entre fibras e as fases do compósito, adicionou-se aos compósitos o teor de $2 \%$ em peso do agente compatibilizante anidrido maleico. A determinação desta porcentagem também foi estabelecida pela análise dos resultados anteriores, os quais a apontaram como concentração ótima.

\subsubsection{Densidade dos compósitos}

Os valores de densidade obtidos para os compósitos tenacificados estão apresentados na Tabela 7. 
Tabela 7 - Densidade dos compósitos tenacificados, em g/ $\mathrm{cm}^{3}, \mathrm{a}(23 \pm 1)^{\circ} \mathrm{C}$

\begin{tabular}{ccc}
\hline E/P-20T & E/P-10T/10S & E/P-20S \\
\hline 1,023 & 1,004 & 0,969 \\
\hline
\end{tabular}

\subsubsection{Propriedades mecânicas}

Os resultados de resistência à tração no escoamento e na ruptura dos compósitos de polipropileno modificados com POE com fibras de sílica (E/P-20S) e com reforço híbrido (E/P-10T/10S), comparativamente a com talco (E/P- 20T), bem como, dos compósitos de polipropileno homopolímero não tenacificados 20T, 10T/10S-2 e S20-2, são mostrados nas Figuras 38 e 39, respectivamente.

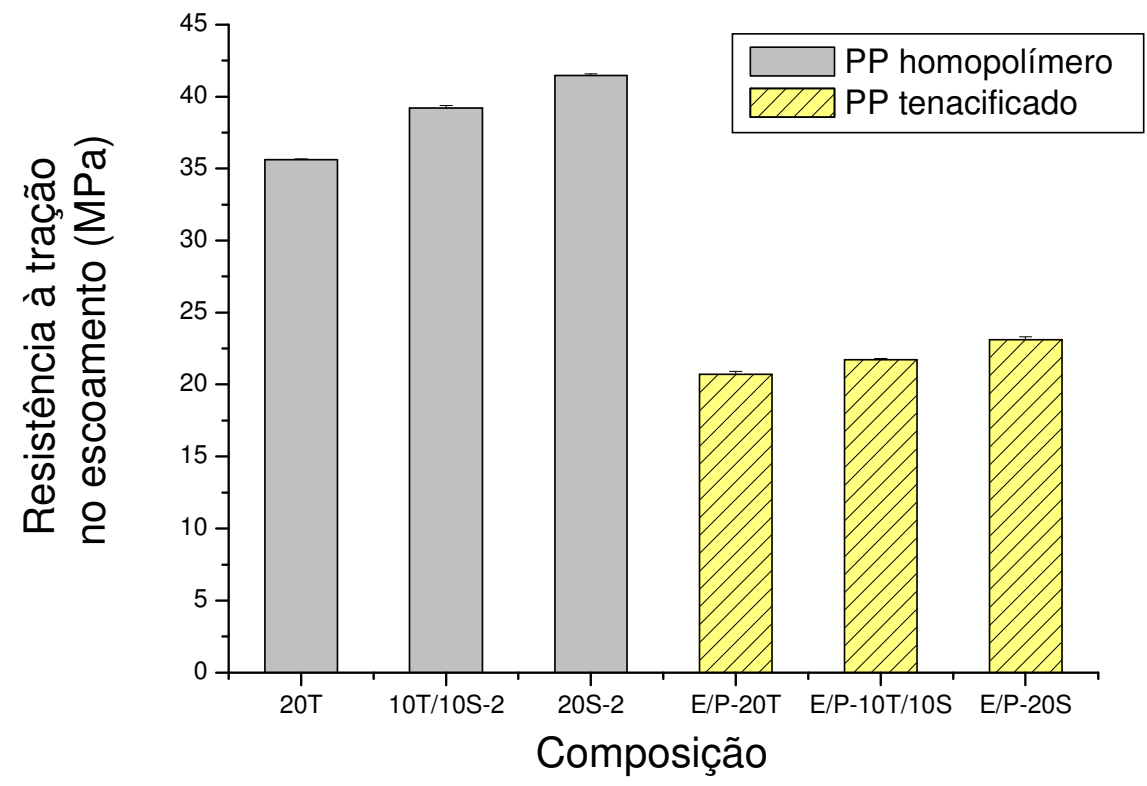

Figura 38 - Valores comparativos entre os compósitos tenacificados (E/P) e não tenacificados (PP homopolímero), obtidos para a propriedade de resistência à tração no escoamento 


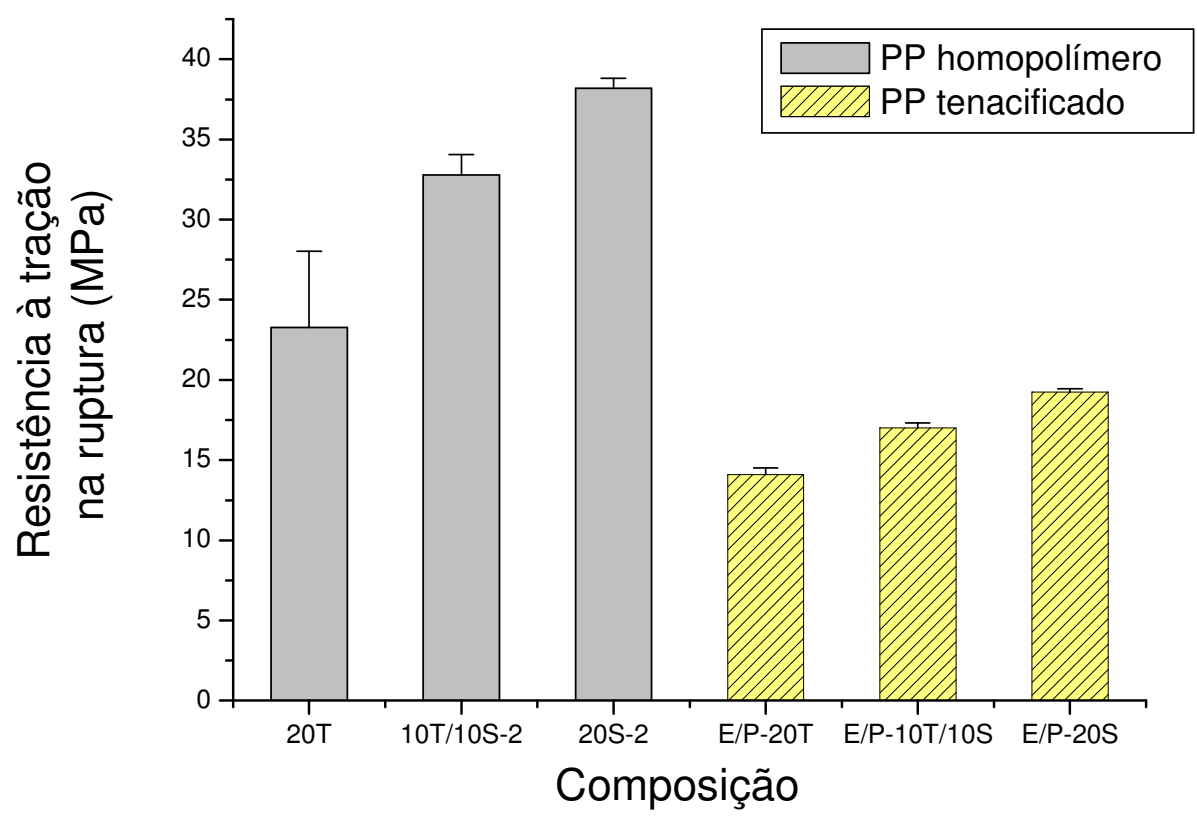

Figura 39 - Valores comparativos entre os compósitos tenacificados $(E / P)$ e não tenacificados (PP homopolímero), obtidos para a propriedade de resistência à tração na ruptura

A adição do copolímero com características elastoméricas POE resultou em uma diminuição da rigidez e de resistência mecânica comparativamente aos compósitos não tenacificados, como esperado. Parte deste efeito também foi proporcionado pela alteração da própria matriz, de polipropileno homopolímero para polipropileno copolímero heterofásico. Este último apresenta menor cristalinidade e maior resistência ao impacto pela presença de etileno na cadeia. Por outro lado, a comparação somente entre os compósitos com a adição do copolímero POE, com talco (E/P- 20T) e com fibra (E/P-20S), demonstrou um desempenho satisfatório da fibra como agente de reforço, porém com valores de tensão na ruptura superiores à rigidez proporcionada pelo talco, em torno de $36 \%$, aproximadamente. Este mesmo comportamento foi observado para a resistência à flexão, para o qual houve um pequeno aumento de 13\%, conforme mostrado na Figura 40. 


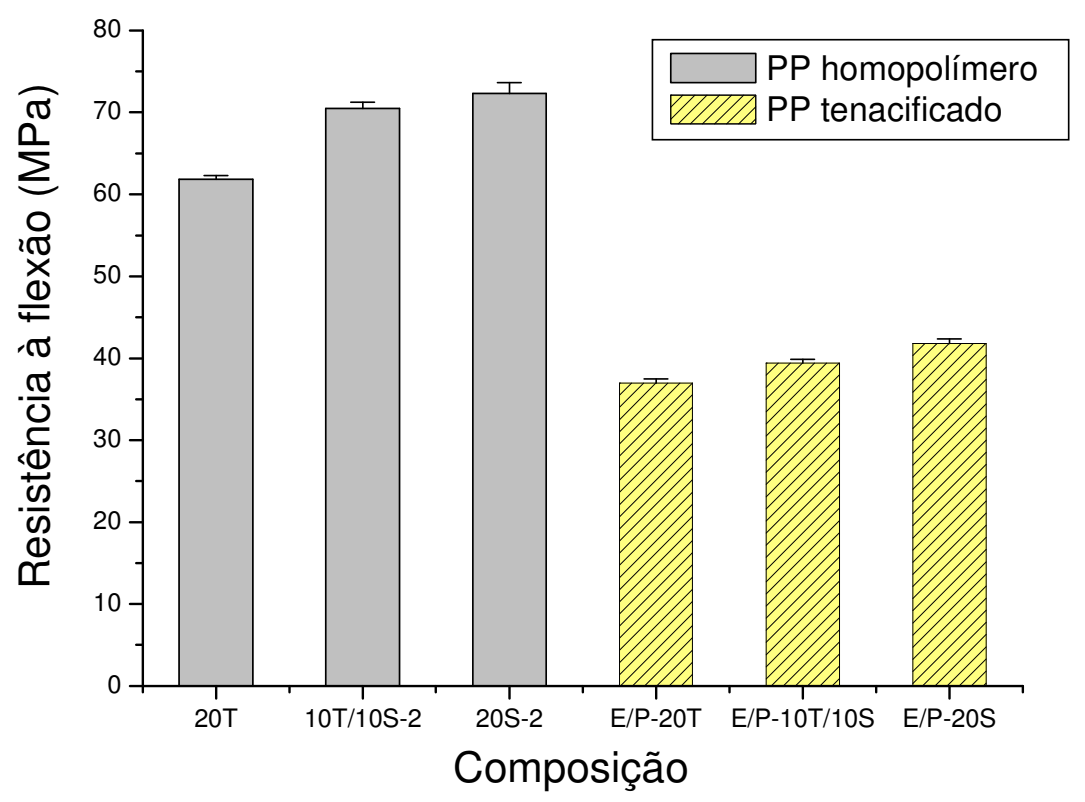

Figura 40 - Valores comparativos entre os compósitos tenacificados $(E / P)$ e não tenacificados (PP homopolímero), obtidos para a propriedade de resistência à flexão

O módulo à flexão para o compósito E/P-20S, mostrado na Figura 41, apresentou uma redução de, aproximadamente, 3,6\% com relação ao compósito com talco E/P-20T. Esta tendência já havia sido observada para os compósitos de polipropileno homopolímero e pode ser interpretada como decorrente, principalmente, da melhor interação das partículas lamelares do talco com esta matriz (frente à da fibra), a qual foi favorecida não só pelo seu fator de forma, mas também pela sua natureza apolar e inerte. 


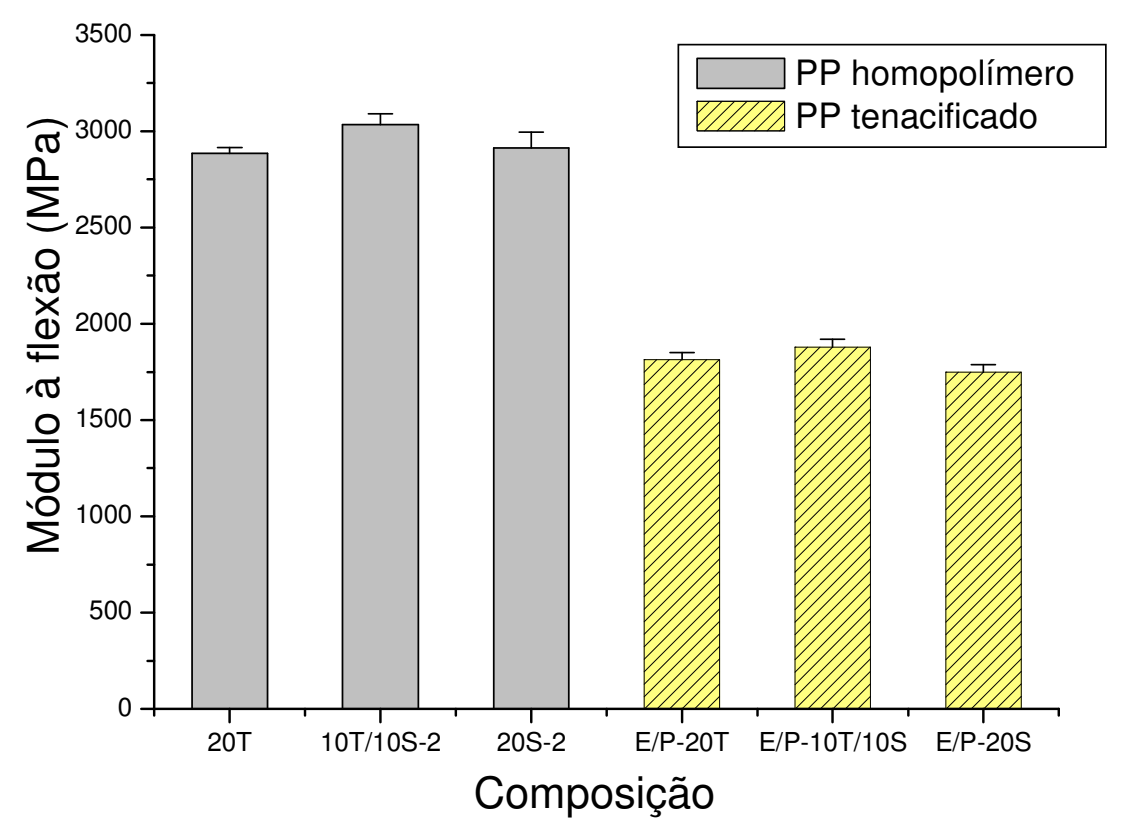

Figura 41 - Valores comparativos entre os compósitos tenacificados (E/P) e não tenacificados (PP homopolímero), obtidos para a propriedade de módulo à flexão

Nas Figuras 42 e 43 são mostrados os valores obtidos para as propriedades de alongamento na ruptura e no escoamento, respectivamente.

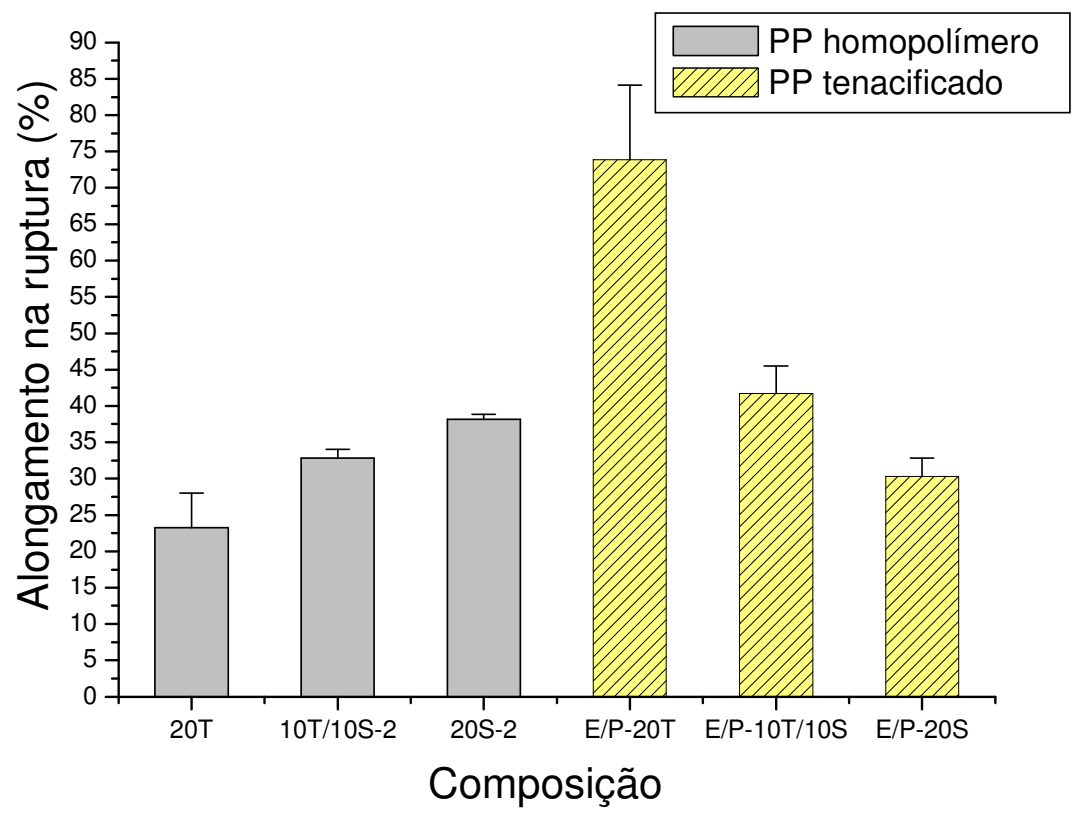

Figura 42 - Valores comparativos entre os compósitos tenacificados (E/P) e não tenacificados (PP homopolímero), obtidos para a propriedade de alongamento na ruptura 


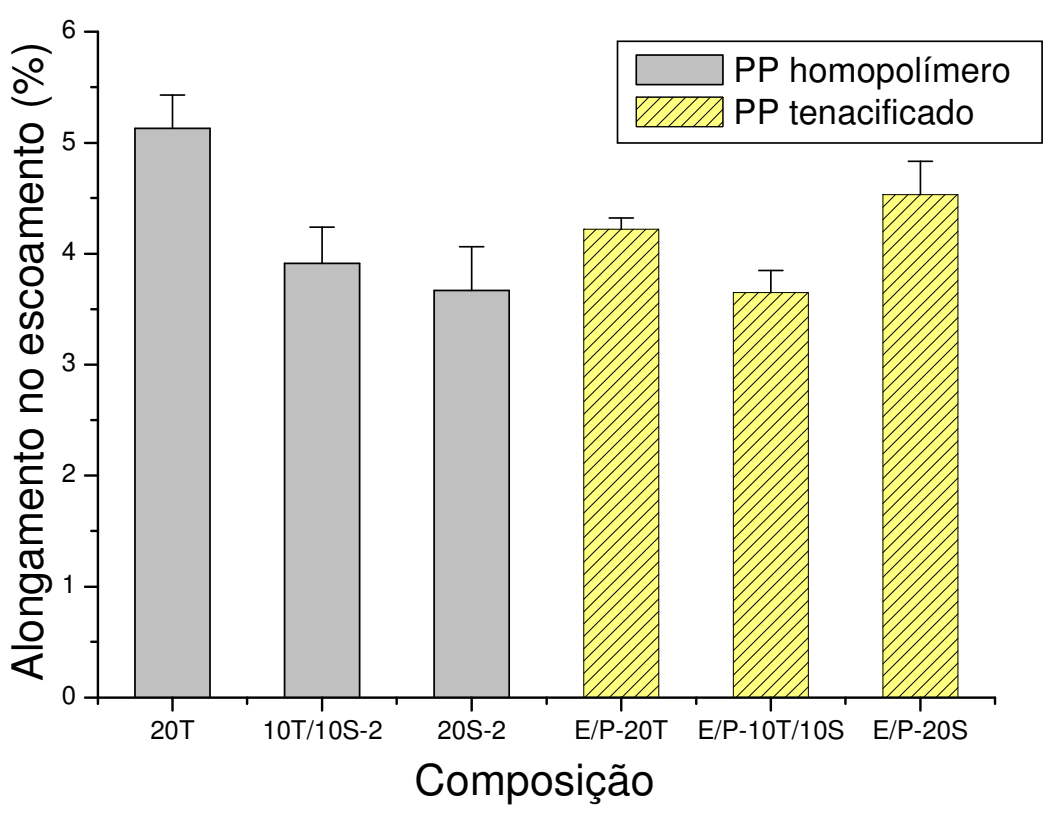

Figura 43 - Valores comparativos entre os compósitos tenacificados $(E / P)$ e não tenacificados (PP homopolímero), obtidos para a propriedade de alongamento no escoamento

Ao contrário do esperado, comparativamente ao compósito de PP homopolímero 20S-2, o compósito de PP copolímero tenacificado E/P-20S apresentou uma diminuição em torno de $21 \%$ para a propriedade de alongamento na ruptura, contrapondo o efeito da sua menor cristalinidade. Por outro lado, o mesmo compósito, E/P-20S, apresentou valores mais altos de alongamento no escoamento, em comparação ao compósito 20T e ao compósito tenacificado E/P20T. A tensão no escoamento é bastante dependente da força interfacial entre as fases. Quando há uma adesão boa entre as fibras e a matriz, a efetiva força interfacial torna-se a resistência ao cisalhamento da matriz. Tomando-se por base os resultados observados para a propriedade de alongamento no escoamento, bem como os da análise de morfologia (discutida a seguir na seção 4.2.5), verificou-se que o copolímero POE, na concentração de 5\%, promoveu uma melhor interface e interfase entre fibra e matriz. As micrografias das amostras do compósito E/P-20S, obtidas por MEV, mostraram a diminuição de vazios na superfície por pull out das fibras, quando comparadas às micrografias obtidas para o compósito 20S (seção 4.1.5). A melhor adesão fibra-matriz pode ter sido decorrente da atuação do $P O E$ como um agente compatibilizante. Esta hipótese tem como base a afinidade química 
boa do copolímero de etileno e 1-octeno com a região amorfa da matriz de polipropileno copolímero (polipropileno-etileno). A semelhança química pode favorecer as interações e as interdifusões de segmentos de cadeia na interface polipropileno - domínios dispersos de borracha. Entretanto, as micrografias também revelaram um grande número de partículas de borracha descoladas pelo processo de cavitação. Este fato é um indício de que, apesar da boa compatibilidade pela semelhança química, a interação ente a matriz de polipropileno e a fase elastomérica pode ainda ser otimizada.

Outra possível explicação para a melhor afinidade observada entre a fibra e o polímero seria por meio de uma alteração de propriedades da matriz causada pelo POE. Esta hipótese foi desconsiderada em razão da conservação da morfologia do polipropileno, como será discutido na seção 4.2.3.

O efeito da tenacificação pela adição do copolímero POE foi observado pelo aumento da energia absorvida por impacto, para corpos de prova confeccionados com entalhe e sem entalhe. Nas Figuras 44 e 45 são mostrados os resultados obtidos para a propriedade de resistência ao impacto Charpy com entalhe, em temperatura ambiente $\left(23^{\circ} \mathrm{C}\right)$ e em temperatura baixa $\left(-30^{\circ} \mathrm{C}\right)$, respectivamente.

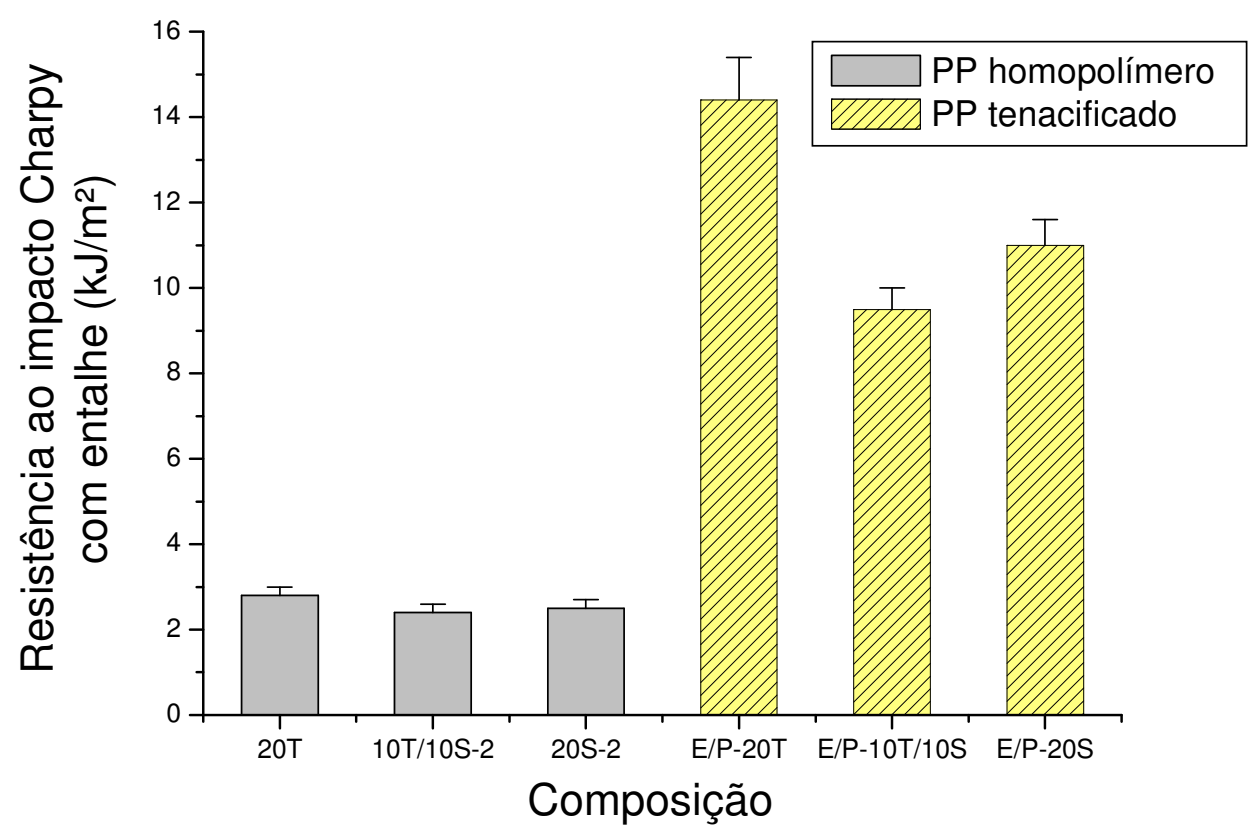

Figura 44 - Valores comparativos entre os compósitos tenacificados $(E / P)$ e não tenacificados (PP homopolímero), obtidos para a propriedade de impacto Charpy com entalhe, a $23^{\circ} \mathrm{C}$ 


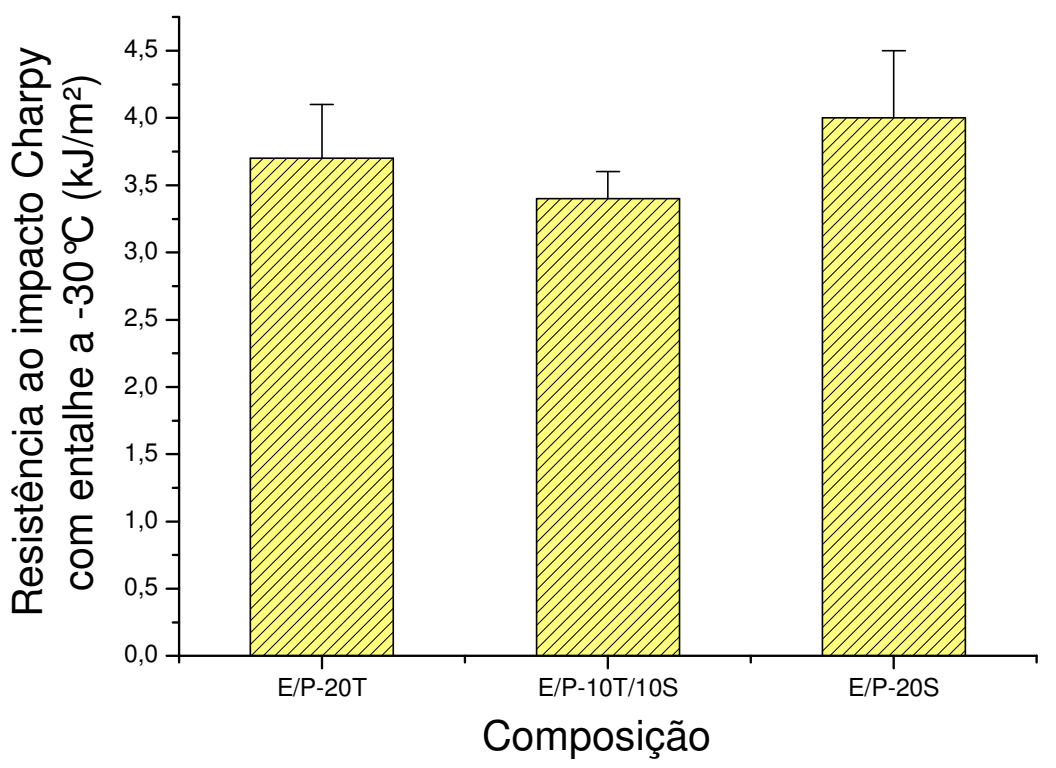

Figura 45 - Valores comparativos entre os compósitos tenacificados (E/P) obtidos para a propriedade de impacto Charpy com entalhe, a $-30^{\circ} \mathrm{C}$

Os tipos de quebra observados para os compósitos tenacificados após impacto com entalhe à temperatura ambiente foram de quebra parcial para os compósitos E/P-20T e E/P-10T/10S, bem como, quebra do tipo dobradiça para o compósito E/P20S. Já na condição sem entalhe, os corpos de prova de todas as formulações tenacificadas não apresentaram quebra a $23^{\circ} \mathrm{C}$. Este comportamento evidencia que nesta condição o copolímero POE estabilizou as trincas formadas na matriz de polipropileno. O tipo de quebra e os resultados obtidos para a resistência ao impacto demonstraram que o compósito com fibras de sílica E/P-20S apresentou tenacidade menor comparativamente ao compósito com talco E/P-20T, seguindo-se a mesma tendência dos compósitos de polipropileno homopolímero. Por outro lado, mantendo-se a mesma base de comparação, a resistência ao impacto destes compósitos em temperatura baixa foi praticamente similar, dentro da margem do erro experimental.

Grandes deformações plásticas na intarface fibra-matriz, bem como o deslocamento e o deslizamento (pull out) das fibras constituem os principais mecanismos de dissipação de energia em compósitos tenacificados durante processos de tensionamento e de fratura por impacto. ${ }^{40}$ Tais mecanismos dificultam a propagação de trincas ou fraturas quando os materiais são solicitados mecanicamente. As trincas, que geralmente se iniciam ao redor das pontas das 
fibras, se propagam pela matriz, sendo interrompidas ao encontrarem outras regiões de interface entre fibra-matriz. Se esta interface for fraca, a fibra irá se deslocar da sua direção principal e, por consequência, a propagação será dificultada. Caso o compósito continue a ser tensionado, ocorrerá um deslizamento da fibra até que a mesma se rompa. Por outro lado, se a adesão interfacial for forte, o deslizamento ou pull out da fibra também ocorrerá, porém a fratura se dará através da matriz.

A alteração do tipo de matriz de polipropileno, de homo para copolímero, bem como a adição de copolímero POE, proporcionou uma significativa melhoria à resistência ao impacto dos compósitos com fibras de sílica. À temperatura ambiente, se observou um ganho de 340\% nesta propriedade para o compósito P/E-20S, comparativamente ao compósito não tenacificado 20S-2. É conhecida a efetividade do copolímero POE quanto à melhoria da tenacidade de matrizes de polipropileno copolímero, principalmente pela compatibilidade entre ambos, a qual é promovida pela presença da fase etileno do polipropileno. ${ }^{71,72,73}$ Como já referenciado na seção 4.1.3 deste trabalho, alguns parâmetros micro estruturais exercem grande influência com relação às propriedades mecânicas destes compósitos, como a morfologia final da blenda, a fração volumétrica e o comprimento das fibras, a adesão interfacial entre fibra e matriz, bem como entre matriz e fase elastomérica. Os resultados obtidos para a resistência ao impacto, tanto a $23^{\circ} \mathrm{C}$, como em temperatura baixa ($30^{\circ} \mathrm{C}$ ), sugerem que as partículas do copolímero POE apresentaram-se com satisfatório tamanho e dispersão na matriz de polipropileno. Estas predições foram confirmadas pela análise morfológica por meio de microscopia eletrônica de varredura (MEV), a ser discutida a seguir, na seção 4.2.6 deste trabalho. Acredita-se que a distância interpartículas $\left(T_{c}\right)$ obtida entre os domínios do compósito E/P-20S foi menor que o valor crítico proposto por $\mathrm{Wu}^{58}$, sendo promovida uma melhor dissipação de energia durante o mecanismo de cavitação. Entretanto, a melhor capacidade de deformação não foi atingida pelos compósitos E/P-10T/10S e E/P20S. Esta poderia ser promovida com o aumento da concentração deste copolímero, o qual acarretaria a diminuição do tamanho e a maior proximidade dos domínios elastoméricos. Por outro lado, este aumento de concentração diminuiria ainda mais os valores obtidos para as propriedades relacionadas à resistência mecânica e rigidez, os quais se apresentaram satisfatórios, contudo apenas ligeiramente superiores ao compósito E/P-20T, reforçado com talco. 
De um modo geral, os resultados obtidos para os compósitos E/P-10T/10S e E/P-20S indicaram que é possível se obter compósitos de polipropileno reforçados com fibras de sílica natural para aplicação em peças internas automotivas. Entretanto, como descrito anteriormente, a melhora das propriedades mecânicas para se obter o melhor balanço possível entre rigidez e impacto, dentre outros fatores, pode ser conseguida por meio da melhor transferência de tensões entre a fibra e a matriz, e entre a matriz e os domínios de borracha. Neste sentido, a otimização do comportamento de compósitos de polipropileno tenacificados e reforçados com sílica pode ser alcançada pelo emprego de diferentes tipos de agentes de compatibilização. A grafitização da fase elastomérica é citada na literatura $^{40,53,73}$ como um fator efetivo de contribuição para uma adesão melhor entre as fases e menor tensão superficial, mesmo quando estas possuem afinidade química. Já a utilização de tratamentos diferentes da superfície das fibras, pode favorecer propriedades específicas, como tensão no escoamento e resistência ao impacto, dependendo do tipo de agente utilizado. ${ }^{74}$

Como citado na seção 2.4.3, Mae et al. ${ }^{54}$ pesquisaram a deformação micro estrutural e o processo de evolução de micro defeitos em blendas ternárias de polipropileno (PP) com borracha de etileno-propileno (EPR) e talco. Os autores citaram que uma melhor interface entre PP-EPR é mais importante que entre o talco e o PP para proporcionar o aumento da rigidez, da resistência e da ductilidade do compósito. A baixa tensão superficial entre as fases promove o processo de deformação plástica pela cavitação fibrilar, que é um indicativo de uma estrutura tenaz.

Silva et al. ${ }^{73}$ investigaram materiais à base de poliolefinas (polipropileno e polietileno de densidade alta) e dos elastômeros metalocêncios de etileno e 1octeno $(E O C)$, bem como propileno e 1-octeno (POC), quanto às propriedades mecânicas, térmicas e morfológicas. Dentre os resultados obtidos, os autores verificaram que o copolímero de propileno e 1-octeno (POC) atuou como um agente compatibilizante em misturas de PP/EOC e aumentou a resistência ao impacto desta blenda. As micrografias de SEM demonstraram que a adição do POC provocou um decréscimo do tamanho médio dos domínios de borracha, como também uma maior uniformidade em termos de distribuição.

Laura et al. ${ }^{74}$ analisaram o efeito do tratamento químico aplicado em fibras de vidro nas propriedades de blendas de poliamida 6 tenacificadas com borracha de 
etileno-propileno funcionalizada com anidrido maleico (EPR-g-MAH). Os seguintes silanos com diferentes grupos funcionais orgânicos foram utilizados no tratamento das fibras: anidridossilano, epoxissilano, aminossilano e octilssilano. Os autores verificaram que o módulo de tração não é afetado pela natureza química do silano empregado, porém, o mesmo não se aplica aos resultados de tensão no escoamento e resistência ao impacto. Em compósitos sem a adição de EPR-g-MAH, foi observado que três tipos de silano apresentaram valores similares para as propriedades mecânicas. O octilssilano demonstrou os resultados piores para as propriedades mencionadas de tensão no escoamento e resistência ao impacto Izod. Contudo, as misturas com anidridossilano obtiveram o melhor comportamento para tais requisitos quando $20 \%$ em peso de EPR-g-MAH foi adicionado à matriz polimérica. Com a introdução da fase elastomérica, o aminossilano foi o mais ineficiente, enquanto que o octilssilano demonstrou resultados intermediários. A diferença de comportamento dos diversos tratamentos químicos foi atribuída ao grau de adesão interfacial fibra-polímero.

\subsubsection{Propriedades térmicas}

Apesar do ensaio de temperatura de amolecimento segundo Vicat não ser o mais adequado para sistemas de mais de uma fase ${ }^{75}$, sendo o teste de temperatura de deflexão térmica (HDT) mais representativo, esta metodologia foi utilizada como um indicativo do comportamento térmico dos compósitos estudados. Os resultados obtidos para compósitos tenacificados e não tenacificados estão mostrados na Figura 46. Estes indicaram uma ligeira melhoria do comportamento térmico do compósito E/P-20S em relação aos compósitos tenacificados E/P-10T/10S e E/P20T, seguindo-se a relação de rigidez entre os mesmos. 


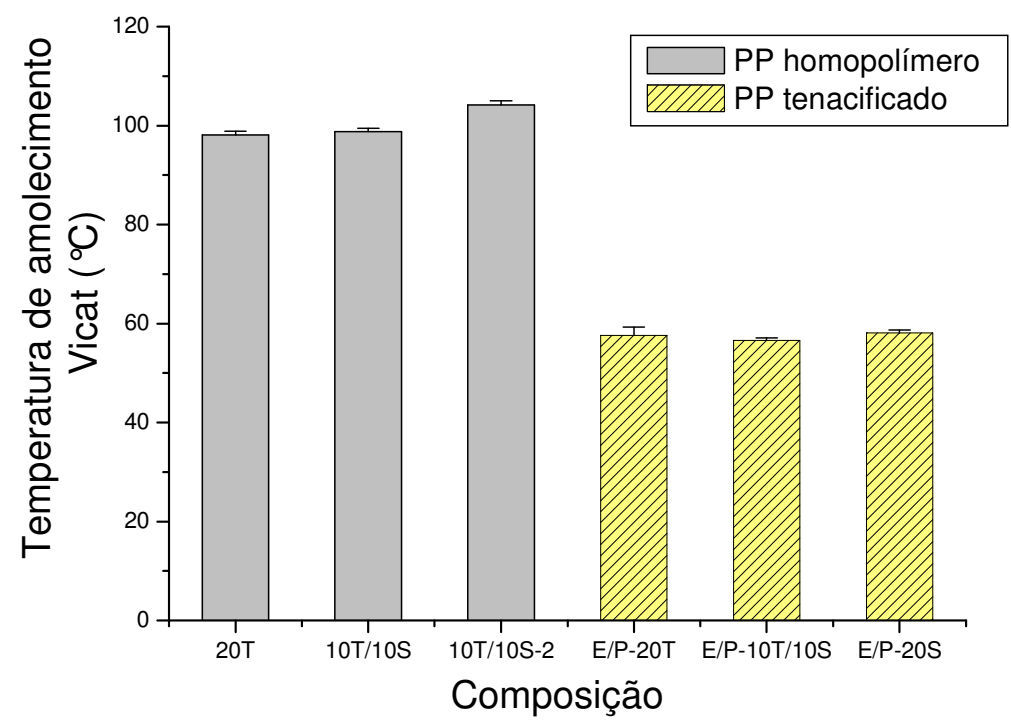

Figura 46 - Valores comparativos entre os compósitos tenacificados $(E / P)$ e não tenacificados (PP homopolímero), obtidos para a propriedade de temperatura de amolecimento segundo Vicat

Na Tabela 8 são apresentados os valores de temperatura de cristalização $\left(T_{c}\right)$, temperatura de fusão $\left(T_{m}\right)$, entalpia de fusão $\left(\Delta \mathrm{H}_{m}\right)$ e grau de cristalinidade $\left(X_{c}\right)$ para os compósitos modificados com POE e para o polímero puro (PP copolímero).

Tabela 8 - Temperatura de cristalização $\left(T_{c}\right)$, temperatura de fusão $\left(T_{m}\right)$, entalpia de fusão $\left(\Delta \mathrm{H}_{\mathrm{m}}\right)$ e grau de cristalinidade $\left(\mathrm{X}_{\mathrm{c}}\right)$ para os compósitos tenacificados

\begin{tabular}{ccccc}
\hline Amostra & $\mathrm{T}_{\mathrm{c}}\left({ }^{\circ} \mathrm{C}\right)$ & $\mathrm{T}_{\mathrm{m}}\left({ }^{\circ} \mathrm{C}\right)$ & $\Delta \mathrm{H}_{\mathrm{m}}(\mathrm{J} / \mathrm{g})$ & $\mathrm{X}_{\mathrm{c}}(\%)$ \\
\hline PP copolímero & 134 & 170 & 50 & 24 \\
E/P-20T & 134 & 169 & 37 & 18 \\
E/P -10T/10S & 133 & 169 & 37 & 18 \\
E/P-20S & 128 & 169 & 39 & 18 \\
\hline
\end{tabular}

A presença das fibras de sílica, do anidrido maleico e do copolímero POE alterou, porém não significativamente, as temperaturas de fusão e de cristalização das misturas, indicando que a morfologia cristalina do polipropileno foi conservada. Os valores de entalpia de fusão e do grau de cristalinidade dos compósitos tenacificados diminuíram em relação ao polímero puro (PP copolímero), não 
funcionalizado. Este comportamento era esperado em função da redução da porcentagem, em peso, da fase cristalina nas composições.

\subsubsection{Anisotropia}

Os resultados apresentados na Tabela 9 indicam que, assim como para 0 compósito 10T/10S-2, os efeitos da anisotropia do compósito E/P-10T/10S são minimizados pela adição de talco.

Tabela 9 - Resultados obtidos para as propriedades de contração longitudinal, transversal e anisotropia para os compósitos tenacificados

\begin{tabular}{cccc}
\hline Amostra & $\begin{array}{c}\text { Contração } \\
\text { Longitudinal (\%) }\end{array}$ & $\begin{array}{c}\text { Contração } \\
\text { Transversal (\%) }\end{array}$ & Anisotropia \\
\hline E/P-20T & $1,04 \pm 0,01$ & $1,63 \pm 0,01$ & $1,63 \pm 0,01$ \\
E/P-10T/10S & $1,00 \pm 0,08$ & $1,66 \pm 0,03$ & $1,66 \pm 0,06$ \\
E/P-20S & $1,01 \pm 0,03$ & $1,92 \pm 0,03$ & $1,90 \pm 0,03$ \\
\hline
\end{tabular}

\subsection{5 $\underline{\text { Propriedades específicas - resistência ao risco }}$}

Cinco placas planas com uma textura usual aplicada em superfícies de peças internas de uma indústria automobilística, injetadas com os compósitos tenacificados E/P-20T, E/P-10T/10S e E/P-20S, foram submetidas ao ensaio de resistência a riscos utilizando-se o equipamento Erichsen modelo 430P, sob carga de $10 \mathrm{~N}$. Os valores obtidos para a leitura da diferença de luminosidade $\left(\Delta \mathrm{L}^{*}-\right.$ Codificação CieLab, ângulo de medição 45\%/0 - D65 ) entre a superfície riscada e não riscada, estão apresentados na Tabela 10. 
Tabela 10 - Resultados obtidos para a propriedade de resistência a riscos para os compósitos tenacificados

\begin{tabular}{ccc}
\hline Amostra & $\Delta \mathbf{L}^{*}\left(\mathbf{4 5} / \mathbf{0}^{\circ}-\mathbf{D} 65\right)$ & Requisito \\
\hline E/P-20T & $5,66 \pm 1,07$ & \\
E/P -10T/10S & $3,41 \pm 0,38$ & $|\Delta L| \leq 1,5$ \\
E/P-20S & $1,10 \pm 0,04$ & \\
\hline
\end{tabular}

A "visibilidade", ou o esbranquiçamento por tensão, ocasionada nas superfícies das amostras está mostrada de forma comparativa na Figura 47.

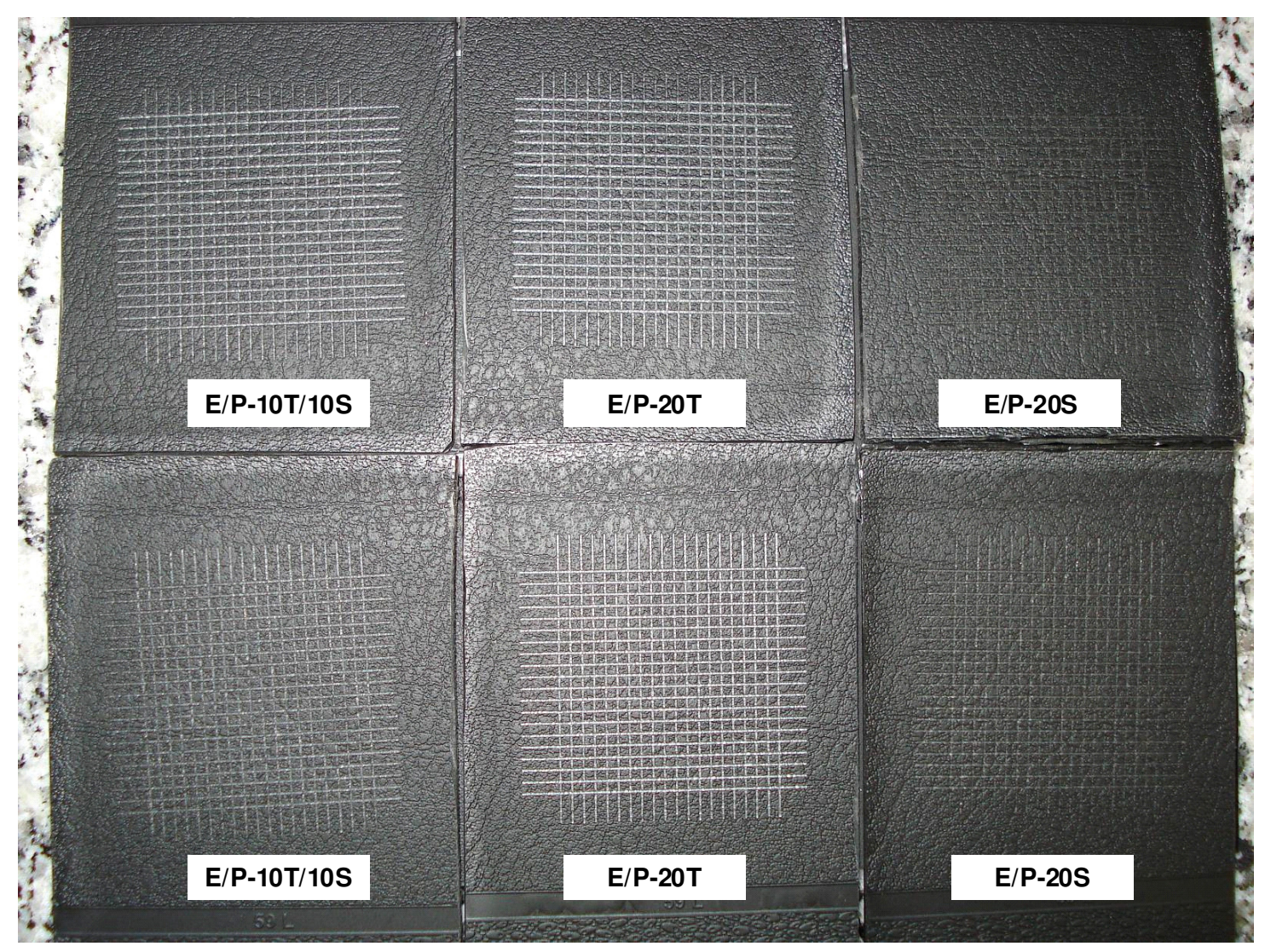

Figura 47 - Comparação visual entre amostras das superfícies riscadas dos compósitos tenacificados E/P-10T/10S, E/P-20T e E/P-20S

De acordo com as exigências de uma montadora de veículos, somente o compósito E/P-20S, com fibras de sílica, estaria considerado apto, em termos de resistência a riscos, para ser utilizado em revestimentos internos como painéis de instrumentos, revestimentos de porta, revestimentos de coluna, consoles, dentre outros. A condição de atendimento é $|\Delta L| \leq 1,5$. O compósito E/P-20S atendeu não 
só ao requisito da análise qualitativa, apresentando valores menores que o especificado pela metodologia empregada, mas também à impressão visual final. De acordo com Hadal et al. ${ }^{67}$, medições quantitativas em função da diferença de tonalidade promovida pelo risco constituem um método consistente e confiável de determinação. Na Figura 48 é mostrada a diferença observada para a superfície deste compósito antes e após a execução do ensaio.

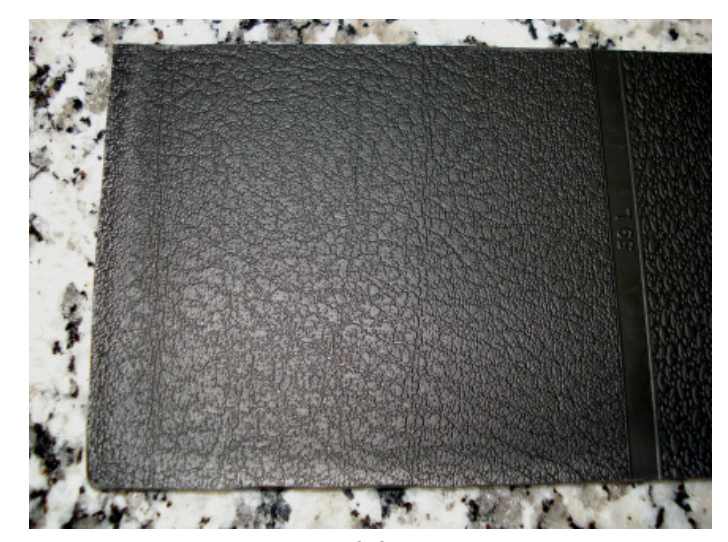

(a)

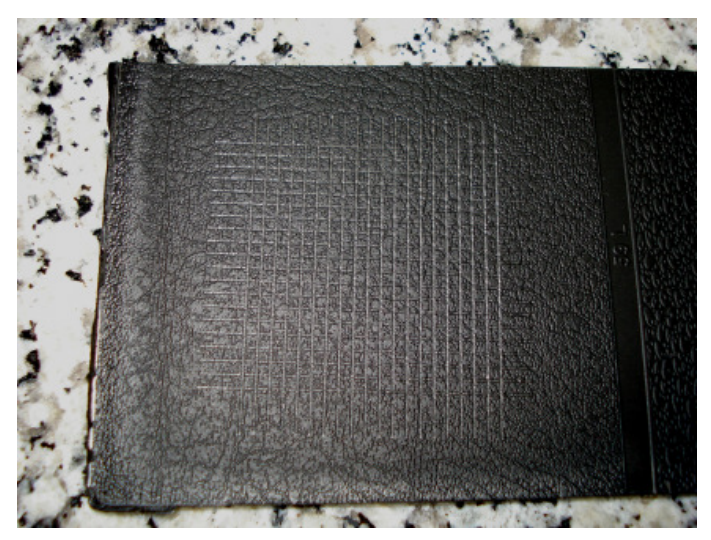

(b)

Figura 48 - Comparação visual entre a superfície de uma placa injetada com o compósito E/P-20S antes (a) e após (b) o ensaio de resistência a riscos

Observa-se que o compósito com talco, E/P-20T apresentou resultados extremamente insatisfatórios. Durante o ensaio, a ponta de teste, ou indentador, promoveu uma significativa deformação plástica na superfície da amostra, maior que a ocorrida na superfície do compósito E/P-20S, como mostrado na Figura 49, obtida por microscopia ótica. O grau de severidade desta deformação está relacionado com o descolamento e deslizamento de partículas ou fibras da matriz polimérica. $O$ talco possui uma estrutura lamelar formada por duas camadas tetraédricas de sílica unidas por uma folha octaédrica de brucita. As lamelas, por sua vez, são unidas por ligações de van der Waals. A alta tensão de cisalhamento gerada durante a formação do risco é suficiente para romper estas ligações e promover a delaminação das partículas do talco, tornando-as expostas. Além disso, a dureza Mohs baixa do talco contribui para o aumento da profundidade do risco. Quanto mais profundo for o risco e quanto mais vazios ou desfribilações promovidas por delaminações estiverem presentes, maior será a "visibilidade" em função da reflexão da luz. 


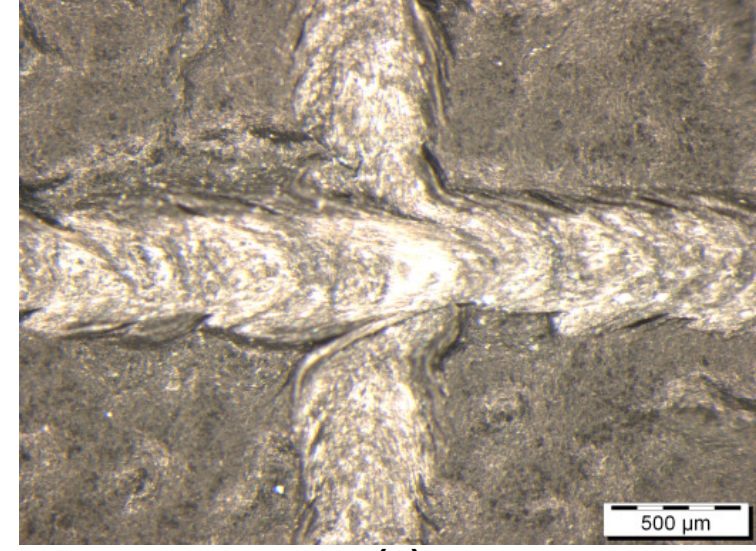

(a)

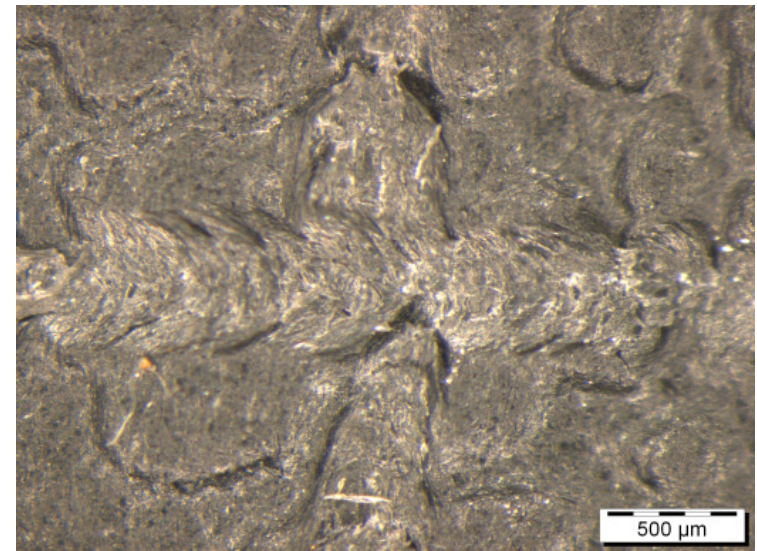

(b)

Figura 49 - Deformações plásticas ocorridas nas superfícies dos compósitos E/P20T (a) e E/P-20S (b)

A estrutura da fibra de sílica, semelhante à da fibra de vidro, também contribuiu para o melhor resultado observado para o compósito E/P-20S, entretanto, vários aspectos podem ser responsáveis pelo melhor comportamento apresentado por este compósito. Sugere-se que, por meio de uma forte interação fibra-polímero e da dispersão satisfatória das fibras, as quais são promovidas por agentes compatibilizantes, houve uma redução significativa de descolamentos ou formação de vazios e fissuras na superfície. A ausência destes vazios causou uma menor deformação da superfície quando esta foi riscada, e, por consequência, uma diminuição do efeito de "visibilidade" do risco.

O grau de cristalinidade não foi, aparentemente, um fator de contribuição quanto ao melhor desempenho do compósito E/P-20S, uma vez, que comparativamente ao compósito E/P-20T, não houve diferenças significativas com relação aos valores obtidos para esta propriedade.

$\mathrm{Na}$ indústria automobilística, alguns recursos são utilizados para minimizar o efeito da riscabilidade em compósitos de polipropileno. A escolha da textura, ou do tipo de rugosidade da superfície, exerce uma grande influência na minimização dos resultados visuais da deformação pelo risco. Compósitos com cores mais claras também "mascaram a visibilidade" da deformação. Por outro lado, novos aditivos estão sendo desenvolvidos e incorporados à formulação de compósitos reforçados com talco, como amidas, óleos de silicones e, mais recentemente, erucamide $\left[\left(\mathrm{CH}_{3}\left(\mathrm{CH}_{2}\right)_{7} \mathrm{CH}=\mathrm{CH}\left(\mathrm{CH}_{2}\right)_{11} \mathrm{CONH}_{2}\right]\right.$, os quais são agentes que migram para a superfície e reduzem o coeficiente de atrito, otimizando a resistência ao risco. No entanto, além de promoverem o aumento do custo das formulações, alguns aditivos 
podem migrar em excesso para a superfície, sob ação de temperatura e exposição à luz solar, por exemplo, tornando a superfície "pegajosa". Este efeito, conhecido como stickiness, causa um aumento de brilho nem sempre desejável. Por estas razões, a utilização de outras partículas ou fibras minerais, como a wollastonita e, como mostrado, as fibras de sílica, constituem interessantes propostas para a melhoria da resistência ao risco.

\subsubsection{Caracterização morfológica (MEV)}

Nas Figuras 50 e 51 são mostradas as micrografias das superfícies das amostras E/P-20T, E/P-10T/10S e E/P-20S, as quais foram fraturadas em temperatura baixa. Observa-se que as partículas do copolímero POE, em todas as misturas estudadas, apresentam-se dispersas na matriz, próximas, com formas arredondadas, com tamanhos pequenos e relativamente uniformes. Cabe ressaltar que as superfícies destas amostras não foram previamente "lavadas" com qualquer tipo de solvente para a diluição da fase elastomérica.

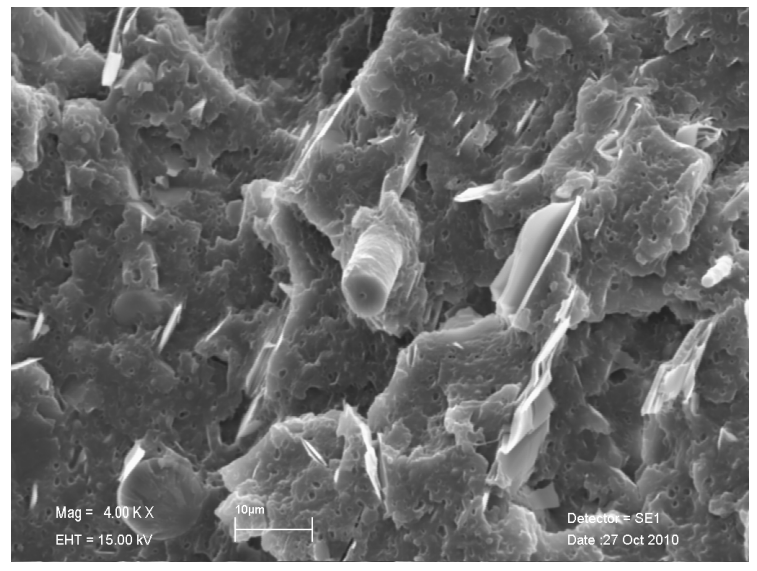

(a)

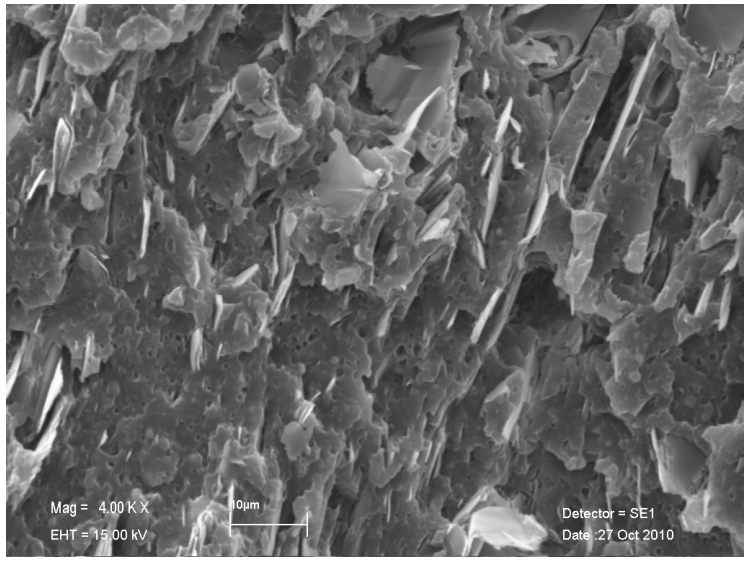

(b)

Figura 50 - Micrografias das superfícies dos compósitos E/P-10T/10S (a) e E/P-20T (b) 


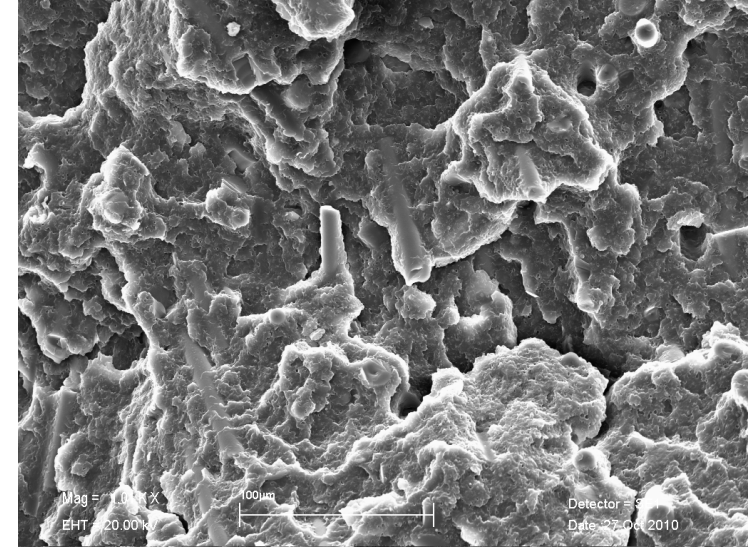

(a)

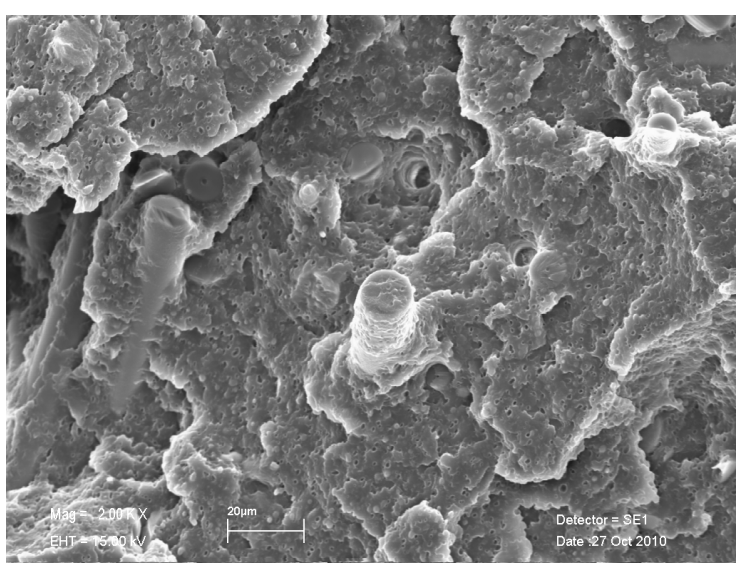

(b)

Figura 51 - Micrografias da superfície do compósito E/P-20S (a e b)

O tamanho, a forma e a distribuição das partículas, ou domínios da fase discreta, dependem da quantidade relativa entre seus componentes e da razão entre as viscosidades da matriz e do elastômero. O comportamento viscoelástico, por sua vez, é dependente da tensão interfacial entre as fases, bem como das condições de processamento da mistura. ${ }^{75,76}$ A dispersão satisfatória dos domínios de POE mostrada nas micrografias dos compósitos pode ser atribuída, dentre outros fatores, à melhor afinidade deste com a matriz de polipropileno, sendo um indicativo da tensão superficial baixa entre as fases.

Na Figura 52 é mostrado um detalhe da morfologia do compósito E/P-20S, decorrente da aproximação da imagem obtida durante a análise de uma região da superfície mostrada na Figura 51(b). 


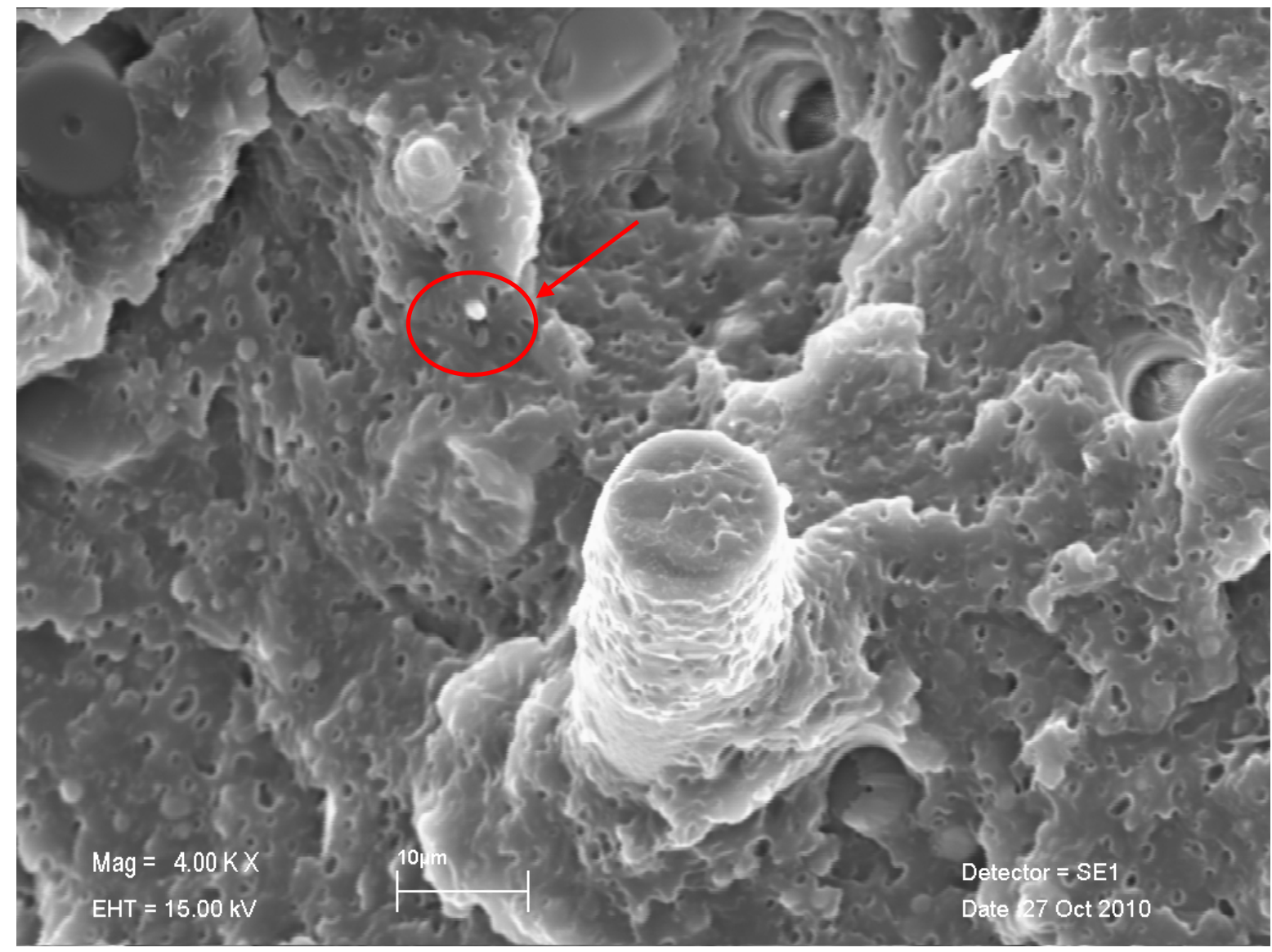

Figura 52 - Micrografia da superfície do compósito E/P-20S

Verifica-se que na região em destaque mostrada na Figura 52 há um descolamento de partículas de POE. A superfície do compósito E/P-20S exibiu uma grande quantidade de vazios, os quais indicaram processos de cavitação da partícula elastomérica por deformação plástica (escoamento), com absorção de energia. A formação destes vazios, ou buracos, é uma das formas de resposta dos polímeros tenacificados às tensões impostas. ${ }^{77}$ Por outro lado, a alta concentração de vazios presentes, indicou que a adesão entre a matriz e a fase elastomérica pode ser ainda melhorada. Observam-se poucos domínios elastoméricos maiores, os quais provavelmente foram formados pela coalescência dos menores. Isto indicou certa estabilidade do mecanismo de fratura, o que é bem positivo. Caso as cavidades apresentassem um aumento de tamanho, elas poderiam iniciar uma fratura prematura do compósito. ${ }^{55}$ Aparentemente, não houve comprometimento à viscosidade da matriz de polipropileno e da sua habilidade em transferir tensões de cisalhamento para a fase elastomérica (tendo em vista os bons resultados obtidos 
para a propriedade de resistência ao impacto). Pesquisas ${ }^{78}$ citam que a adição do copolímero POE ao polipropileno não proporciona variações significativas na viscosidade do fundido.

A comparação visual do tamanho das partículas de POE mostradas na Figura 52 , em relação à medida da barra de referência $(10 \mu \mathrm{m})$ desta micrografia, permitiu constatar que o valor do diâmetro médio dos domínios está em torno de $2 \mu \mathrm{m}$. Este resultado é considerado satisfatório, entretanto, um tamanho médio inferior a $1 \mu \mathrm{m}$ seria o ideal para a obtenção de compósitos com melhores valores de resistência ao impacto. $^{73}$

Na Figura 53 é mostrado um detalhe da morfologia do compósito E/P-20S, decorrente da aproximação da imagem obtida durante a análise de uma região da superfície mostrada na Figura 51(a). Observa-se uma melhor molhabilidade e adesão entre a fibra e a matriz, superior à apresentada pelos compósitos não tenacificados. Estes resultados estão em concordância com os valores obtidos para as propriedades mecânicas e de resistência a riscos.

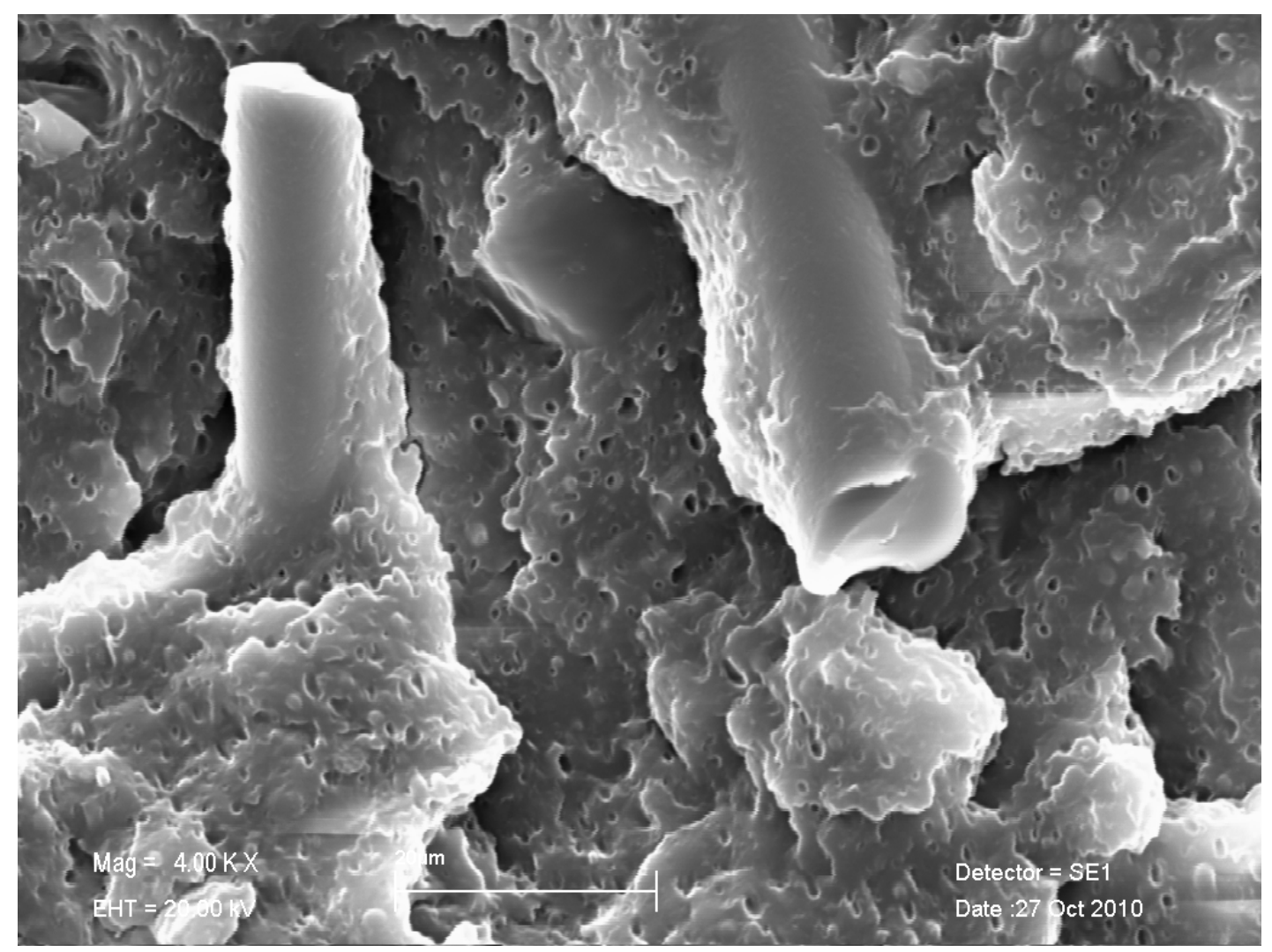

Figura 53 - Micrografia da superfície do compósito E/P-20S 


\section{CONCLUSÕES}

De modo geral, os resultados obtidos neste trabalho sugerem que as fibras curtas de sílica amorfa constituem uma alternativa potencial de reforço para compósitos de polipropileno empregados na indústria automotiva, com atribuição de propriedades boas e com a vantagem de redução de peso.

As seções 5.1 e 5.2 descrevem as principais conclusões referentes aos tipos de compósitos investigados.

\subsection{COMPÓSITOS DE POLIPROPILENO HOMOPOLÍMERO}

As formulações com teor de $20 \%$ de fibra de sílica, nas quais se adicionou 0 compatibilizante anidrido maleico, apresentaram resultados satisfatórios quanto à resistência mecânica e à rigidez, evidenciando uma melhor adesão e transferência de tensões do polímero para as fibras. Em termos comparativos, o módulo de flexão obtido para o compósito 20S-2 foi, aproximadamente, $86 \%$ superior ao do polipropileno homopolímero puro. Houve um ganho de $17 \%$ para a tensão no escoamento do compósito $20 \mathrm{~S}-2$ em relação à formulação com talco, 20T. Como esperado, para compósitos poliméricos reforçados com fibras ou partículas rígidas, as quais restringem a mobilidade da cadeia molecular do polímero, houve o comprometimento das propriedades relacionadas à tenacidade. Por outro lado, não houve diferença significativa frente à resistência ao impacto com entalhe do polímero puro. A energia absorvida para a propagação das trincas foi baixa em função da característica frágil do polipropileno homopolímero, não havendo alterações de valores mesmo com a melhor interação fibra-matriz e independentemente do mecanismo envolvido no processo.

A adição da fibra de sílica aumentou a resistência térmica dos compósitos e a interação interfacial contribuiu ainda mais para a elevação da temperatura de amolecimento conforme Vicat. As análises, por intermédio da técnica DSC, indicaram que houve um ganho de $3^{\circ} \mathrm{C}$ para a temperatura de cristalização do 
compósito 20S-2 em relação ao PP homo, o qual pode ser atribuído à formação de núcleos em um estágio primário e em temperatura alta, durante o processo de resfriamento. Este efeito de nucleação é favorecido pela presença do compatibilizante anidrido maleico, a não ser que este esteja em excesso.

Os valores satisfatórios obtidos para o comportamento frente a emissões voláteis indicaram que o compósito 20S-2 pode ser aplicado em peças do interior do veículo, sem prejuízo à saúde ou ao bem estar dos ocupantes. Os resultados de emissões e de odor permitiram verificar que o sistema de estabilização escolhido mostrou-se eficiente quanto à inibição dos mecanismos de degradação termooxidativa. Os níveis baixos de emissões de carbono também foram valores indicativos de parâmetros adequados de processamento, apesar das condições adversas proporcionadas pela rigidez e pela abrasividade das fibras de sílica.

O compósito híbrido 10T/10S-2, com adição de talco e anidrido maleico, apresentou um bom balanço para as propriedades mecânicas e efeitos de anisotropia.

Considerando-se a formulação com a presença de $20 \%$ de fibras de sílica, por meio das propriedades investigadas sugere-se que a concentração ótima do compatibilizante interfacial, a qual corresponde ao ponto de melhor equilíbrio dos requisitos de rigidez e tenacidade, foi de $2 \%$ em peso. Este teor pode corresponder ao ponto de saturação da interface fibra-polímero, quanto à hipótese de formação de uma camada interfacial constituída de PP-co-siloxano, com resistência alta ao cisalhamento, porém mais deformável.

As micrografias eletrônicas de varredura das superfícies de fratura à baixa temperatura evidenciaram o efeito de uma boa molhabilidade das fibras pela adição do anidrido maleico. Por outro lado, para os compósitos 20S-2 e 10T/10S-2 ainda existem algumas fibras desacopladas, com pouca molhabilidade e adesão à matriz. O tratamento das fibras empregando aminopropiltrietoxissilano não foi totalmente efetivo provavelmente em razão do rendimento baixo da reação para a hidrofobização da superfície da fibra de sílica, ou por uma afinidade química "parcial" com a matriz. 


\subsection{COMPÓSITOS DE POLIPROPILENO MODIFICADOS COM POE}

A alteração do tipo de matriz de polipropileno, de homo para copolímero, bem como a adição do copolímero $\mathrm{POE}$, proporcionou uma significativa melhoria à resistência ao impacto dos compósitos com fibras de sílica. À temperatura ambiente, se observou um ganho de $340 \%$ nesta propriedade para o compósito E/P-20S, comparativamente ao compósito não tenacificado 20S-2. Em contrapartida, houve o comprometimento das propriedades de rigidez e de resistência mecânica, apesar dos valores obtidos serem ligeiramente superiores aos obtidos para a formulação E/P-20T, com adição de talco.

A presença das fibras de sílica, do anidrido maleico e do copolímero POE alterou, porém não significativamente, as temperaturas de fusão e de cristalização das misturas, indicando que a morfologia cristalina do polipropileno foi conservada.

$A$ formulação E/P-20S, em comparação à formulação E/P-20T, apresentou resultados superiores quanto à resistência a riscos na superfície, tanto em análise quantitativa, como em avaliação visual. O tipo de estrutura e forma da fibra, assim como a melhor interação fibra-polímero, foram fatores significantes para a redução de descolamentos ou formação de vazios e fissuras na superfície das amostras. A diminuição destes defeitos contribuiu para uma deformação menor da superfície pelo risco e, por consequência, um menor efeito de "visibilidade" ou esbranquiçamento por tensão.

A análise morfológica dos compósitos tenacificados demonstrou uma boa dispersão dos domínios de etileno e 1-octeno, bem como partículas com formas arredondadas, com tamanhos pequenos e relativamente uniformes. O POE atuou como um agente compatibilizante, melhorando a adesão fibra-polímero. Entretanto, as micrografias também revelaram um grande número de partículas de borracha descoladas pelo processo de cavitação. Apesar da boa compatibilidade pela semelhança química, a interação ente a matriz de polipropileno e a fase elastomérica pode ainda ser otimizada. 


\section{REFERÊNCIAS BIBLIOGRÁFICAS}

1 COMUNIDADE EUROPÉIA. O Parlamento Europeu e o Conselho da União Européia. Regulamento (CE) no 443/2009 de 23 de abril de 2009. Define normas de desempenho em matéria de emissões dos automóveis novos de passageiros como parte da abordagem integrada da Comunidade para reduzir as emissões de $\mathrm{CO}_{2}$ dos veículos ligeiros. Lex: Jornal Oficial da União Européia, p. L140/1- L140/15, 5 dez. 2009.

2 CARVALHO, G. M. X.; MANSUR, H. S.; VASCONCELOS, W. L.; ORÉFICE, R. L. Obtenção de compósitos de resíduos de ardósia e polipropileno. Polímeros: Ciência e Tecnologia, São Carlos, v. 17, n. 2, p. 98-103, 2007.

3 ISHIZAKI, M. H.; VISCONTE, L. L. Y. Caracterização mecânica e morfológica de compósitos de polipropileno e fibras de coco verde: influência do teor de fibra e das condições de mistura. Polímeros: Ciência e Tecnologia, São Carlos, v. 16, n. 3, p. 182-186, 2006.

4 PREMALAL, H. G. B.; ISMAIL, H.; BAHARIN, A. Comparison of the mechanical properties of rice husk powder filled polypropylene composites with talc filled polypropylene composites. Polymer Testing, v. 21, p. 833-839, 2002.

5 EL-MIDANY A. A.; IBRAHIM S. S. The effect of mineral surface nature on the mechanical properties of mineral-filled polypropylene composites. Polymer Bulletin, v. 64, p. 387-389, 2010.

6 MORELAND, J. E. Silica fillers, extenders, and reinforcements. In: KATZ, H. S.; MILEWSKI, J. V. Handbook of fillers and reinforcements for plastics. $15^{\text {th }}$ ed. New York: Van Nostrand Reinhold, 1978,639p.

7 NURDINA, A. K.; MARIATTI, M.; SAMAYAMUTTHIRIAN, P. Effect of singlemineral filler and hybrid-mineral filler additives on the properties of polypropylene composites. Journal of Vinyl \& Additive Technology, DOI 10,10002/vnl.20173, 2009. Disponível em: <htt:// www.intersciense.wiley.com>. Acesso em: 05 maio 2010.

8 SALIBA, C. C.; ORÉFICE, R. L.; CARNEIRO, J. R. G.; DUARTE, A. K.; SCHNEIDER, W. T.; FERNANDES, M. R. F. Effect of the incorporation of a novel natural inorganic short fiber on the properties of polyurethane composites. Polymer Testing, v. 24, p. 819-825, 2005. 
9 OLIVEIRA, C. A.; SOUSA, J. A. Anisotropia mecânica em moldados por injeção de compósitos de polipropileno com reforço híbrido de fibra de vidro e talco. In: CONGRESSO BRASILEIRO DE ENGENHARIA E CIÊNCIA DOS MATERIAIS, 17", 2006, Foz do Iguaçu, PR, Anais 17ํㅡㄹ CBECiMat, Foz do Iguaçu, 2006, p. 2932-2943.

10 RABELLO, M. Aditivação de polímeros. São Paulo; Artiliber, 2000, 242 p.

11 SATO, A. K. Desenvolvimento e caracterização de um compósito híbrido de polipropileno homopolímero e micro fibra de sílica amorfa e fibra de madeira, utilizando agente de acoplagem, 2008, 109 p. Dissertação (Mestrado) Faculdade de Engenharia Químca, Universidade Estadual de Campinas, Campinas SP, 2008.

12 SEGATELLI, M. G. Avaliação das propriedades mecânicas e da morfologia de compósitos ternários de poliamida 6 , borracha de etileno-propileno-dieno e fibras curtas de sílica, 2005, 94 p. Dissertação (Mestrado) - Instituto de Química, Universidade Estadual de Campinas, Campinas - SP, 2005.

13 MAIER, C.; CALAFUT, T. Polypropylene: the definitive user's guide and databook. New York: Plastic Design Library, 432 p., 1998.

14 CANEVAROLO JR., S. V. Ciência dos polímeros: um texto básico para tecnológicos e engenheiros. São Paulo: Editora Artliber, 2ª Edição, 280 p., 2006.

15 GALLI, P; HAYLOCK, J.C.; SIMONAZZI, T. Manufacturing and properties of polypropylene copolymers. In: KARGER-KOCIS, J. Popypropylene: structure, blends and composites. Germany: Chapman \& Hall, $1^{\text {st }}$ edition, v. 2, 205 p., 1995.

16 CUNHA, F. R. Modelos para a predição de propriedades finais de polímeros a partir de variáveis operacionais, 2010, 380 p. Tese de Doutorado - Escola de Química, Universidade Federal do Rio de Janeiro, Rio de Janeiro - RJ, 2010.

17 TOKUMOTO, S. Deformação plástica do polipropileno isotático: aspectos do mecanismo, propriedades e morfologia, 2003, 248 p. Tese de Doutorado Ciência dos Materiais, Universidade Federal do Rio Grande do Sul, Porto Alegre, 2003.

18 DALPIAZ, G. Estudo do efeito de cargas minerais em compósitos poliméricos particulados em matriz de polipropileno, 2006, $170 \mathrm{p}$. Tese de Doutorado - Engenharia de Minas, Metalurgia e de Materiais, Universidade Federal do Rio Grande do Sul, Porto Alegre - RS, 2006. 
19 TRIPATHI, D. Practical guide to polypropylene. United Kingdom: Rapra Technology Ltd., 104 p., 2002.

20 TEDESCO, A. Propriedades de blendas ternárias de polipropileno, 2007, 132 p. Tese de Doutorado - Ciência dos Materiais, Universidade do Rio Grande do Sul, Porto Alegre - RS, 2007.

21 MOORE JR., E. P. Poypropylene Handbook: polymerization, characterization, properties, processing, applications. New York: Hansen Publishers, 419 p., 1996.

22 GALLI, P.; HAYLOCK, J. C.; SIMONAZZI, T. Manufacturing and propeties of polypropylene copolymers In: J. Karger-Kocsis. Polypropylene: Structure, blends and composites. London: Chapman \& Hall, 205 p., 1995.

23 FERRANTE, M. Seleção de materiais. São Carlos: Editora EduFSCar, $2^{2}$ Edição, 286 p., 2002.

24 CALISTER JR., W. D. Ciência e Engenharia de Materiais: uma introdução. Rio de Janeiro: Editora LCT, 7- Edição, 705 p., 2008.

25 PUKÁNSZKY, B. Particulate filled polypropylene: structure and properties. In: KARGER-KOCIS, J. Popypropylene: structure, blends and composites. Germany: Chapman \& Hall, $1^{\text {st }}$ edition, v. 3, 392 p., 1995.

26 RANDOSTA, J. A.; TRIVEDI, N. Talc. In: KATZ, H. S.; MILEWSKI, J. V. Handbook of fillers and reinforcements for plastics. $15^{\text {th }}$ ed. New York: Van Nostrand Reinhold, 1978, 639p.

27 BRANCIFORTI, M. C.; OLIVEIRA, C. A.; SOUSA, J. A. Molecular orientation, crystallinity, and flexural correlations in injection molded polypropylene/talc composites. Polymer Advanced Technologies, v. 21, p. 322-330, 2010.

28 LOPES, P. E.; SOUSA, J. A. Influência das condições de processamento nas propriedades mecânicas de compósitos de polipropileno com fibras de vidro. Polímeros: Ciência e Tecnologia, São Carlos, v. 9, n. 1, p. 85-96, 1999.

29 SOUZA, J. A.; HAGE JR., E. Compósitos de Termoplásticos. Apostila do Curso de Aperfeiçoamento em Tecnologia de Plásticos - 7ํㅡㅁódulo. Departamento de Engenharia de Materiais (DEMa), Universidade de São Carlos, 2008. 
30 JANCAR, J. Engineered interphases in polypropylene composites. In: KARIAN, H. G. Handbook of polypropylene and polypropylene composites. New York: Marcel Dekker, Inc., 559 p., 1999.

31 LOPES, P. E.; SOUSA, J. A. Modificação nas características da interface/interfase em compósitos de polipropileno/fibras de vidro com compatibilizante PP-g-MAH e sua influência nas propriedades mecânicas. Polímeros: Ciência e Tecnologia, São Carlos, v. 9, n. 4, p. 99-103, 1999.

32 CRUZ, M. C. A. Correlações entre propriedades dinâmico-mecânicas e durabilidade sob fadiga mecânica em compósitos de polipropileno/polipropileno maleificado / fibra de vidro. 2006, 213 p. Dissertação (Mestrado) - Faculdade de Engenharia de Materiais, Universidade Federal de São Carlos - SP, 2006.

33 CONSTABLE, R. C. Chemical coupling agents for filled and glass-reinforced polypropylene composites. In: KARIAN, H. G. Handbook of polypropylene and polypropylene composites. New York: Marcel Dekker, Inc., 559 p., 1999.

34 PLUEdDEMANN, E. P. Silane Coupling Agents. New York: Plenun Press, $2^{\text {nd }}$ Edition, 253 p., 1991.

35 AGUIAR, L. G. Modelagem matemática do processo de enxertia do anidrido maleico em polipropileno na forma fundida, 2009, 106 p. Dissertação (Mestrado) - Engenharia Química - Escola Politécnica da Universidade de São Paulo, 2009.

36 BARBOZA, A. C. R. N. Polipropileno carregado com microesferas ocas de vidro, 2002, 85 p., Dissertação (Mestrado) - Química - Universidade Estadual de Campinas - SP, 2002.

37 KARIAN, H. G. Mega-coupled polypropylene composites of glass fibers. In: KARIAN, H. G. Handbook of polypropylene and polypropylene composites. New York: Marcel Dekker, Inc., 559 p., 1999.

38 KARIAN, H. G. Handbook of Polypropylene and Polypropylene Composites. $2^{\text {nd }}$ Edition, New York: Marcel Dekker Inc., 2003, Chapter 17: p. 578-581.

39 ABREU, F. O. M. S.; FORTE, M. M. C.; LIBERMAN, S. A. Propriedades mecânicas e morfologia de blendas de polipropileno. Polímeros: Ciência e Tecnologia, São Carlos, v. 16, n. 1, p. 71-78, 2006. 
40 GARAKANI, M. M.; AREFAZAR, A.; NAZOCKDAST, H. Study on morphological, rheological, and mechanical properties of PP/SEBS-MA/SGF hybrid composites. Journal of Applied Polymer Science, v. 104, p. 2704-2710, 2007.

41 LOPES, P. E.; SOUSA, J. A. Influence of PP-g-MAH compatibilizer characteristics on interphase and mechanical properties of glass fiber reinforced polypropylene composites. In: Polymer Processing Society Annual Meeting, $18^{\text {th }}$, Guimarães Portugal, 2002. São Carlos: NRPP/UFsCAR, 2002. 1 CD-ROM.

42 CRUZ, M. C. A.; MOTEZUKI, J. E.; LOPES, P. E.; SOUSA, J. A. Influence of maleated polypropylene on hygrothermal ageing of polypropylene/PP-g-MAH/glass fiber composites. In: Polymers Processing Society Annual Meeting, PPS 24, Salermo - Italy, 2008.

43 ISMAIL, H.; HONG, H. B.; PING, C. Y.; ABDUL KHALIL, H. P. S. The effects of a compatibilizer on the properties fo polypropylene/silica/white husk ash hybrid composites. Journal of Reinforced Plastics and Composites, v. 21, p. 1685-1696, 2002. Disponível em: < HTTP://jirp.sagepub.com>. Acesso em: 03 de mar. 2010.

44 ZOUKRAMI, F.; HADDAOUI, N.; VANZEVEREN, C.; SCLAVONS, M.; DEVAUX, $\mathrm{J}$. Effect of compatibilizer on the dispersion of untreated silica in a polypropylene matrix. Polymer International, v. 57, p. 756-763, 2008.

45 EBENGOU, R. H. Adsorption as a mechanism for nucleating activity: A thermodynamic explanation. Journal of Polymer Science, v. 35, p. 1333-1338, 1997. Disponível em: < http://cat.inist.fr>. Acesso em: 18 de ago. 2010.

46 TORO, P.; QUIJADA. R.; MURILO, O.; YAZDANI-PEDRAM, M. Study of the morphology and mechanical proprerties of polypropylene composites with silica or rice-husk. Polymer International, v. 54, p. 730-734, 2005.

47 FÉLIX, A. H. O. Compósitos de polipropileno com fibra de vidro utilizando viniltrietoxisilan como agente de adesão, 2002, 115 p. Dissertação (Mestrado) - Faculdade de Engenharia Química, Universidade Federal do Rio Grande do Sul, Porto Alegre - RS, 2002.

48 SAMAL, S. K.; MOHANTY, S.; NAYAK, S. K. Polypropylene - bamboo/glass fiber hybrid composites: fabrication and analysis of mechanical, morphological, thermal, and dynamic mechanical behavior. Journal of Reinforced Plastics and Composites, v. 28, n. 22, p. 2729-2747, 2009. 
49 SHAKERI, A.; RAGHIMI, M. Studies on mechanical performance and water absorption of recycled newspaper/glass fiber - reinforced polypropylene hybrid composites. Journal of Reinforced Plastics and Composites, v. 29, n. 7, p. 9941005, 2010.

50 JARUKUMJORN, K; SUPPAKARN, N. Effect of glass fiber hybridization on properties o sisal fiber-polypropylene. Composites: Part B, v. 40, p.623-627, 2009.

51 MORELLI, C. L.; POUZADA, A. S.; SOUSA, J. A. Influence of hybridization of glass fiber and talc on the mechanical performance of polypropylene composites. Journal of Applied Polymer Science, v. 114, p. 3592-3601, 2009.

52 XIE, H.; ZHANG, S.; XIE, D. An efficient way to improve the mechanical properties of polypropylene/short glass fiber composites. Journal of Applied Polymer Science, v. 96, p. 1414-1420, 2005.

53 DENAC, M.; MUSIL, V.; SMIT, I. Polypropylene/talc/SEBS (SEBS-g-MA) composites. Part 2. Mechanical properties. Composites: Part A, v. 36, p. 12821290, 2005.

54 MAE, J.; OMIYA, M.; KISHIMOTO, K. Microstructural observation and simulation of micro damage evaluation of ternary polypropylene blend with ethylene-propylenerubber (EP) and talc. Journal of Solid Mechanics and Materials Engineering, v. 2, p. 1018-1036, 2008.

55 ZUIDERDUIN, W. C. J.; WESTZAAN, C.; HUÉTINK, J.; GAYMANS, R. J. Toughening of polypropylene with calcium carbonate particles. Polymer, v. 44, p. 261-275, 2002.

56 THIO, Y. S.; ARGON, A. S.; COHEN, R. E.; WEINBERG, M. Toughening of isotatic polypropylene with CaCO3 particles. Polymer, v. 43, p. 3661-3674, 2002.

57 OSHINSKI, A. J.; KESKKULA, H.; PAUL, D. R. Rubber toughening of polyamides with functionalized block copolymers: 1.Nylon-6. Polymer, v. 33, p. 268-283, 1992.

58 WU, S. Phase structure and adhesion in polymer blends: A criterion for rubber toughening. Polymer, v. 26, p. 1855-1863, 1985.

59 XIANG, Q.; XANTHOS, M.; MITRA, S.; PATEL, S. H.; GUO, J. Effects of melt reprocessing on volatile emissions and structural / rheological changes of 
unstabilized polypropylene. Polymer Degradation and Stability, v. 77, p. 93-102, 2002.

60 BERNSTEIN, R.; THORNBERG, S. M.; ASSINK, R. A.; IRWIN, A. N.; HOCHREIN, J. M.; BROWN, J. R.; DERZON, D. K.; KLAMO, S. B.; CLOUGH, R. L. The origins of volatile oxidation products in the thermal degradation of polypropylene, identified by selective isotopic labeling. Polymer Degradation and Stability, v. 92, p. 2076-2094, 2007.

61 BLEDZKI, A. K.; KESSLER, A.; LIESER, J. Odour reduction on plastics and its measurement. Polymer Testing, v. 18, p. 63-71, 1999.

62 GUADARRAMA, A.; MÉNDEZ, R.; DE SAJA, J. A. Conducting polymer-based array for the discrimination of odours from trim plastic materials used in automobiles. Analytica Chimica Acta, v. 455, p. 41-47, 2002.

63 WONG, M.; LIM, G. T.; MOYSE, A.; REDDY, J. N.; SUE, H.-J. A new test methodology for evaluating scratch resistance of polymers. Wear, v. 256, p. 12141227, 2004.

64 BROWNING, R. L.; JIANG, H.; SUE, H.-J. Scratch behavior of polymeric materials. In: FRIEDRICH, K.; SCHLARB, A. K. Tribology of polymeric nanocomposites. $1^{\text {st }}$ ed., The Netherlands: Elsevier, 568 p., 2008.

65 BRISCOE, B. J.; EVANS, P. D.; PELILO, E.; SINHA, S. K. Scratching maps for polymers. Wear, v. 200, p. 137-147, 1996.

66 SURFACE MACHINES - Products - Scratch 4 Machine®. Disponível em: <http:Ilwww.surfacemachines.com>. Acesso em: 31 de out. 2010.

67 HADAL, R.; DASARI, A.; ROHRMANN, J.; MISRA, R. D. K. Susceptibility to scratch surface damage of wollastonite-and-talc-containing polypropylene micrometric composites. Materials Science and Engineering A, v. 380, p. 326-339, 2004.

68 SPINACÉ, M. A. S.; FERMOSELI, K. K. G.; DE PAOLI, M-A. Recycled polypropylene reinforced with curaua fibers by extrusion. Journal of Applied Polymer Science, v.112, p. 3686-3694, 2009. 
69 OSMAN, H; ISMAIL, H.; MARIATTI, M. Comparison of reinforcing efficiency between recycled newspaper (RPN)/carbon black (CB) and recycled newspaper (RPN) / silica hybrid filled polypropylene (PP) / natural rubber (NR) composites. Journal of Reinforced Plastics and Composites, v. 29, p. 60-74, 2010.

70 THOMASON, J.L. The influence of fibre length and concentration on the properties of glass fibrer reinforced polypropylene: 5. Injection moulded long and short fibre PP. Composites: Part A, v. 33, p. 1641-1652, 2002.

71 PAUL, S; KALE, D. D. Impact modification of polypropylene copolymer with a polyolefinic elastomer. Journal of Applied Polymer Science, v. 76, p. 1480-1484, 2000.

72 YIN, J.; ZHANG, Y.; ZHANG, Y. Fracture behavior and deformation mechanism of polypropylene/ethylene-octene copolymer/magnesium hydroxide ternary phase composites. Journal of Applied Polymer Science, v. 98, p. 937-967, 2005.

73 SILVA, A. L. N.; ROCHA, M. C. G.; GUIMARÃES, M. J. O. C.; LOVISI, J.; COUTINHO, F. M. B.; MARIA, L. C. S. M. Desenvolvimento de materiais à base de poliolefinas e elastômeros metalocênicos. Polímeros: Ciência e Tecnologia, São Carlos, v. 11, n. 3, p. 135-141, 2001.

74 LAURA, D. M.; KESKKULA, H.; BARLOW, W. J.; PAUL, D. R. Effect of glass fiber surface chemistry on the mechanical properties of glass fiber reinforced, rubbertoughened nylon 6. Polymer, v. 42, p. 4673-4687, 2002.

75 MÉLO, T. J. A.; CARVALHO, L. H. Propriedades mecânicas e morfologia de uma blenda polimérica de PP/HIPS compatibilizada com SEBS. Polímeros: Ciência e Tecnologia, São Carlos, v. 10, n. 2, p. 82-89, 2000.

76 ABREU, F. O. M. S.; FORTE, M. M. C.; LIBERMAN, S. A. Propriedades mecânicas e morfologia de blendas de polipropileno com TPES. Polímeros: Ciência e Tecnologia, São Carlos, v. 16, n. 1, p. 71-78, 2006.

77 GONÇALEZ, V. Modificação de resina epoxídica com poliéter e poliéster e sua utilização em compósitos com fibras de carbono, 2006, 88p. Dissertação (Mestrado) - Ciência e Tecnologia de Polímeros do Instituto de Macromoléculas Professora Eloísa Mano, Universidade Federal do Rio de Janeiro - RJ, 2006 
78 CHIU, H. T.; HSIAO, Y. K. Compatibilization of poly(ethylene terephthalate)/polypropylene blends with maleic anhydride grafted polyethyleneoctene elastomer. Journal of Polymer Research, v. 13, p. 153-160, 2006. 